\title{
Isolation and functional analysis of differentially expressed genes in human prostate cancer
}

\author{
Dissertation \\ zur Erlangung des Doktorgrades \\ der Mathematisch-Naturwissenschaftlichen Fakultäten \\ der Georg-August-Universität zu Göttingen
}

vorgelegt von

Michal Grzmil

aus Tarnobrzeg / Polen

Göttingen 2002 
D7

Referent: Prof. Dr. W. Engel

Korreferentin: PD Dr. S. Hoyer-Fender

Tag der mündlichen Prüfung: 28.01.2003 


\section{CONTENTS}

\section{ABBREVIATIONS}

1.1 Human prostate cancer : an overview 1

1.2 Staging of prostate cancer 3

1.3 Susceptibility genes in prostate carcinoma 4

1.4 Diagnostic markers of prostate cancer $\quad 6$

1.4.1 New putative prostate cancer markers identified by microarray analysis 6

1.4.2 Serum markers in prostate carcinognesis $\quad 7$

1.5 Aims of the study 9

2. MATERIALS AND METHODS 10

2.1 Chemicals and reagents $\quad 10$

2.2 Solutions and buffers $\quad 12$

2.3 Sterilization of solutions and equipments $\quad 15$

2.4 Bacterial strains and mediums $\quad 15$

2.5 Eukaryotic cell lines $\quad 15$

2.6 Plasmids and cDNA fragments 16

2.7 Synthetic oligonucleotide primers 16

2.8 Antibodies $\quad 19$

2.9 Isolation of nucleic acids $\quad 19$

2.9.1 Small-scale preparation of plasmid DNA (Mini prep) 19

2.9.2 Preparation of bacterial glycerol stocks 20

2.9.3 Large-scale preparation of plasmid DNA (Midi prep) 20

2.9.4 Isolation of total RNA from eukaryotic cells 20

2.9.5 Isolation of total RNA from tissues $\quad 20$

2.9.6 Isolation of poly $(\mathrm{A})^{+}$-enriched RNA 21

2.9.7 Determination of nucleic acid concentration 21

2.10 Cloning techniques $\quad 22$

2.10.1 Restriction analysis of DNA $\quad 22$

2.10.2 Isolation of DNA fragments from agarose gels 22

2.10.3 Dephosphorylation of 5 ' ends of DNA 22

2.10.4 Phenol-chloroform extraction and ethanol precipitation 23

2.10.5 Filling-up reaction of DNA ends 23

2.10.6 Ligation of DNA fragments 23

2.10.7 Subcloning of PCR and RT-PCR products 23

2.10.8 Transformation of competent cells with plasmid DNA 24

$2.11 \mathrm{Gel}$ electrophoresis and blotting techniques $\quad 25$

2.11.1 Agarose gel electrophoresis of DNA 25

2.11.2 Agarose gel electrophoresis of RNA and Northern blot analysis 25 
2.11.3 DNA and RNA molecular weight ladders 26

2.12 Sequencing 26

2.13 One-step RT-PCR 27

2.14 Labeling and hybridization of nucleic acids 28

2.14.1 Generation of ${ }^{32} \mathrm{P}$ labeled cDNA by using the ,random prime“ method 28

2.14.2 Northern blot hybridization with radioactive labeled cDNA-probes 28

2.15 Isolation of differentially expressed genes (Atlas Array) 29

2.15.1 Overview of the Atlas Array procedure 29

2.15.2 Preparation of whole cDNA probes from total RNA 31

2.15.3 DNase treatment of total RNA

2.15.4 Poly(A) ${ }^{+}$RNA enrichment $\quad 31$

2.15.5 Whole cDNA probe synthesis 32

2.15.6 Purification of labeled cDNA probes by column chromatography 32

2.15.7 Hybridization of Atlas Arrays with labeled cDNA probes 33

2.16 Analysis of gene expression of multiple tumor samples 34

(Cancer Profiling Array)

2.17 Protein techniques $\quad 34$

2.17.1 Isolation of total proteins from eukaryotic cells 34

2.17.2 Determination of protein concentration $\quad 35$

2.17.3 Electrophoresis of proteins $\quad 35$

2.17.4 Western blotting of proteins onto nitrocellulose filters 36

2.17.5 Staining of polyacrylamide gel 36

2.17.6 Incubation of protein-bound membranes with antibodies 36

2.18 Preparation of laser capture microdissection-derived total RNA 37

2.18.1 Laser capture microdissection of prostate cancer cells 38

2.18.2 RNA extraction from LCM samples $\quad 39$

2.18.3 Agilent RNA LabChip Techniques $\quad 39$

2.19 Real-time RT-PCR analysis $\quad 40$

2.19.1 Real time RT-PCR by using SYBR Green I dye $\quad 40$

2.19.2 Real time RT-PCR by using standard dual-labeled probes $\quad 42$

2.20 Eukaryotic cell culture methods $\quad 44$

2.20.1 Cell culture conditions $\quad 44$

2.20.2 Preparation of conditioned medium $\quad 44$

2.20.3 Trypsinization of eukaryotic cells 44

2.20.4 Cryoconservation and thawing of eukaryotic cells 45

2.20.5 Stable transfection of PC-3 cells 45

2.20.6 Matrigel assay $\quad 45$

2.20.7 Cell proliferation assay $\quad 46$

2.21 Gene silencing by RNA interference $\quad 47$

2.21.1 Overview of the RNAi mechanism $\quad 47$

2.21.2 Transfection of eukaryotic cells with siRNAs 49

2.22 Analysis of cell death and apoptosis $\quad 50$

2.22.1 Trypan blue-staining of eukaryotic cells 50

2.22.2 In situ end-labeling (ISEL) 51

2.22.3 DAPI staining of eukaryotic cells 51

2.22.4 Immunocytochemical staining of eukaryotic cells (Caspase-3) 52 


\section{RESULTS}

3.1. Inhibition of insulin-like growth factor type I receptor (IGF-IR) expression in human prostate cancer cells

3.1.1 Down-regulation of IGF-IR expression in PC-3 cells transfected with the $\mathrm{pMT} / \mathrm{EP}$ vector containing the IGF-IR cDNA in antisense orientation

3.1.2. Inhibition of IGF-IR gene expression leads to reduced cellular invasion of human prostate cancer cells

3.1.3 Inhibition of IGF-IR gene expression leads to reduced cell proliferation of human prostate cancer cells

3.1.4 Atlas Array analysis in PC-3 cells showing a reduced level of IGF-IR expression

3.1.5 Suppression of IGF-IR expression induces IGFBP-3 expression in PC-3 cells

3.1.6 Northern blot analysis of macrophage inhibitory cytokine-1 (MIC-1) expression

3.1.7 Inhibition of IGF-IR gene expression leads to PC-3 cell death

3.1.8 Inhibition of IGF-IR expression down-regulates MMP-2 expression in human prostate cancer cells

3.1.9 Laser-capture microdissection and expression of IGF-IR and IGFBP-3 in human prostate cancer

3.1.10 Cancer Profiling Array analysis of IGFBP-3 expression in different human cancers

3.2 Isolation and identification of differentially expressed genes in prostate carcinoma

3.2.1 Atlas Array analysis in prostate carcinoma

3.2.2 Quantitative RT-PCR analysis of the isolated genes on RNA from normal prostate and prostate cancer tissue

3.2.3 Array and Northern blot analysis of BI-1 expression in human prostate cancer

3.2.4 Laser-capture microdissection and BI-1 expression analysis in human prostate cancer

3.2.5 Cancer Profiling Array analysis of BI-1 expression in different human cancers

3.2.6 Down-regulation of BI-1 expression in PC-3 cells by using the RNAi technique

3.2.7 Induction of PC-3 cell death by using siRNAs against the human $B I-1$ gene

3.2.8 Down-regulation of BI-1 expression in LNCaP cells by using the RNAi technique

3.2.9 Induction of apoptosis in LNCaP cells by using siRNAs against the human $B I-1$ gene

3.2.10 Induction of apoptosis in LNCaP and PC-3 cells by using RNA interference technique

\section{DISCUSSION}


5.3 The role of the IGF-IR in tumor metastasis

5.4 Isolation of differentially expressed genes in human prostate carcinoma

5.5 Apoptosis in prostate carcinogenesis (role of Bax inhibitor-1)

5.6 BI-1 expression in human prostate cancer and other cancers

119

5.7 Down-regulation of BI-1 expression leads to prostate cancer cell death

120

5.8 Further perspectives

References

Acknowledgments

Curriculum Vitae 


\section{ABBREVIATIONS}

ATP

AP

BCIP

BrET

BSA

bp

${ }^{\circ} \mathrm{C}$

cDNA

$\mathrm{Ci}$

cRNA

DMSO

dNTP

DNA

DNase

DTT

E.coli

EDTA

$\mathrm{EtOH}$

g

$\mathrm{h}$

IPTG

$\mathrm{kb}$

LB

M

$\mathrm{MeOH}$

$\mu \mathrm{g}$

$\mu 1$

$\mu \mathrm{M}$

$\mathrm{mg}$

$\mathrm{mM}$
Adenosine triphosphate

Alkaline phosphatase

5-bromo-4-choro-3-indolyl-phosphate

Ethidium bromide

Bovine serum albumin

Base pairs

Celsius

Complementary DNA

Curie

Complementary RNA

Dimethyl sulfoxyde

Deoxyribonucleotide phosphate

Deoxyribonucleic acid

Deoxyribonuclease

1,4-Dithio-DL-threitol

Escherichia coli

Ethylenediamine tetraacetic acid

Ethanol

Gravity

Hour

Isopropyl B-D-thiogalactopyranoside

Kilobase

Luria Bertani medium

Molar (moles per litre)

Methanol

Microgram

Microlitre

Micromolar

Milligram

Millimolar 


\begin{tabular}{|c|c|}
\hline $\min$ & Minute \\
\hline $\mathrm{ml}$ & Millilitre \\
\hline MOPS & 3-(N-Morpholino)propanesulfonic acid \\
\hline mRNA & messenger RNA \\
\hline MW & Molecular weight \\
\hline ng & Nanogram \\
\hline $\mathrm{nl}$ & Nanolitre \\
\hline $\mathrm{NaCl}$ & Sodium chloride \\
\hline OD & Optical density \\
\hline $\mathrm{ON}$ & Over night \\
\hline PBS & Phosphate buffered saline \\
\hline PCR & Polymerase chain reaction \\
\hline pmol & Picomolar \\
\hline RNA & Ribonucleic acid \\
\hline RNase & Ribonuclease \\
\hline $\mathrm{rpm}$ & Rotations per minute \\
\hline RT & Room temperature \\
\hline RT-PCR & Reverse transcriptase polymerase chain reaction \\
\hline SDS & Sodium dodecyl sulfate \\
\hline SDS-PAGE & SDS-polyacrylamide gel electrophoresis \\
\hline $\sec$ & Second \\
\hline $\mathrm{U}$ & Unit \\
\hline UV & Ultraviolet \\
\hline Vol & Volume \\
\hline $\mathrm{w} / \mathrm{v}$ & Weight : volume ratio \\
\hline
\end{tabular}




\section{INTRODUCTION}

\subsection{Human prostate cancer : an overview}

Prostate cancer is the most frequently diagnosed solid tumor in men, and the second leading cause of cancer death in males from western countries (Greenlee et al. 2000). The incidence of prostate cancer as reported by Hsing et al. (2000) varies markedly throughout the world, with United States, Canada, Sweden, Australia, and France having the highest rates (ranging from 48.1 to 137.0 cases per 100,000 person-years as estimated between the 1988-1992 period), whereas most European countries have intermediate rates (23.9 to 31.0 cases per 100,000 person-years). The lowest prevalence is observed in Asian populations (2.3 to 9.8 cases per 100,000 person-years). Prostate cancer differs from other solid tumors in that it exists in a histological or latent form. The clinically evident form affects approximately $15 \%$ of American men in their lifetime. The latent form can be identified in approximately $30 \%$ of men over the age of 50 and in $60 \%$ to $70 \%$ of men over the age of 80 (Carter and Coffey 1990, Wingo et al. 1998).

At least in its early stages, prostate cancer appears to be hormone-dependent. Androgendependent prostate cancer can be treated with androgen deprivation strategies such as castration or antiandrogens, but progression to androgen-independent cancer, for which there are no satisfactory treatments, usually occurs. Furthermore, if diagnosed after the carcinoma metastasizes, prostatic cancer is a fatal disease for which there is no cure (Rinker-Schaeffer et al. 1994). As approximately $50 \%$ of patients diagnosed for prostate cancer develop metastases and therefore an incurable disease, prevention of cancer development is a life-saving and costeffective health strategy (Pienta 1998).

The definitive known risk factors, in addition to family history, are only age and race. After the age of 50, both incidence and mortality rates of prostate cancer increase at nearly exponential rates (Wingo et al. 1995). African-american men living in the United States have a higher incidence rate of clinical prostate cancer than white men of similar education and socioeconomic classes (Baquet et al. 1991). Probable risk factors include dietary fat and hormones. Increasing fat content in diet is associated with increasing prostate cancer incidence in Japan. Potential risk factors include vasectomy, cadmium exposure, vitamin A intake and vitamin $\mathrm{D}$ concentration. As there are no major known risk factors of prostate 
cancer that easily take effect, avoidance of potential risk factors and chemoprevention with finasteride and retinoids are the possibilities for prevention (Pienta 1998, Pentyala et al. 2000). As prostate cancer tends to transform to androgen-independent disease with time, early diagnosis has a decisive role in effective treatment of the disease. In the USA, the American Cancer Society and the American Urological Association recommend digital rectal examination and a prostate-specific antigen (PSA) blood test annually starting at age 50 (Pienta 1998). PSA is the best and only widely used prostate cancer serum marker currently. Some modifications have been made to the assay, such as measurement of free and total PSA, which have increased its diagnostic value.

Prostate cancer development and mechanisms behind malignant transformation in prostate cancer are only partially known. Because of its importance as a common disease, better understanding of the molecular mechanisms is essential in order to examine new diagnostic and therapeutic strategies. Differential gene expression is one possibility to investigate changes and potential effects on genes in different disease states and processes. Several methods, such as subtractive hybridization, differential display and microarray-technology can be used for the detection of differentially expressed genes.

During the last few years, several putative prostate cancer markers have been found, but none of them have so far made a breakthrough in clinical use (Dhanasekaran et al. 2001, Elgamal et al. 2000, Lintula and Stenman 1997) Therefore, there is a clear need to identify molecular targets for novel therapeutic approaches to either prevent the progression of prostate cancer to androgen independence or to treat androgen-independent prostate cancer. It is also essential to generate new tests for the diagnosis of prostate cancer and for potential discrimination between androgen-dependent and androgen-independent prostate cancer. Further, it is even more important to find markers to identify patients who benefit from the treatments. With the identification of metastasis related genes, serum markers for cancer metastasis may come into sight in the near future. 


\subsection{Staging of prostate cancer}

In human prostate cancer tissue, gene expression is correlated with gleason score and advanced pathological stages and it can differ between various stages. These clasified "stages" are based on the tumor size, the character of its cells, and the extent of metastasis. Two systems commonly are used for staging prostate cancer: the Jewett-Whitmore system and the TNM (tumor, node, metastases) system. In the Jewett-Whitmore system (Fig. 1), prostate cancer is classified first as stage A, B, C, or D. Stages A and B cancers are considered curable. Stages $C$ and D are treatable, but their prognoses are discouraging. The TNM (tumor, node, metastases) system describes stages which are similar to those of the Jewett-Whitmore System but with more specific alphanumeric subcategories (Table 1).

\section{STAGE I}

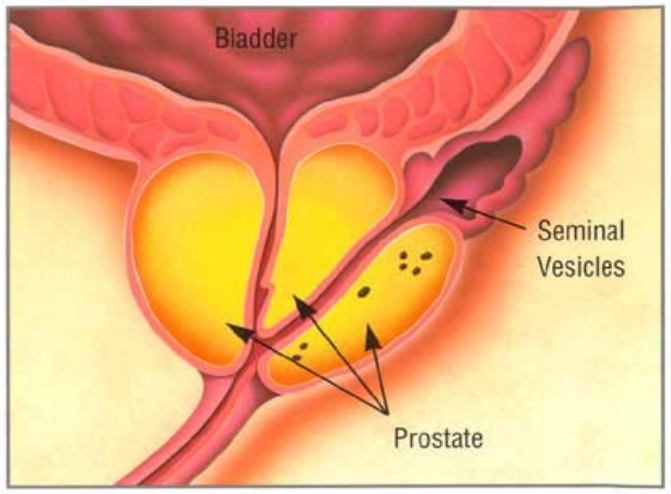

\section{STAGE III}

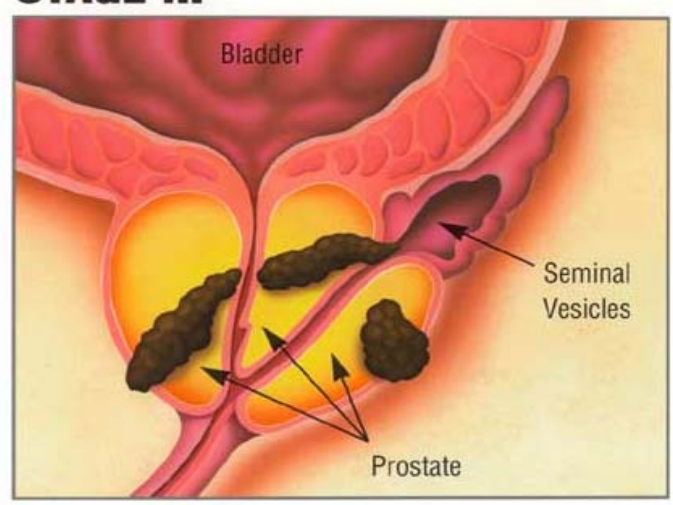

\section{STAGE II}

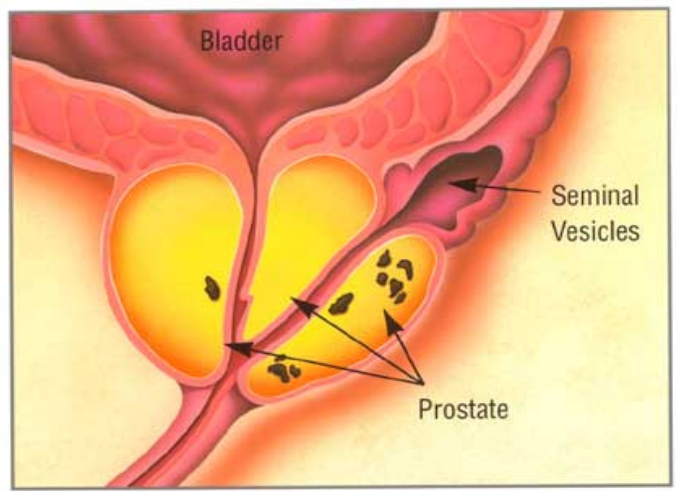

\section{STAGE IV}

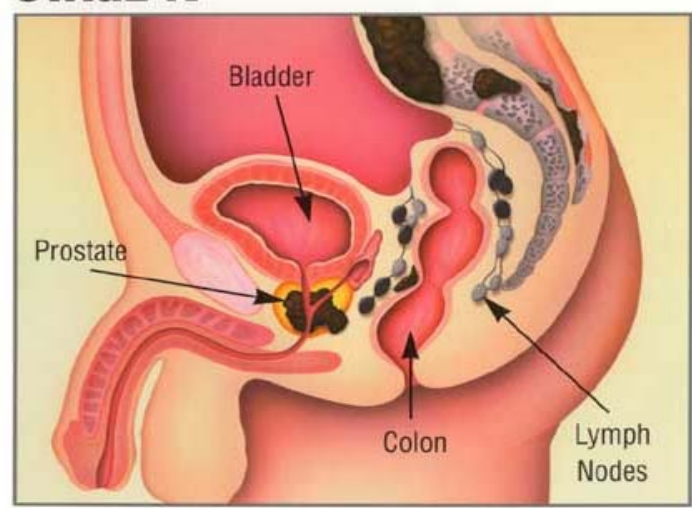

Figure 1. Staging of prostate cancer. Jewett-Whitmore system (Whitmore 1984)

Stage A, very early and without symptoms; cancer cells confined to the prostate. Stage B, confined to the prostate, but palpable (detectable by digital rectal exam) and/or detectable by elevated PSA. Stage C, cancer cells found outside the prostate capsule (membrane covering the prostate); spread confined to surrounding tissues and/or seminal vesicles. Stage D, metastasis (spread) to regional lymph nodes, or to distant bones, organs (e.g., liver, lungs), and/or other tissues. 


\section{Primary tumor (pT)}

TX Tumor cannot be assessed

T0 No evidence of primary tumor

T1 Clinically not palpable or visible by imaging

T1a Found incidental to other surgery; present in $5 \%$ or less of tissue

T1b Found incidental to other surgery; present in $5 \%$ or more of tissue

T1c Identified by needle biopsy

T2 Tumor confined within prostate

T2a Involving half a lobe or less of prostate

T2b Involving half a lobe

T2c Involving both lobes

T3 Tumor extends through prostate capsule

T3a Extends through one lobe

T3b Extends through both lobes

T3c Extends into seminal vesicles

T4 Involves structures other than seminal vesicles

T4a Invades bladder neck, external sphincter, or rectum

T4b Invades muscles and/or pelvic wall

\section{Regional Lymph Nodes (N)}

NX Nodes cannot be assessed

No No regional node metastasis

N1 Single node metastasis, 2 centimeters $(\mathrm{cm})$ or less at largest point

N2 Single node metastasis, $2 \mathrm{~cm}$ to $5 \mathrm{~cm}$ at largest point, or multiple nodes, no larger than $5 \mathrm{~cm}$ at largest point

N3 Metastasis larger than $5 \mathrm{~cm}$ in any node

\section{Distant Metastasis (M)}

MX Metastasis cannot be assessed

M0 No distant metastasis

M1 Distant metastasis

M1a Distant lymph node(s) involved

M1b Bone(s) involved

M1c Other site(s) involved

Table 1. Staging of prostate cancer . TNM Classification of malignant tumours (Bostwick 1997)

\subsection{Susceptibility genes in prostate carcinoma}

Familiar prostate cancer forms approximately $10 \%$ of all prostate cancers and $45 \%$ of cases in men younger than 55 years of age (Moul et al. 1997). The importance of inherited predisposition to prostate cancer is also supported by the finding that monozygotic twins have a 4-fold increased concordance rate of prostate cancer compared with dizygotic twins (Carter et al. 1992). In support of this latter observation, it has recently been estimated, using the combined data from 44,788 pairs of twins listed in Swedish, Danish, and Finnish twin registries, that $42 \%$ of all prostate-cancer risk may be explained by inheritable factors 
(Lichtenstein et al. 2000). The first segregation analysis suggested that inherited predisposition was due to a rare, highly penetrant autosomal dominant allele(s) with a population frequency of 0.003 , and with carriers having an $88 \%$ cumulative risk of disease by $85 \mathrm{yr}$ of age compared with only 5\% in noncarriers (Carter et al. 1992). These studies thus supported the presence of at least one highly penetrant autosomal dominant prostate cancer predisposition gene. However, consistently higher risks observed in brothers of prostate cancer affected relatives compared with sons of affected individuals have led to hypotheses of an Xlinked, recessive, and/or imprinted component to the genetics of prostate cancer susceptibility (Monro et al. 1995). As reviewed by Simard et al.(2002), the localization of six prostate cancer susceptibility loci, hereditary prostate cancer HPC1 gene at 1q24, prostate carcinoma tumor antigen-1 PCAP at 1q42, hereditary prostate cancer HPCX gene on the X chromosome at $\mathrm{Xq} 27$, predisposing for prostate and brain tumor $C A P B$ gene at $1 \mathrm{p} 36$, hereditary prostate cancer $H P C 20$ gene at $20 \mathrm{q} 13$ and hereditary prostate cancer ELAC2 gene at $17 \mathrm{p} 11$ have been described and then tested on independent data sets.

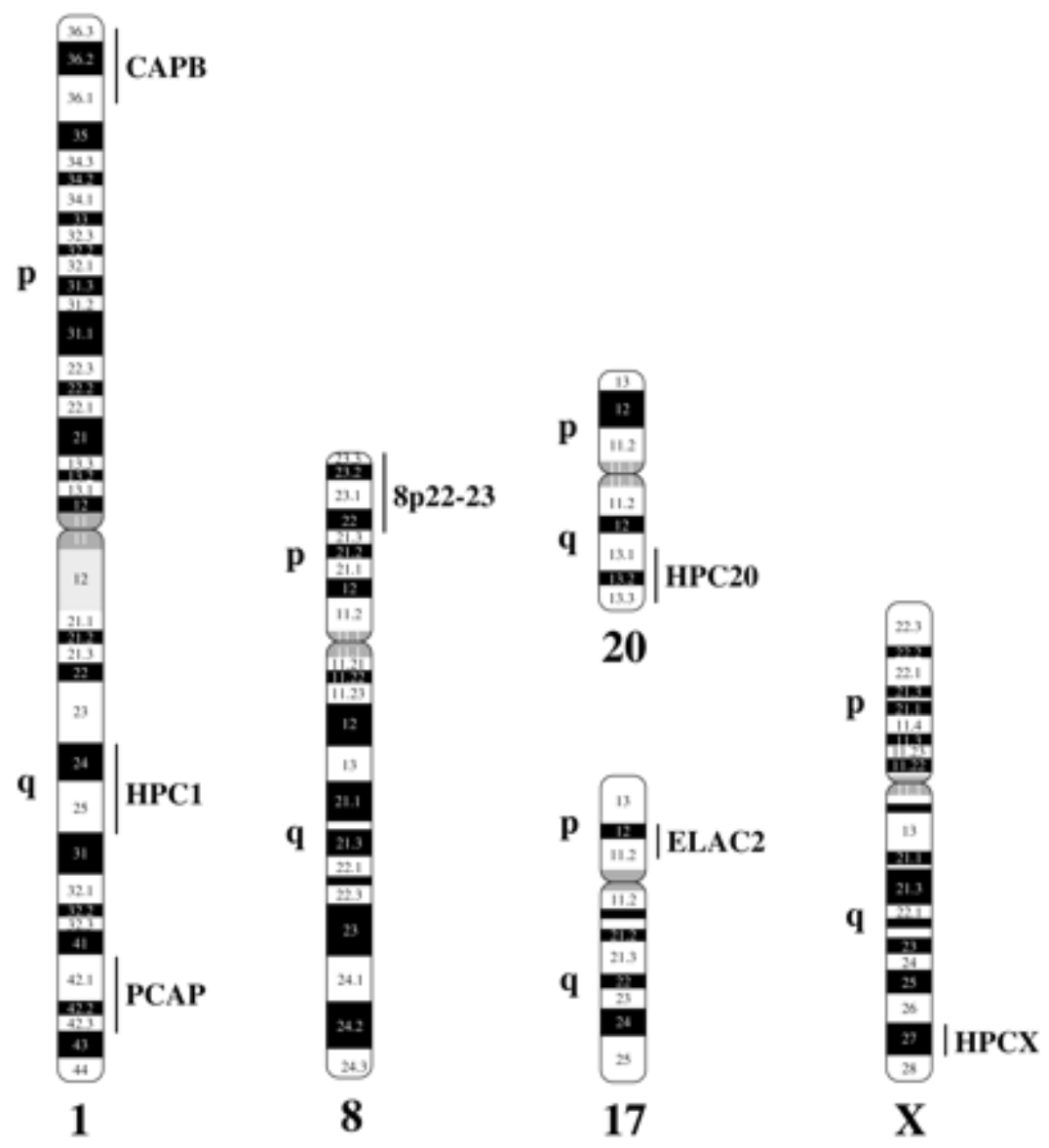

Figure 2. Localization of prostate cancer susceptibility loci reported in the literature

(Simard at al. 2002) 
Another recently published study presents evidence for linkage to a new locus, at 8p22-23 (Xu et al. 2001), which is of interest knowing that several lines of evidence have implicated the short arm of chromosome 8 as harboring genes important for prostate cancer (Fig. 2). Thus, identification of several susceptibility loci harboring predisposing genes indicates the genetic heterogeneity of prostate cancer.

\subsection{Diagnostic markers of prostate cancer}

\subsubsection{New putative prostate cancer markers identified by microarray analysis}

The DNA microarray technology offers the ability to screen thousands of genes in parallel. This genome-wide approach has been used successfully to classify tumors and identify novel biomarkers associated with cancer (Golub et al. 1999, Dhanasekaran et al. 2001). Before drawing conclusions about the expression of a specific gene, it is thought to be necessary to demonstrate independent experimental validations (King et al. 2001) using techniques such as quantitative real-time PCR, Northern blots, in situ hybridization, immunohistochemistry, or tissue microarrays. Table 2 lists new putative prostate cancer markers recently identified by microarray analysis that show altered levels of expression in prostate cancer. In addition, the significance of presented biomarkers was further confirmed by other methods than microarray techniques in prostate carcinoma. 


\begin{tabular}{l|r}
\hline \multicolumn{1}{c|}{ GENE NAMES } & REFERENCES \\
\hline 1. Genes with up-regulated expression in prostate cancer & \\
Polycomb group protein enhancer of zeste homolog 2 (EZH2) & Varambally et al. 2002 \\
Delta-catenin (CTNND2) & Burger et al. 2002 \\
Alpha-methylacyl-CoA racemase (P504S) & Jiang et al. 2002 \\
Transcriptional regulator ERG & Ernst et al. 2002 \\
LDL-phospholipase A2 & Ernst et al. 2002 \\
Pyrroline 5-carboxylate reductase 1 & Ernst et al. 2002 \\
Hepsin (HPN) & Dhanasekaran et al. 2001 \\
Serine/threonine kinase pim-1 (PIM-1) & Dhanasekaran et al. 2001 \\
Macrophage inhibitory cytokine (MIC-1) & Welsh et al. 2001 \\
2. Genes with down-regulated expression in prostate cancer & \\
Ataxia telangiectasia group D-associated protein (ATDC) & Erivastava et al. 2001 \\
\hline Uteroglobin & Ernst et al. 2002 \\
\hline
\end{tabular}

Table 2. Putative prostate cancer markers identified by microarray analysis

\subsubsection{Serum markers in prostate carcinognesis}

Diagnosis of prostate cancer through blood sampling is nowadays mainly based only on change in serum PSA concentration (Lindblom and Liljegren 2000). An improvement for the assay has been the determination of percentage of free serum PSA, which is especially helpful with PSA values of 4-10 ng/ml (Martinez-Pineiro et al. 2000). However, methodological weaknesses do exist (Patel et al. 2000). Determination of serum levels of human prostatespecific glandular kallikrein (KLK2) has been recently applied for the diagnosis of prostate cancer (Recker et al. 2000, Becker et al. 2000). The detection of prostate-specific membrane antigen (PSM) from the blood samples of metastatic prostate cancer patients was a promising finding for the detection of the disease. However, circulating leukocytes have later shown to 
express the PSM gene (Lintula and Stenman 1997), therefore intensive work for PSM RTPCR test standardization is needed in order to obtain a diagnostic assay (Elgamal et al. 2000). Recently, it was reported by Chan and coworkers (2002) that plasma levels of insulin-like growth factor-I (IGF-I) and circulating binding protein, IGF binding protein-3 (IGFBP-3) have been associated with the advanced-stage of prostate cancer. In addition, the IGF-I axis through IGF type-I receptor (IGF-IR) plays an important role in the pathogenesis of prostate cancer (Baserga 1999).

\begin{tabular}{l|c}
\hline \multicolumn{1}{c|}{ GENE NAMES } & REFERENCES \\
\hline Prostate-specific antigen (PSA) & Carter and Pearson 1999 \\
Human glandular kallikerin (KLK2) & Partin et al. 1999 \\
Endthotelin-1 & Pirtskhalaishvili and Nelson 2000 \\
Prostatic acid phosphatase & Lowe and Trauzzi 1993 \\
Vascular endothelial growth factor (VEGF) & Duque et al. 1999 \\
Insulin-like growth factor I (IGF-I) & Pollak et al. 1998 \\
IGF binding protein 3 (IGFBP-3) & Giovannucci 1999 \\
Prostate-specific membrane antigen (PSM) & Elgamal et al. 2000 \\
\hline
\end{tabular}

\section{Table 3. Serum markers in prostate carcinogenesis}

Clinically useful diagnostic markers for prostate cancer are few (reviewed by Marzo et al. 2001). Currently there are no useful predictive markers for prostate cancer progression to androgen-independent disease. The development of new assays is important in order to diagnose prostate cancer more efficiently, and foremost to diagnose those forms of disease that will most likely benefit from treatment. Studies on differential gene expression are one way of discovering potential prostate cancer markers. 


\subsection{Aims of the study}

1. As the insulin-like growth factor I receptor (IGF-IR) was reported to play an important role in cellular homeostasis of prostate carcinoma, we employed the antisense RNA strategy to reduce endogenous $I G F-I R$ gene expression in human prostate carcinoma PC-3 cells.

The specific topics of the study were:

- To establish stable transfected PC-3 cells using the expression vector pMT/EP producing both IGF-IR antisense cRNA and sense cRNA (control).

- To determine the down-regulation of endogenous $I G F-I R$ expression in the $I G F-I R$ antisense-RNA transfected PC-3 cells.

- To investigate phenotypical changes of the $I G F-I R$ antisense-RNA transfected PC-3 cells (invasion, proliferation and apoptosis).

- To isolate differentially expressed genes in IGF-IR antisense-RNA transfected PC-3 cells and to confirm their altered expression in other PC-3 cellular clones of $I G F-I R$ antisense-RNA transfected PC-3 cells.

- To further characterize isolated differentially expressed genes in patients with prostate carcinoma on laser captured microdissected-derived material.

- To further analyze these differentially expressed genes in different human tumors.

2. In the second part of this work, the cDNA array technique was employed to isolate differentially expressed genes which could serve as potential human prostate cancer markers.

The specific topics of the study were:

- To isolate differentially expressed genes between normal prostate and prostate carcinoma tissues and to confirm their altered expression.

- To characterize further isolated differentially expressed genes in patients with prostate carcinoma on laser captured microdissected derived-material.

- To down-regulate expression of the isolated differentially expressed gene in human prostate carcinoma cells (PC-3 and LNCaP) by using the RNA interference (RNAi) technique.

- To investigate phenotypical changes of both PC-3 and LNCaP cells displaying a reduced expression of the selected genes (Bax inhibitor-1). 


\section{MATERIALS AND METHODS}

\subsection{Chemicals and reagents}

Chemicals which are not included in the list below were purchased from the companies Roth (Karlsruhe) and Merck (Darmstadt), respectively.

Agar

Agarose

Alkaline phosphatase

Ammonium acetate

Ampicillin

Ampuwa

Aprotinin

Bacto-Tryptone

Chloroform

Dextran sulfate

Diethylpyrocarbonate (DEPC)

Dimethylsulfoxid (DMSO)

dNTPs (100 mM)

Dye Terminator Mix

Developer

Ethanol

Ethidium bromide

Ficoll 400

FKS

Formaldehyde

Formamide

Glycerol

Hygromycin B

IPTG
Difco, Detroit, USA

Gibco/BRL, Karlsruhe

Boehringer, Mannheim

Fluka, Neu Ulm

Sigma, Deisenhofen

Fresenius AG, Bad Homburg

Sigma, Deisenhofen

Difco, Detroit, USA

Baker, Deventer, NL

Amersham, Freiburg

Sigma, Deisenhofen

Merck, Darmstadt

Boehringer, Mannheim

Applied Biosystems; Amersham, Braunschweig

Kodak, Darmstadt

Baker, Deventer, NL

Sigma, Deisenhofen

Amersham, Freiburg

Gibco/BRL, Karlsruhe

Gibco/BRL, Karlsruhe

Fluka, Neu Ulm

Gibco/BRL, Karlsruhe

Calbiochem, San Diego, USA

Biomol, Hamburg 
Isoamyl alcohol

Klenow-DNA-Polymerase

$\mathrm{Kb}$ Ladder

Leupetin

Salmon sperm DNA

B-Mercaptoethanol

Orange-G

PBS

Phenol

PMSF

Proteinase K

Radiochemicals : [ $\left.\alpha^{32} \mathrm{P}\right]-\mathrm{dCTP}$, $\left[\alpha^{32} \mathrm{P}\right]-\mathrm{dATP}$

Restriction enzymes

Reverse Transkriptase

RNase A

RNase Inhibitor

RNA Ladder

Sodium Dodecyl Sulfate (SDS)

$\mathrm{T}_{4}$-DNA-Ligase

$\mathrm{T}_{4}$-DNA-Polymerase

Taq-DNA-Polymerase

Tris

Tween 20

Vecta Shield with DAPI

X-Gal
Fluka, Neu Ulm

Amersham, Braunschweig

Gibco/BRL, Karlsruhe

Sigma, Deisenhofen

Sigma, Deisenhofen

Serva, Heidelberg

Sigma, Deisenhofen

Gibco/BRL, Karlsruhe

Gibco/BRL, Karlsruhe

Sigma, Deisenhofen

Boehringer, Mannheim

Amersham, Braunschweig

Gibco/BRL, Karlsruhe

Gibco/BRL, Karlsruhe

Gibco/BRL, Karlsruhe

Boehringer, Mannheim

Gibco/BRL, Karlsruhe

Serva, Heidelberg

Boehringer, Mannheim

Boehringer, Mannheim

Amersham, Braunschweig

Sigma, Deisenhofen

Fluka, Neu Ulm

Vecta, USA

Biomol, Hamburg 


\subsection{Solutions and buffers}

All standard buffers and solutions were prepared according to Sambrook et al. (1989).

Coomassie Solution :

$30 \%(\mathrm{v} / \mathrm{v})$ Methanol

$10 \%(\mathrm{v} / \mathrm{v})$ Acetic Acid

$0.5 \%(\mathrm{w} / \mathrm{v})$ Coomassie Brilliant Blue R 250

Denaturing Solution

$1,5 \mathrm{M} \mathrm{NaCl}$

$0,5 \mathrm{M} \mathrm{NaOH}$

Denhardt's Solution (50x)

$1 \%$ BSA

$1 \%$ Polyvinylpyrrolidon

$1 \%$ Ficoll 400

in $20 \times \mathrm{SSC}(\mathrm{pH} 7.0)$

dNTP-Mix (25 mM)

$100 \mathrm{mM}$ dATP

$100 \mathrm{mM}$ dGTP

$100 \mathrm{mM}$ dCTP

$100 \mathrm{mM}$ dTTP

Glycin buffer

$1.44 \%(w / v)$ Glycin

$0.3 \%(\mathrm{w} / \mathrm{v})$ Tris

$0.1 \%(\mathrm{w} / \mathrm{v}) \mathrm{SDS}$

Hybridization Solution

$5 \times \mathrm{SSC}$

$5 \mathrm{x}$ Denhardt's Solution

$10 \%$ Dextran sulfate

$0.1 \%$ SDS

Salmon Sperm DNA

$100 \mu \mathrm{g} / \mathrm{ml}$

LB-Agar

10 g Bacto-Trypton 
$5 \mathrm{~g}$ Yeast extract

$10 \mathrm{~g} \mathrm{NaCl}$

15 g Agar

Per $1000 \mathrm{ml} \mathrm{H}_{2} \mathrm{O}$

LB-Medium

10 g Bacto-Trypton

$5 \mathrm{~g}$ Yeast extract

$10 \mathrm{~g} \mathrm{NaCl}$

Per $1000 \mathrm{ml} \mathrm{H}_{2} \mathrm{O}$

E1 buffer (Mini prep)

$50 \mathrm{mM}$ Tris-Cl, $\mathrm{pH} 8.0$

$10 \mathrm{mM}$ EDTA

$100 \mu \mathrm{g} / \mathrm{ml}$ RNase A

E2 buffer (Mini prep)

$200 \mathrm{mM} \mathrm{NaOH}, 1 \%$ SDS

E3 buffer (Mini prep)

3.0 M Natrium acetate (pH 5.5)

Lysis buffer for proteins

$150 \mathrm{mM} \mathrm{NaCl}$

$10 \mathrm{mM}$ EDTA

50 mM Tris-HCl, pH 7.6

$1 \%$ Triton X-100

$1 \%$ Proteinases inhibitors:

Leupetin $(1 \mu \mathrm{g} / \mathrm{ml})$

Aprotinin $(1 \mu \mathrm{g} / \mathrm{ml})$

PMSF $(1 \mu \mathrm{g} / \mathrm{ml})$

Methyl-blue solution

$0.5 \mathrm{M} \mathrm{NaAc}$

$0.04 \%$ Methyl-blue

MOPS buffer (10x)

$50 \mathrm{mM} \mathrm{NaAc}$

10 mM EDTA

200 mM MOPS (pH 7.0) 
Neutralization Solution

PBS buffer

PBT buffer

Running buffer

$\operatorname{SSC}(20 x)$

Stop Mix I

Stop Mix II

TBE buffer (5x)
$1.5 \mathrm{M} \mathrm{NaCl}$

$1 \mathrm{M}$ Tris- $\mathrm{HCl}(\mathrm{pH} 7.0)$

$130 \mathrm{mM} \mathrm{NaCl}$

$7 \mathrm{mM} \mathrm{Na}_{2} \mathrm{HPO}_{4}$

$4 \mathrm{mM} \mathrm{NaH}_{2} \mathrm{HPO}_{4}$

$0.1 \%$ Tween 20 in PBS (1x)

$25 \mathrm{mM}$ Tris

152 mM Glycin

$0.1 \%$ SDS

$3 \mathrm{M} \mathrm{NaCl}$

0.3 M Tri-Natrium citrate

pH 7.0 with $\mathrm{NaOH}$

95\% Formamid

20 mM EDTA

0.05\% Brom-phenol-blue

$0.05 \%$ Xcylencyanol

15\% Ficoll

$200 \mathrm{mM}$ EDTA

$0.1 \%$ Orange $\mathrm{G}$

$225 \mathrm{mM}$ Tris $\mathrm{pH} 8.3$

$225 \mathrm{mM}$ Boric acid

10 mM EDTA

10 mM EDTA

$100 \mathrm{mM}$ Tris $\mathrm{pH} 8.0$ 


\subsection{Sterilization of solutions and equipments}

All solutions, which are not heat sensitive, were sterilized at $121^{\circ} \mathrm{C}, 105 \mathrm{~Pa}$ for $60 \mathrm{~min}$ in an autoclave (Webeco, Bad Schwartau). Heat sensitive solutions were filtered through a disposable sterile filter ( 0.2 to $0.45 \mu \mathrm{m}$ pore size, Millipore, Morlsheim). Plastic ware was autoclaved, as described above. Glass ware was sterilized overnight in an oven at $220^{\circ} \mathrm{C}$.

\subsection{Bacterial strains and mediums}

Competent cells E. coli DH5a (Hanahan, 1983) were used for plasmid transformation.

LB-Medium: $1 \%$ bactotryptone; $0.5 \%$ yeast extract; $0.5 \mathrm{NaCl}$; $\mathrm{pH} 7.0$ (supplemented with 50 $\mu \mathrm{g} / \mathrm{ml}$ ampicillin to maintain selection pressure)

Agar plates: LB-Medium $+1.5 \%$ agar (supplemented with $50 \mu \mathrm{g} / \mathrm{ml}$ ampicillin, $2 \%$ X-gal and $1 \mathrm{mM}$ IPTG)

\subsection{Eukaryotic cell lines}

PC-3 Human prostate adenocarcinoma cell line, ATCC, Rockville, USA

Androgen-independent cells (Kaighn et al. 1979; Ohnuki et al. 1980)

LNCaP Human prostate adenocarcinoma cell line, ATCC, Rockville, USA

Androgen-dependent cells (Horoszewicz et al. 1983)

NIH3T3 Mouse embryonic fibroblast cell line, ATCC, Rockville, USA

"NIH Swiss Mouse" 


\subsection{Plasmids and cDNA fragments}

$\begin{array}{ll}\text { pGEM/3Zf }+ & \text { Promega, Wisconsin, USA } \\ \text { pGEM-T } & \text { Promega, Wisconsin, USA } \\ \text { pGEM-T Easy } & \text { Promega, Wisconsin, USA } \\ \text { pMT/EP } & \text { Trojan et al. } 1993 \\ \text { pSPORT 1 } & \text { RZPD, Berlin } \\ \text { pT7T3D-Pac } & \text { RZPD, Berlin }\end{array}$

Human cDNA fragments used for Northern blot experiments

$\beta$-actin (1.6 kb) cut out with Not I and Sal I from image clone, pSPORT 1 with subcloned cDNA for human $\beta$-actin (IMAGp998L23787)

BI-1 (1.4 kb) cut out with Not I and Eco RI from image clone, pT7T3D-Pac with subcloned cDNA for human BI-1 (IMAGp998B10404)

IGFBP-3 (0.7 kb) cut out with Not I and Eco RI from image clone, pT7T3D-Pac with subcloned cDNA for human $\beta$-actin (IMAGp998N15824)

IGF-IR $(0.7 \mathrm{~kb})$ cut out with Hind III and Bam HI from pMT/EP with subcloned cDNA for human IGFIR (Burfeind et al. 1996)

MIC-1 (1.0 kb) RT-PCR product was generated by using primers described below, subcloned to pGEMT-Easy and cut out with Eco RI

\subsection{Synthetic oligonucleotide primers}

The synthetic oligonucleotide primers used either for sequencing of constructs or cDNA probes were ordered from NAPS (Göttingen) and Roth (Karlsruhe), respectively.

Insulin-like growth factor type I receptor (IGF-IR):

IGF-IR Forward (Fw)

5' - AGG AAT GAA GTC TGG CTC CGG - 3'

IGF-IR Reverse (Rev)

5' - GCA GCA CTC ATT GTT CTC GGT GC - 3' 
Macrophage inhibitory cytokine-1 (MIC-1):

MIC-1 Fw

5' - ACG CTG AAT GGC TCT CAG AT - 3'

MIC-1 Rev

5' - AAT ACA GCT GTT TGG GCA GG - 3'

Standard sequencing primers:

SP6

$\mathrm{T} 3$

$\mathrm{T} 7$

T7 modified
5' - AGG TGA CAC TAT AGA ATA C - 3'

5' - AAT TAA CCC TCA CTA AAG GG - 3'

5'-GTA ATA GCA CTC ACT ATA GGG C-3'

5' - TAA TAC GAC TCA CTA TAG GGA - 3'

The synthetic oligonucleotide primers used for real time RT-PCR analysis by using SYBR Green I dye were ordered from NAPS (Göttingen) and Roth (Karlsruhe).

Complement component $1 \mathrm{~s}(\mathrm{C} 1 \mathrm{~s})$ :

C1s Fw:

5'- CTG ACG GCT GCT CAT GTT GT -3'

C1s Rev:

5'- CCC CAC CAC TGT CCC CTT TA -3'

Ferritin heavy chain (FeHC):

FeHC Fw:

5'- GGG CTG AAT GCA ATG GAG TG -3'

FeHC Rev:

5'- GGT AAA GGA AAC CCC AAC ATG -3'

Mammary tumor $8 \mathrm{kDa}$ protein (MAT-8):
MAT-8 Fw:
5'- CCC GCT ATG ATG GAA GTG TT -3'
MAT-8 Rev:
5'- GGA CTT TGA GGC TTG TTG GA -3'

Peptidyl-prolyl cis-trans isomerase A (PpctIM):

PPctIM-A Fw:

5'- TAC GGG TCC TGG CAT CTT GT -3'

PPctIM-A Rev:

5'- AGC TAG GCA TGG GAG GGA AC -3'

RNA-binding protein regulatory subunit DJ-1protein (RBPDJ-1):

RBPDJ-1 Fw:

5'- GAT GCC AGC CTT GAA GAT GC -3'

RBPDJ-1 Rev:

5'- GGA CAG CGA CTT CTG AAC ACA -3' 
Vacuolar-type ATP sythase subunit F (VATF):

VATF Fw: 5'- GCC CAC CAG CAG TCC ATC -3'

VATF Rev: 5'- CAA GAA TAT GAC TTT AAT TTA ACA -3'

The synthetic oligonucleotide primers and their dual-labeled probes used for real time RTPCR were ordered from Qiagen (Hilden).

Human $ß$-actin (ß-actin):

B-actin Fw:

5 '-TCACCCACACTGTGCCCATCTACGA-3'

B-actin Rev:

5'-GGTAACCGTTACTCGCCAAGGCGAC-3'

B-actin probe:

5 `-TEXAS RED-ATGCCCTCCCCCATGCCATCCTGCGT-BHQ-3

Bax inhibitor-1 (BI-1):

BI-1 Fw:

5'-ACGGACTCTGGAACCATGAA-3`

BI-1 Rev: 5'-AGCCGCCACAAACATACAA-3’

BI-1 probe: 5`FAM-ATATAACCCCGTCAACGCAGCAGCACC-3`TAMRA Insulin-like growth factor binding protein 3 (IGFBP-3):

IGFBP-3 Fw: 5'-GAACTTCTCCTCCGAGTCCAA-3'

IGFBP-3 Rev: 5'-GAGTTACACGACTCAGGGTC-3'

IGFBP-3 probe: 5'FAM-GGTCCCTGCCGTAGAGAAA-3'TAMRA

Insulin-like growth factor type-1 receptor (IGF-IR):

IGF-IR Fw:

5'-CCGAAGGTCTGTGAGGAAGA-3

IGF-IR Rev:

5'-AATGGCGGATCTTCACGTAG-3'

IGF-IR probe:

5'FAM-TGCTCAGATGCTCCAAGGATGCA-3'TAMR

Matrix metalloproteinase-2 (MMP-2):

MMP-2

5'-CCAAGTGGTCCGTGTGAAGT-3'

MMP-2

5'-CATGGTGAACAGGGCTTCAT-3'

MMP-2 probe:

5'FAM-ATGGGAACGCCGATGGGGAG-3'TAMRA 


\subsection{Antibodies}

Primary and secondary antibodies described below were used for Western blot experiments.

goat polyclonal antibody against human BI-1 (A-18)

goat polyclonal antibody against human IGFBP-3 (C-19)

mouse monoclonal antibody against $\alpha$-tubulin (clone B-5-1-2)

rabbit polyclonal antibody against human IGF-IR $\alpha(\mathrm{N}-20)$

anti-goat IgG Alkaline phosphatase conjugate (A-4062)

anti-rabbit IgG Alkaline phosphatase conjugate (A-3687)

anti-mouse IgG Alkaline phosphatase conjugate (A-9316)
Santa Cruz Biotechnology Inc., Heidelberg

Santa Cruz Biotechnology Inc., Heidelberg

Sigma-Aldrich Chemie GmbH, Munich

Santa Cruz Biotechnology Inc., Heidelberg

Sigma-Aldrich Chemie GmbH, Munich

Sigma-Aldrich Chemie GmbH, Munich

Sigma-Aldrich Chemie GmbH, Munich

\subsection{Isolation of nucleic acids}

\subsubsection{Small-scale preparation of plasmid DNA (Mini prep)}

$5 \mathrm{ml}$ of LB medium with ampicillin was inoculated with a single $E$. coli colony and incubated overnight at $37^{\circ} \mathrm{C}$ with shaking. $3 \mathrm{ml}$ of this culture was centrifuged at $5000 \mathrm{x} \mathrm{g}$ for $10 \mathrm{~min}$. The pellet was resuspended in $100 \mu \mathrm{l}$ of solution E1. After adding $200 \mu \mathrm{l}$ and $150 \mu \mathrm{l}$ of solution E2 and E3, respectively, the pellet was incubated on ice for $5 \mathrm{~min}$, and centrifuged at $10000 \mathrm{x} \mathrm{g}$ at $4^{\circ} \mathrm{C}$. The supernatant was transferred into a new tube, and $1 \mathrm{ml}$ of $100 \%$ ethanol was added to precipitate the DNA. It was then stored at $-20^{\circ} \mathrm{C}$ for $30 \mathrm{~min}$, centrifuged at $10000 \mathrm{x}$ g for $30 \mathrm{~min}$ and finally the pellet was dissolved in $30 \mu \mathrm{l}$ of sterile $\mathrm{H}_{2} \mathrm{O}$. 


\subsubsection{Preparation of bacterial glycerol stocks}

To $1 \mathrm{ml}$ resuspended bacteria in LB medium $250 \mu 180 \%(\mathrm{v} / \mathrm{v})$ sterile glycerol was added. The suspension was mixed well and stored at $-80^{\circ} \mathrm{C}$.

\subsubsection{Large-scale preparation of plasmid DNA (Midi prep)}

$100 \mathrm{ml}$ of LB medium with ampicillin was inoculated with a transformed E. coli stock and incubated overnight at $37^{\circ} \mathrm{C}$ with shaking. The plasmid DNA was isolated with the PlasmidMidi Kit (Qiagen, Hilden) according to the user manual and dissolved in $100 \mu 1$ of sterile $\mathrm{H}_{2} \mathrm{O}$. The isolated plasmid DNA was further used for transfection, sequencing, restriction analysis and subcloning.

\subsubsection{Isolation of total RNA from eukaryotic cells}

Total RNA from eukaryotic cells was isolated with the RNeasy Mini Kit (Qiagen) according to the user manual and resuspended in 80-100 $\mu$ l RNase-free water. The measured concentrations varied between 0.5 to $1.0 \mu \mathrm{g}$ per $\mu 1$.

\subsubsection{Isolation of total RNA from tissues}

Radical prostatectomy specimens of patients suffering from prostate cancer were freshly obtained from the Urological Clinic of the University Hospital, Georg-August-University of Göttingen

100-200 mg tissue sample was homogenized in 1-2 $\mathrm{ml}$ of lysis buffer supplemented with $\beta$ mercaptoethanol by using a glass-teflon homogenizer. Total RNA from prostate and matched prostate carcinoma tissue (Gleason score 5, tumor stage pT3aN0) was isolated with the RNeasy Mini Kit (Qiagen) according to the manufacturer's instructions and resuspended in 80-100 $\mu 1$ RNase-free water. The measured concentrations varied between 0.5 to $1.0 \mu \mathrm{g}$ per $\mu \mathrm{l}$. 


\subsubsection{Isolation of poly (A) ${ }^{+}$-enriched RNA}

To isolate polyadenylated mRNA from total RNA, the Qiagen Oligotex kit was employed. The purification procedure makes use of oligo-dT coated latex particles that provide a hybridization carrier on which nucleic acids containing polyadenylic acid sequences can efficiently immobilized and easily recovered. $100 \mu \mathrm{g}$ of total RNA was used according to the user manual and finally 1-2 $\mu \mathrm{g}$ of poly (A) ${ }^{+}$RNA was eluted with $20 \mu 1$ RNase-free water.

\subsubsection{Determination of nucleic acid concentration}

The concentration of nucleic acids was determined photometrically by measuring the absorption of the samples at $260 \mathrm{~nm}$ (Spectrophotometer Ultrospec 300pro, Amersham, Braunschweig) DNA and RNA quality, i.e. contamination with salt and protein was checked by the measurements at 230,280, and $320 \mathrm{~nm}$. The concentration can be calculated according to the formula: $\quad \mathrm{C}=(\mathrm{E} 260-\mathrm{E} 320) \times \mathrm{f} \times \mathrm{c}$

$\mathrm{C}=$ concentration of sample $(\mu \mathrm{g} / \mu \mathrm{l})$

E $260=$ absorption at $260 \mathrm{~nm}$

E $320=$ absorption at $320 \mathrm{~nm}$

$\mathrm{f}=$ dilution factor

$\mathrm{c}=$ concentration (standard) / absorption (standard)

For double stranded DNA : $\mathrm{c}=0.05 \mu \mathrm{g} / \mu 1$

For single stranded DNA : $\mathrm{c}=0.03 \mu \mathrm{g} / \mu \mathrm{l}$

For RNA : $\mathrm{c}=0.04 \mu \mathrm{g} / \mu \mathrm{l}$ 


\subsection{Cloning techniques}

\subsubsection{Restriction analysis of DNA}

Restriction enzyme digestions were performed by incubating double-stranded DNA molecules with an appropriate amount of restriction enzyme in its respective buffer as recommended by the supplier, and at the optimal temperature for the specific enzyme. These reactions were usually incubated for 1-3 hours or over night to insure complete digestion at the optimal temperature for enzyme activity which was typically $37^{\circ} \mathrm{C}$.

\subsubsection{Isolation of DNA fragments from agarose gels}

For the isolation of DNA fragments from agarose gels the QIAEX-II kit (Qiagen) was employed. After separation of DNA on an agarose gel, the DNA band which had to be isolated was excised with a razor blade, weighed and treated as described in the user manual. Isolated DNA fragments were checked on agarose gels and used for subcloning or as a probe for Northern blot experiments.

\subsubsection{Dephosphorylation of 5' ends of DNA}

To prevent the recircularization of plasmids without insertion of foreign DNA, alkaline phosphatase treatment was performed. Alkaline phosphatase catalyses the hydrolysis of 5'phosphate residues from DNA. The following items were mixed: 1-5 $\mu$ g vector DNA, $5 \mu 110$ $\mathrm{x}$ reaction buffer, $1 \mu \mathrm{l}$ alkaline phosphatase $(1 \mathrm{U})$ in a total volume of $50 \mu 1$ and incubated at $37^{\circ} \mathrm{C}$ for $30 \mathrm{~min}$. Then the reaction was stopped by heating at $85^{\circ} \mathrm{C}$ for $15 \mathrm{~min}$. The dephosphorylated DNA was purified by phenol/ chloroform extraction and ethanol precipitation. 


\subsubsection{Phenol-chloroform extraction and ethanol precipitation}

Protein impurities were removed by vigorous shaking of nucleic acid solution with an equal volume of phenol/chloroform/isoamyl alcohol mixture $(25: 24: 1)$. The emulsion was then centrifuged for $1 \mathrm{~min}, 10000 \mathrm{xg}$, at room temperature (RT), and the upper aqueous phase was collected, mixed with an equal volume of chloroform and centrifuged (1 min, RT, $10000 \mathrm{x} \mathrm{g})$. Finally, the upper aqueous phase was collected for precipitation.

Nucleic acids were precipitated by addition of $\mathrm{NaAc}$ (final conc. $0.3 \mathrm{M}$ ) and 2.6 volume of absolute ethanol. The mixture was then vortexed and centrifuged $\left(5 \mathrm{~min}, 4^{\circ} \mathrm{C}, 10000 \mathrm{x} \mathrm{g}\right)$. The pellet was washed with 70\% ethanol and centrifuged (5 min, RT, $10000 \mathrm{x} \mathrm{g}$ ). After washing, the supernatant was aspirated and the pellet was air dried. The dried pellet was redissolved in sterile RNase free water or TE buffer.

\subsubsection{Filling-up reaction of DNA ends}

0.1-4 $\mu \mathrm{g}$ of digested DNA was mixed with $0.05 \mathrm{mM}$ dNTPs and 1-5 $\mathrm{U}$ of Klenow fragment. The reaction was incubated at $37^{\circ} \mathrm{C}$ for $10 \mathrm{~min}$, then stopped by heating at $75^{\circ} \mathrm{C}$ for $10 \mathrm{~min}$. Then, DNA was purified by phenol/ chloroform extraction and ethanol precipitation.

\subsubsection{Ligation of DNA fragments}

The ligation of an insert into a vector was carried out in the following reaction mix: $25-50 \mathrm{ng}$ vector DNA, 50-100 ng insert DNA, $1 \mu$ l ligation buffer $(10 \mathrm{x}), 1 \mu \mathrm{T} 4 \mathrm{DNA}$ ligase $(5 \mathrm{U} / \mu \mathrm{l})$ in a total volume of $10 \mu \mathrm{l}$. Blunt-end ligations were carried out at $16{ }^{\circ} \mathrm{C}$ overnight, whereas sticky-end ligations were carried out at room temperature for 2-4 hours.

\subsubsection{Subcloning of PCR and RT-PCR products}

Taq and other polymerases have a terminal transferase activity which results in the nontemplated addition of a single nucleotide to the 3'-ends of PCR products. In the presence of all four dNTPs, dA is preferentially added. This terminal transferase activity is the basis of the 
TA-cloning strategy. For the subcloning of PCR or RT-PCR products, the pGEM-T (Easy) Vector system which has $5^{\star} \mathrm{T}$ overhangs was employed. The following items were mixed;

$50 \mathrm{ng}$ of pGEM-T or pGEM-T Easy Vector

PCR product (3:1, insert: vector ratio)

$1 \mu 1$ T4 DNA Ligase 10x buffer

$1 \mu 1$ T4 DNA Ligase

in a total volume of $10 \mu 1$

The contents were mixed and the reaction was incubated overnight at $16{ }^{\circ} \mathrm{C}$.

\subsubsection{Transformation of competent cells with plasmid DNA}

Frozen competent $E$. coli $\mathrm{DH} 5 \alpha$ cells were thawed on ice and mixed with a small volume (5$10 \mu \mathrm{l})$ of plasmid DNA (1-100 ng). Incubation on ice for $20 \mathrm{~min}$ was followed by a heat shock for $2 \mathrm{~min}$ at $42^{\circ} \mathrm{C}$. Cells were placed back on ice for $2 \mathrm{~min}$ and $400 \mu \mathrm{l}$ antibiotic-free LB medium were added. After an incubation step for 1 hour at $37^{\circ} \mathrm{C}, 25 \mu \mathrm{l}$ and $75 \mu \mathrm{l}$ cell suspensions, respectively, were plated out on agar plates supplemented with $50 \mu \mathrm{g} / \mathrm{ml}$ ampicillin. The plates were then incubated overnight at $37^{\circ} \mathrm{C}$, single colonies were picked and inoculated into $5 \mathrm{ml} \mathrm{LB}$ medium supplemented with $100 \mu \mathrm{g} / \mathrm{ml}$ ampicillin. The cell suspension was further used for plasmid preparations or preparation of bacterial glycerol stocks. 


\subsection{Gel electrophoresis and blotting techniques}

Gel electrophoresis is the technique by which mixtures of charged macromolecules, especially nucleic acids and proteins, are rapidly resolved in an electrical field.

\subsubsection{Agarose gel electrophoresis of DNA}

Agarose gels are used to electrophorese nucleic acid molecules from as small as $150 \mathrm{bp}$ to more than $50 \mathrm{~kb}$, depending on the concentration of the agarose and the precise nature of the applied electrical field (constant or pulse). $0.5-2 \mathrm{~g}$ of agarose was dissolved in $100 \mathrm{ml} 0.5 \mathrm{x}$ TBE buffer, boiled in the microwave, then cooled down to about $50^{\circ} \mathrm{C}$ before adding $3 \mu 1$ ethidium bromide $(10 \mathrm{mg} / \mathrm{ml})$. The 0.5 to $2 \%(\mathrm{w} / \mathrm{v})$ gels were poured into a horizontal gel chamber. $10-20 \mu 1$ of DNA sample was mixed with $4 \mu 1$ of stop mix I, applied on gel and run at $50-150 \mathrm{~V}$.

\subsubsection{Agarose gel electrophoresis of RNA and Northern blot analysis}

(Maniatis and Efstratiadis 1980)

Single-stranded RNA molecules often have small regions that can form base-paired secondary structures. To prevent this, the RNA should be run on a denaturing agarose gel which contains formaldehyde, and additionally is pre-treated with formaldehyde and formamide.

$2 \mathrm{~g}$ of agarose was dissolved in $20 \mathrm{ml}$ of $10 \mathrm{x}$ MOPS buffer and $144 \mathrm{ml}$ of DEPC water. After cooling it to about $50^{\circ} \mathrm{C}, 36 \mathrm{ml}$ of formaldehyde $(37 \%)$ was added, stirred and poured into a vertical gel chamber. To $10-20 \mu \mathrm{g}$ of total RNA (or 0.5 to $1 \mu \mathrm{g}$ of mRNA),

$2 \mu 110 \times$ MOPS

$3 \mu 1$ Formaldehyde

$8 \mu 1$ Formamid (40\%)

$1.5 \mu 1$ Ethidium bromide

were added and the samples were denatured at $65^{\circ} \mathrm{C}$ for $10 \mathrm{~min}$, and chilled on ice before applying to the gel together with $6 \mu 1$ of stop mix II. The gel was run at $60 \mathrm{~V}$ for about $6-8$ 
hours. Subsequently after separation on a denaturing agarose gel, the RNA samples were transferred to a Hybond-C nylon membrane (Amersham Pharmacia Biotech, Buckinghamshire) by using the Turbo-blotter (Schleicher \& Schuell, Dassel) according to the user manual. The RNA was fixed onto the membrane by incubating it for 2 hours at $80^{\circ} \mathrm{C}$ and used for hybridization.

\subsubsection{DNA and RNA molecular weight ladders}

To determe the size of the nucleic acids fragments on agarose gels, molecular weight ladders were loaded in parallel.
$1 \mathrm{~kb}$ DNA Ladder
Gibco BRL, Karlsruhe
100 bp DNA Ladder
Gibco BRL, Karlsruhe
0.24-9.5 RNA Ladder
Gibco BRL, Karlsruhe

\subsection{Sequencing}

The non-radioactive sequencing was achieved with Dye Terminator Cycle Sequencing-Kit (ABI, Weiterstadt). The principle of this procedure is based on the method described by Sanger et al. (1992). The sequencing reaction was carried in a total volume of $10 \mu 1$ containing $1 \mu \mathrm{g}$ plasmid DNA or 100-200 ng purified PCR products, 10 pmol primer and $4 \mu 1$ reaction mix (contains dNTPs, dideoxy dye terminators and Taq DNA polymerase). Elongation and chain termination takes place during the following program in a thermocycler: 5 min denaturing followed by 25 cycles $95^{\circ} \mathrm{C} 30 \mathrm{sec}$, denaturing; $55^{\circ} \mathrm{C} 15 \mathrm{sec}$, annealing; $70^{\circ} \mathrm{C} 4 \mathrm{~min}$, elongation. After the sequencing reaction, the DNA was precipitated with $1 / 10$ volume $3 \mathrm{M} \mathrm{NaAc}$ and 2.5 volume $100 \%$ ethanol. The pellet was dissolved in $4 \mu 1$ of loading buffer, denatured at $95^{\circ} \mathrm{C}$ for $3 \mathrm{~min}$ and finally loaded onto the sequence gel. The reaction products were analyzed with an automatic sequencing equipment, namely DNA Sequencer 377 (ABI, Weiterstadt) by using Mac Molly Tetra Software Packets (Softgene, Berlin). 
The obtained sequences were analyzed with a BLAST program (Altschul et al. 1990) by using the sequence data base Genbank (www.ncbi.nlm.nih.gov) and EMBL (www.ebi.ac.uk).

\subsection{One-step RT-PCR}

To obtain specific RT-PCR products, the QIAGEN OneStep RT-PCR kit was employed which contains optimized components that allow both reverse transcription and PCR amplification to take place in what is commonly referred to as a "one-step" reaction.

Master mix;

5 x Qiagen OneStep RT-PCR buffer

$\underline{\text { Per reaction }}$

dNTP mix (containing $10 \mathrm{mM}$ of each dNTP)

$10 \mu 1$

Forward primer (10 pmol)

$2 \mu 1$

Reverse primer (10 pmol)

$1 \mu 1$

Qiagen OneStep RT-PCR Enzyme Mix

$1 \mu 1$

$2 \mu 1$

RNase inhibitor (20 units per $1 \mu \mathrm{l}$ )

$1 \mu 1$

RNase-free water

$31 \mu 1$

$2 \mu \mathrm{l}(2 \mu \mathrm{g})$ of total RNA isolated from PC-3 cells was added to $48 \mu \mathrm{l}$ of prepared Master mix in a PCR tube, the sample was placed in the thermal cycler and the RT-PCR program run according to the user manual. After the amplification step the sample was checked on an agarose gel.

Thermal cycler conditions:

Reverse transcription:

$30 \min \quad 50{ }^{\circ} \mathrm{C}$

Initial PCR activation step:

$15 \min \quad 95^{\circ} \mathrm{C}$

40 cycles

Denaturation:

$30 \mathrm{sec}$

$94{ }^{\circ} \mathrm{C}$

Annealing:

$40 \mathrm{sec} \quad 56-60^{\circ} \mathrm{C}$ (depending on primers)

Extension:

$1 \mathrm{~min} \quad 72^{\circ} \mathrm{C}$ 


\subsection{Labeling and hybridization of nucleic acids}

\subsubsection{Generation of ${ }^{32} \mathrm{P}$ labeled cDNA by using the „random prime“" method}

The Ready Prime kit II (Amersham, Braunschweig) was employed for labeling DNA fragments with $\left[\alpha-{ }^{32} \mathrm{P}\right]$ isotopes. The method relies on the random priming principle developed by Feinberg and Vogelstein (1989). The reaction mix contains dATP, dGTP, dTTP, Klenow fragment (4-8 units) and random oligodeoxyribonucleotides, primarily 9-mers. 25-50 ng of DNA was denatured in a total volume of $46 \mu 1$ at $95^{\circ} \mathrm{C}$ for $15 \mathrm{~min}$. It was then transferred to the Ready Prime reaction cup, mixed thoroughly by vortexing, and finally $4 \mu 1$ of $\left[\alpha^{-}{ }^{32} \mathrm{P}\right] \mathrm{dCTP}(40 \mu \mathrm{Ci})$ was added to the reaction mixture. The labeling reaction was carried out at $37^{\circ} \mathrm{C}$ for 1-3 hours. Then, the labeled DNA was purified with the use of MicroSpin G25 Columns (Amersham) and the specific radioactivity was measured by using a scintillation counter (Tri-Carb 1600TR, Packard Instruments, Warrenville, USA) and varied between 4 to $10 \times 10^{7} \mathrm{cpmA}$.

\subsubsection{Northern blot hybridization with radioactive labeled cDNA-probes}

The membrane to be hybridized was first equilibrated in $2 \times \mathrm{SSC}$, then transferred to a hybridization bottle. After adding $10 \mathrm{ml}$ of Rapid-hyb buffer (Amersham), the membrane was incubated for 2 hours in the hybridization oven at an appropriate temperature which was usually $65^{\circ} \mathrm{C}$. Then, the labeled probe and salmon DNA $(3 \mathrm{mg})$ were denatured at $95^{\circ} \mathrm{C}$ for 10 min and added to the hybridization solution. The hybridization was carried out overnight in the oven. Next day, the filters were washed at room temperature (RT) for 15 min in $2 \times$ SSC followed by 5 to $15 \mathrm{~min}$ in $0.5 \mathrm{x} \mathrm{SSC}$ and $0.5 \% \mathrm{SDS}$ (weight/volume) at $65^{\circ} \mathrm{C}$. After drying the filter, it was sealed in saran wrap and exposed to an autoradiogram overnight at $-70^{\circ} \mathrm{C}$ or to a phosphor-imager screen (Bio-Rad, Hercules, USA) at RT. Then, the hybridization signals were quantified with the Molecular Imager FX (Bio-Rad) by using the Quantity one software (Bio-Rad). 


\subsection{Isolation of differentially expressed genes (Atlas Array)}

To identify genes which are differentially expressed between two RNA populations the Atlas Select ${ }^{\mathrm{TM}}$ Human Tumor Array and Atlas Human Cancer 1.2 Array from Clontech (Palo Alto, CA, USA) were used. Atlas Arrays are nylon membranes on which cDNA fragments from hundreds of genes have been immobilized. With Atlas, one simple hybridization experiment provides a visual profile of gene expression in the investigated samples.

The Atlas Select ${ }^{\mathrm{TM}}$ Human Tumor Array is a premade array of known and novel human cDNAs that were found to be up- or down-regulated in human tumors using Clontech PCRSelect ${ }^{\mathrm{TM}}$ cDNA subtraction. This array contains immobilized cDNAs of differentially expressed genes from five different human tumors, i.e. bladder, breast, liver, lung and prostate carcinoma and includes 437 differentially expressed cDNAs of which 61 are unknown sequences, 16 have partial homology to known sequences, nine have homology to known ESTs, and 365 are known genes. The Atlas ${ }^{\mathrm{TM}}$ Human Cancer 1.2 Array contains 1.176 unique cDNA fragments for human genes involved in many aspects of cancer and tumor biology, e.g., cell-cycle regulation, apoptosis, angiogenesis, cell-cell interactions, invasion, cell adhesion and motility.

\subsubsection{Overview of the Atlas Array procedure}

(Chalifour et al., 1994; Lockhart et al. 1996)

The Atlas procedure is outlined in Figure 3. Identical membranes are included with each purchase, so the expression profiles of different mRNA populations can be compared side-byside. The first step was to synthesize probe mixtures by reverse transcribing each RNA population using the cDNA Synthesis (CDS) Primer Mix included in the kit and $\left[\alpha-{ }^{32} \mathrm{P}\right]$ dATP. The CDS Primer Mix is a mixture of primers specific for different type of Atlas Array. These Primer Mixes ensure that cDNAs are only synthesized for the genes on a particular Atlas Array. Each radioactively labeled probe mix was then hybridized to separate Atlas Arrays. After a high-stringency wash, the hybridization patterns were analyzed by autoradiography and quantified by phosphorimaging. The relative expression levels of a given 
cDNA from two different RNA populations were assessed by comparing the signal obtained with a probe from one RNA source to that obtained with a probe from another source.

\section{Tissue 1}

\section{Tissue 2}

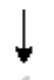

RNA isolation

RNA Sample 1

RNA Sample 2

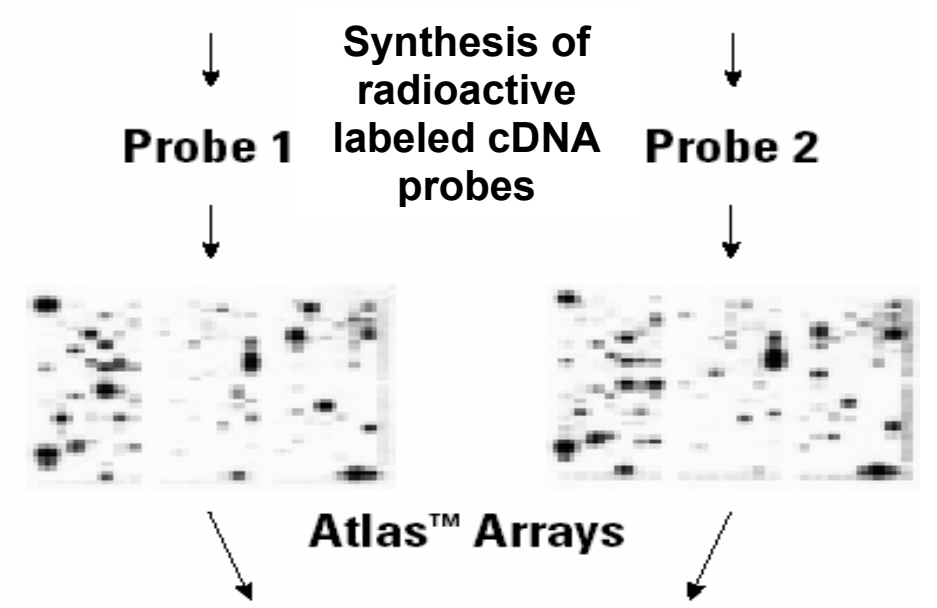

Analysis of differentially expresed genes

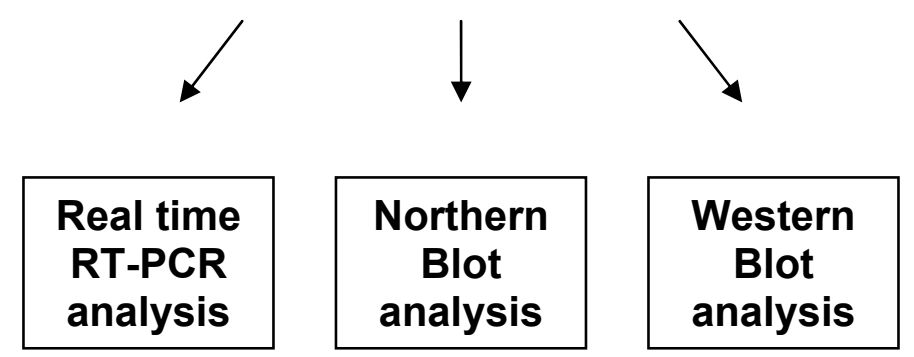

Figure 3. Schematic representation of the broad-scale expression profiling with Atlas ${ }^{\mathrm{TM}}$ Arrays. (modified after Clontech protocol \# PT3140-1)

Side-by-side hybridizations with radioactive labeled cDNA probes prepared from two different RNA populations allowed the simultaneous comparison of the expression levels of all the cDNAs on the array. Furthermore, the expression of identified genes was verified by Northern blot, quantitative RTPCR and Western blot analysis, respectively. The RNA populations that were compared by this method included normal prostate and prostate tumor samples and PC-3 cells cultured in the different in vitro conditions. 


\subsubsection{Preparation of whole cDNA probes from total RNA}

To analyze gene expression patterns using the arrays described above, cDNA probes were generated from total RNA samples. The Atlas ${ }^{\mathrm{TM}}$ Pure Total RNA Labeling System (Clontech) was used in conjunction with reagents supplied with the Atlas Arrays to synthesize highly sensitive Atlas cDNA probes directly from total RNA. The key components in the Atlas Pure System are streptavidin-coated magnetic beads and biotinylated oligo(dT) which allow to carry out both poly(A) ${ }^{+}$-RNA enrichment and probe synthesis in a single procedure. This simplicity is possible because probes are synthesized while poly $(\mathrm{A})^{+}-\mathrm{RNA}$ remains bound to the magnetic beads, eliminating potentially troublesome intermediate poly $(\mathrm{A})^{+}-\mathrm{RNA}$ purification steps. By using this procedure, Atlas probes made from total RNA produce results that are just as reliable as those from pure poly(A) ${ }^{+}$-RNA, a clear advantage when only small amounts of tissues or cells are available.

\subsubsection{DNase treatment of total RNA}

First, total RNA $(50 \mu \mathrm{g})$ was treated with RNase-free DNase I (Clontech) according to the user manual where the following reagents were combined: $100 \mu 1$ of total RNA $(1 \mathrm{mg} / \mathrm{ml}), 20$ $\mu 110 \times$ DNase I buffer, $10 \mu \mathrm{l}$ DNase I (1 unit/ml), $70 \mu 1$ deionized water, mixed and incubated at $37^{\circ} \mathrm{C}$ for $30 \mathrm{~min}$. Next, $20 \mu \mathrm{l}$ of $10 \mathrm{x}$ termination mix was added and the RNA samples were purified by phenol/ chloroform extraction and ethanol precipitation. The air dried pellet was dissolved in $50 \mu \mathrm{l}$ RNase-free water and $4 \mu 1$ of the RNA mixture was checked on a denaturing agarose gel to verify RNA yield and purity.

\subsubsection{Poly(A) ${ }^{+}$RNA enrichment}

To prepare Streptavidin Magnetic Beads, $15 \mu 1$ of beads per probe synthesis reaction were aliquoted into one $0.5-\mathrm{ml}$ tube and separated on a magnetic particle separator (Bioworld, Dublin, USA). The supernatant was discarded and beads were washed three times with $150 \mu 1$ of $1 \mathrm{x}$ binding buffer. Subsequently, beads were resuspended in $15 \mu 11 \mathrm{x}$ binding buffer per reaction and kept at room temperature until use. To $45 \mu \mathrm{l}(50 \mu \mathrm{g})$ of DNAse treated total RNA $1 \mu 1$ of biotinylated oligo(dT) was added and thoroughly mixed by pipetting. The sample was 
incubated at $70^{\circ} \mathrm{C}$ for $2 \mathrm{~min}$ in the preheated thermal cycler and cooled to RT for $10 \mathrm{~min}$. Next, $45 \mu 12 \times$ binding buffer and $15 \mu$ l washed beads were added to each RNA sample, mixed well by pipetting and incubated on a shaker at $1.500 \mathrm{rpm}$ for $25-30 \mathrm{~min}$ at RT. Then, the beads were separated using the magnetic separator, the supernatant was discarded and the beads were washed two times with $50 \mu 11 \mathrm{x}$ wash buffer and one time with $50 \mu 11 \mathrm{x}$ reaction buffer. Finally, the beads were resuspended in $6 \mu$ RNase-free water.

\subsubsection{Whole cDNA probe synthesis}

Master mix for all labeling reactions was prepared plus one extra reaction by combining the following in a $0.5-\mathrm{ml}$ microcentrifuge tube at room temperature:

per reaction

$5 \mathrm{x}$ reaction buffer

$4 \mu 1$

10 x dNTP Mix (for dATP label

$2 \mu 1$

$\left[\alpha-{ }^{32} \mathrm{P}\right] \mathrm{dATP}(10 \mu \mathrm{Ci} / \mu \mathrm{l})$

$5 \mu 1$

DTT $(100 \mathrm{mM})$ $0.5 \mu 1$

Total volume

To the resuspended beads $4 \mu \mathrm{l}$ of CDS Primer Mix was added, mixed well by pipetting and incubated in the preheated thermal cycler at $65^{\circ} \mathrm{C}$ for $2 \mathrm{~min}$. Then, the temperature of the thermal cycler was reduced to $50^{\circ} \mathrm{C}$ and the samples were incubated for $2 \mathrm{~min}$. During this incubation step, $2 \mu 1$ MMLV Reverse Transcriptase per reaction was added to the Master mix ( $6 \mu 1$ MMLV RT for the 3-reaction Master mix). After completion of the 2-min incubation at $50^{\circ} \mathrm{C}, 13.5 \mu \mathrm{l}$ of Master Mix was added to each reaction tube. The samples were incubated at $50^{\circ} \mathrm{C}$ for $25 \mathrm{~min}$ and after completion of the 25 -min incubation $2 \mu 110 \mathrm{x}$ Termination Mix was added and labeled probes were purified with column chromatography.

\subsubsection{Purification of labeled cDNA probes by column chromatography}

To purify the labeled cDNA from nonincorporated ${ }^{32} \mathrm{P}$-labeled nucleotides and small $(<0.1$ $\mathrm{kb}) \mathrm{cDNA}$ fragments, the following procedure for each reaction tube was used. The Atlas 
cDNA probe synthesis reactions were diluted to $200 \mu 1$ total volume with buffer NT2, mixed well by pipetting and pipetted into a NucleoSpin Extraction Spin Column placed in a 2-ml collection tube and centrifuged at $10000 \mathrm{x} g$ for $1 \mathrm{~min}$. Then, the NucleoSpin column was inserted into a fresh 2-ml Collection Tube, $400 \mu \mathrm{l}$ buffer NT3 was added to the column, centrifuged at $10000 \mathrm{x} \mathrm{g}$ for $1 \mathrm{~min}$. and the flow-through was discarded. This washing step with NT3 buffer was repeated twice. Next, the NucleoSpin column was transferred to a clean 1.5-ml microcentrifuge tube, $100 \mu 1$ of buffer NE was added and the column was allowed to soak for $2 \mathrm{~min}$. After completion of the 2-min incubation step, the column was centrifuged at $10000 \mathrm{x} g$ for $1 \mathrm{~min}$ to elute the purified probe. The radioactivity of the probe was checked by using the Liquid scintillation analyzer 1600TR (Packard). $2 \mu 1$ of each purified probe was added to $5 \mathrm{ml}$ of scintillation fluid in separate scintillation-counter vials. The ${ }^{32} \mathrm{P}$-labeled samples were counted and counts were multiplied by a dilution factor of 50. Whole cDNA probes synthesized from total RNA using this procedure had a total activity of $2-5 \times 10^{6} \mathrm{cpm}$.

\subsubsection{Hybridization of Atlas Arrays with labeled cDNA probes}

To $5 \mathrm{ml}$ of prewarmed ExpressHyb solution $\left(68^{\circ} \mathrm{C}\right)$ heat-denatured sheared salmon sperm DNA $(0.5 \mathrm{mg})$ was added and kept at $68^{\circ} \mathrm{C}$ until use. Prewetted Atlas Arrays were placed into a hybridization tube filled with water. The water was poured off and the membrane was adhered to the inside wall of the tube without creating air pockets. Then, $5 \mathrm{ml}$ of the prepared hybridization solution was added to each tube and the membranes were prehybridized for 30 min with continuous agitation at $68^{\circ} \mathrm{C}$ and at 5-7 rpm. During this incubation $5 \mu 1$ Cot-1 DNA $(1 \mathrm{mg} / \mathrm{ml})$ was added to the labeled cDNA probe. Subsequently, the probe was incubated at $95^{\circ} \mathrm{C}$ for $10 \mathrm{~min}$ and cooled on ice for $2 \mathrm{~min}$. The prepared cDNA probe mixture was directly added to the prehybridization solution and the filters were hybridized overnight at $68^{\circ} \mathrm{C}$. The Atlas Arrays were washed four times in wash solution 1 ( $2 \times \mathrm{SSC}, 1 \% \mathrm{SDS})$ at $68^{\circ} \mathrm{C}$ for 30 min and one time in wash solution $2(0.1 \mathrm{x} \mathrm{SSC}, 0.5 \% \mathrm{SDS})$ at $68^{\circ} \mathrm{C}$ for $30 \mathrm{~min}$. Then, one final 5-min wash in $2 \times$ SSC with agitation at RT was performed. The damp membranes were immediately transferred into a plastic wrap and exposed to X-ray film at $-70^{\circ} \mathrm{C}$ or to a phosphorimaging screen at room temperature. The signals were scanned after a 3-day exposure by using a Molecular Imager FX (Bio-Rad GmbH, Munich) and analyzed by using the Quantity one software (Bio-Rad). 


\subsection{Analysis of gene expression of multiple tumor samples (Cancer Profiling Array)}

The Cancer Profiling Array (Clontech) is a nylon membrane that contains more than 240 cDNA pairs, each pair representing cDNAs generated from RNAs of tumor and normal tissue from a single patient. This array provides a high-throughput format for analyzing differential gene expression. After identifying a differentially expressed gene with Atlas Arrays the Cancer Profiling Array can be used to view the distribution of a differentially expressed gene across many samples. Some samples represent different stages of malignancy for one type of the tumor, therefore a particular tumor stage can be correlated with distinctive gene expression patterns. In addition to clinical samples, the array contains cancer cell line samples and negative and positive controls. Amplified full-length cDNA accurately preserves the relative abundance of mRNA in a sample, making the array suitable for detecting differential expression of a gene across many different samples. The quantitative profiling of gene expression on the array is normalized to three different house-keeping genes.

The Cancer Profiling Array was used to determine the role of particular genes (IGFBP-3 and BI-1) in a broad range of cancer cell types. The cDNA fragments for IGFBP-3 and BI-1 were labeled as described above in section 2.14.1 and the labeled probes were hybridized to the Cancer Profiling Array as described in paragraph 2.14.7. The signals were scanned after a 1day exposure by using a Molecular Imager FX (Bio-Rad GmbH, Munich, Germany) and analyzed by using the Quantity one software (Bio-Rad).

\subsection{Protein techniques}

\subsubsection{Isolation of total proteins from eukaryotic cells}

The cells were cultured at $37^{\circ} \mathrm{C}$ in a humidified incubator with $5 \% \mathrm{CO}_{2}$ and grown to $80-90 \%$ confluence before isolation of total proteins. Cells were washed with PBS and $300 \mu 1$ of lysis buffer per big $\left(75 \mathrm{~cm}^{2}\right)$ cell culture flask (Greiner Nunc, Nürtingen) was added. The whole cell lysate was collected with a cell scraper and transferred to a separate $15 \mathrm{ml}$ Falcon tube. The sample was homogenized by using ultrasound (Sonifier 250, Branson Ultrasonic, 
Danbury, USA) and centrifuged for $5 \mathrm{~min}$ at $10000 \mathrm{x}$. The supernatant was the whole cell lysate which was used for Western blotting or stored at $-20^{\circ} \mathrm{C}$.

\subsubsection{Determination of protein concentration}

The concentration of protein was determined photometrically by measuring absorption of the samples at $260 \mathrm{~nm}$ and $280 \mathrm{~nm}$ in a spectrophotometer (Ultrospec 300pro, Amersham, Braunschweig). The concentration can be calculated according to the formula:

$$
\begin{aligned}
& \mathrm{C}=(1.55 \times \mathrm{A} 280)-(0.76 \times \mathrm{A} 260) \times \mathrm{f} \\
& \mathrm{C}=\text { concentration of sample }(\mu \mathrm{g} / \mu \mathrm{l}) \\
& \text { A } 280=\text { absorption at } 280 \mathrm{~nm} \\
& \text { A } 260=\text { absorption at } 260 \mathrm{~nm} \\
& \mathrm{f}=\text { dilution factor }
\end{aligned}
$$

\subsubsection{Electrophoresis of proteins}

The NuPAGE® Pre-Cast Gel System (Invitrogen) is a polyacrylamide gel system for high performance gel electrophoresis and is based on SDS-PAGE gel chemistry (Laemmli 1970). It consists of NuPAGE® Bis-Tris Pre-Cast Gels and specially optimized buffers which have an operating $\mathrm{pH}$ of 7.0, giving the system several advantages over existing polyacrylamide gel systems with an operating $\mathrm{pH}$ of 8.0. A neutral $\mathrm{pH}$ increased stability in both proteins and gels, providing with increased confidence in electrophoretic results.

To $26 \mu \mathrm{l}(50 \mu \mathrm{g})$ of whole protein lysate $10 \mu \mathrm{l}$ of $4 \mathrm{x}$ NuPAGE LDS (Sample buffer) and $4 \mu 1$ of DTT (Reducing Agent) were added. The samples were denatured at $70^{\circ} \mathrm{C}$ for $10 \mathrm{~min}$, chilled at room temperature for $5 \mathrm{~min}$, mixed and followed by gel electrophoresis using the NuPage 10\% Bis-Tris pre-cast gel in 1 x MES buffer (Invitrogen). To determine the size of the proteins on a gel, $10 \mu 1$ of a pre-stained molecular weight standard (See Blue Plus2, Invitrogen) was loaded. The gel was run at $150 \mathrm{~V}$ for 2 hours at RT. 


\subsubsection{Western blotting of proteins onto nitrocellulose filters}

(Gershoni and Palade 1982)

Transfer buffer: $25 \mathrm{mM}$ Tris $\mathrm{pH} 8.3$

$150 \mathrm{mM}$ Glycine

$10 \%$ Methanol

After the electrophoresis of proteins on a polyacrylamide gel, the gel and the nitrocellulose membrane Hybond-C (Amersham), which was cut at the size of the gel, were equilibrated in Transfer buffer for $10 \mathrm{~min}$. Three sheets of Whatman GB004 filter paper (Schleicher \& Schull, Dassel) were cut and soaked in the transfer buffer. The gel was placed on the membrane and subsequently on the pre-soaked filter papers. Another three sheets of presoaked filter paper were applied to complete the sandwich model, and it was placed into an electro-blotter (Biometra, Göttingen). The transfer was carried out at $100 \mathrm{~mA}$ at RT for 1-2 hours.

\subsubsection{Staining of polyacrylamide gel}

To asses transfer efficiency of proteins onto nitrocellulose membranes, the gel was incubated overnight in Coomassie blue solution and washed in water for 2-3 hours at RT.

\subsubsection{Incubation of protein-bound membranes with antibodies}

The membrane was first incubated in wash solution with 5\% non-fat dry milk for 1 hour at RT followed by an incubation step with a primary antibody at the recommended antibody dilution in wash solution with $2 \%$ non-fat dry milk for 1 hour at RT. Then, the membrane was washed five times in wash solution with $2 \%$ dry milk for 5 to $10 \mathrm{~min}$ and incubated with the appropriate secondary antibody at 1:10000 dilution in wash solution with $2 \%$ non-fat dry milk for 1 hour at RT. After an 1-hour incubation step the membrane was washed five times in wash solution with $2 \%$ dry milk, one time in wash solution without dry milk and one time in P3 buffer for $5 \mathrm{~min}$ at RT. Finally, the proteins on the membrane were visualized by an 
incubation step in the dark with $10 \mathrm{ml}$ of staining solution (alkaline phosphatase substrate solution) for $15 \mathrm{~min}$ and rinsed with water to stop the reaction.

Wash solution:

$150 \mathrm{mM} \mathrm{NaCl}$

$100 \mathrm{mM}$ Tris/ $\mathrm{HCl} \mathrm{pH} 7.5$

P3 buffer:

$100 \mathrm{mM} \mathrm{NaCl}$

$50 \mathrm{mM} \mathrm{MgCl} 2$

$100 \mathrm{mM}$ Tris/HCl pH 9.5

Staining Solution: $\quad 45 \mu \mathrm{l} \mathrm{NBT}(75 \mathrm{mg} / \mathrm{ml}$ in DMF)

$35 \mu 1 \mathrm{BCIP}(50 \mathrm{mg} / \mathrm{ml}$ in DMF) in $10 \mathrm{ml}$ of P3 buffer

(Carl Roth \& Co., Karlsruhe)

\subsection{Preparation of laser capture microdissection-derived total RNA}

These studies were performed in cooperation with Dr. Bernhard Hemmerlein from the Department of Pathology, Georg-August-University of Göttingen.

Laser capture microdissection (LCM) is a technique used to isolate selected subpopulations of cells from complex tissues. Under direct microscopic visualization laser pulses dissect selected cells from cryosections or sections from paraffin-embedded tissue supported on a transparent thermoplastic film. After LCM, cells adhere to their film support, these cells can be transferred to small scale extraction procedures to isolate proteins, DNA and RNA.

Differential expression analysis in epithelial tumors and prostate cancer in particular benefits from the LCM technique since prostate cancer cells only make up a very small dispersed portion within cancerous tissue. Bulk tumorous tissue normally is contaminated with stromal, endothelial and inflammatory cells as the normal epithelial component often represents only $5-10 \%$ of the entire prostate. Prostate cancer due to its infiltrative nature, with individual tumor acini infiltrating through stroma and directly adjacent to benign prostatic epithelium, 
makes the isolation of pure tumor cells extremely difficult (Rubin 2001). Thus, RNA amounts from LCM are too small to be quantified with traditional spectro-photometry. It can be overcome by a new capillary electrophoresis technique for quantitation as well as integrity analysis. Here, it was used a newly developed extension of this method allowing for measurements even in a picogram scale.

\subsubsection{Laser capture microdissection of prostate cancer cells}

Radical prostatectomy specimens of patients suffering from prostate cancer were freshly obtained from the Urological Clinic of the University Hospital. Specimens were immediately cut in three mm thick transversal slices. One slice being suspicious of containing carcinoma, the dissected tissue (less than $0.5 \mathrm{~cm}$ in any one dimension) was simply submerged in approximately 5 volumes of RNAlater (Ambion Europe Ltd., Cambridgeshire, UK) (e.g., a $0.5 \mathrm{~g}$ sample requires about $2.5 \mathrm{ml}$ of RNAlater) at room temperature. The solution permeates the cells and stabilizes the RNA. Then, the tissue soaked in RNA later ${ }^{\mathrm{TM}}$, was mapped and cut into small tissue blocks which were stored in RNA later ${ }^{\mathrm{TM}}$ at $-20^{\circ} \mathrm{C}$ (the tissue does not freeze) until further use. The rest of the prostate, especially adjacent prostate slices, were fixed in formalin and embedded in paraffin for standard routine histological examination. Staging was performed according to the UICC classification. Tumors were graded using the Gleason score. According to the adjacent paraffin sections, RNA later ${ }^{\mathrm{TM}}$ preserved tissue was selected. Cryostat sections were haematoxylin-eosin stained and the tissue was morphologically characterized. Tumor-containing tissue blocks and tumor-free prostate tissue of the same case were selected for microdissection. Five micron thick cryostat sections were mounted on slides coated with a $1.35 \mu \mathrm{m}$ thin polyethylene naphtalene membrane (obtained from P.A.L.M, Microlaser Technologies, Bernried). Sections were immediately washed with $70 \%$ ethanol in diethyl pyrocarbonate-treated (DEPC) water for 2 hours followed by staining with $37.5 \%$ Harris' modified haematoxylin solution (Merck, Darmstadt) in RNA later ${ }^{\text {TM }}$ for 1 min. Color was developed by incubation with $70 \%$ ethanol/DEPC-treated tap water for two hours. Slides were finally dipped in pure ethanol and xylol, air-dried and subjected to contactfree laser microdissection (P.A.L.M., Bernried) at $200 \mathrm{x}$ magnification. The dissected tissue was catapulted into caps of PCR vials and collected in RLT buffer (Qiagen, Hilden) substituted with $\beta$-mercaptoethanol. 


\subsubsection{RNA extraction from LCM samples}

Total cellular RNA from LCM samples was extracted with the RNeasy Mini Kit (Qiagen, Hilden) according to the user manual and resuspended in $20 \mu 1$ RNase-free water. RNA integrity and quantity was assessed using the Agilent Bioanalyzer 2100 with a RNA Pico LabChip $^{\circledR}$ Kit (Agilent Technologies, Waldbronn). Additional controls were performed by analyzing isolated total RNA samples from unstained tissue sections and the remaining tissue after microdissection.

\subsubsection{Agilent RNA LabChip Techniques}

The 6000 Nano (Pico) LabChip kit together with the Agilent Bioanalyzer 2100 provides information on the quality and quantity of RNA samples. The assay kit is designed primarily to check the quality and to determine the concentration of total RNA and mRNA samples. It contains a marker, which allows for sample alignment and permits easy comparison of samples enabling to distinguish different types of mRNA based on the electrophoretic traces and provides enhanced RNA quantitation simultaneous with the assessment of RNA quality. The RNA 6000 Nano (Pico) LabChip kit allows detection of total RNA down to a few ng (pg) with speed and accuracy.

According to the user manual, $9.0 \mu 1$ of the prepared gel-dye mix was loaded in each of the RNA chip wells, $5 \mu$ of the RNA 6000 marker was loaded into each of the 12 sample wells and $1 \mu \mathrm{l}$ of the RNA 6000 ladder was pipetted into a well, marked with the ladder symbol. Finally, $1 \mu$ of RNA sample was pipetted into each of the 12 sample wells. The chip was placed in the provided adapter and vortexed for $1 \mathrm{~min}$ at the IKA vortexer set-point. Then, the chip was transferred to the Agilent 2100 bioanalyzer and the run was started within five min. Both quality and concentration of RNA samples were analyzed by using the Agilent 2100 bioanalyzer software (Agilent Technologies). 


\subsection{Real-time RT-PCR analysis}

These studies were performed in cooperation with Dr. Paul Thelen from the Department of Urology, Georg-August-University of Göttingen

The availability of a technology for kinetic, real time measurements of a PCR in process greatly expands the benefits of the PCR reaction. Real-Time analysis of PCR enables truly quantitative analysis of template concentration. All real-time PCR systems rely upon the detection and quantitation of a fluorescent reporter, a signal which increases in direct proportion to the amount of PCR product in a reaction. In the simplest and most economical format, that reporter is the double-strand DNA-specific dye SYBR Green (Molecular Probes). One of the most popular alternatives to SYBR Green is the TaqMan probe (dual labeled probes) which is a hybridization probe relying on fluorescence resonance energy transfer (FRET) for quantification.

\subsubsection{Real time RT-PCR by using SYBR Green I dye}

SYBR Green I dye intercalates into double-stranded DNA and produces a fluorescent signal. The intensity of the signal is proportional to the amount of dsDNA present in the reaction. Therefore, in each step of the PCR reaction, the signal intensity increases as the amount of product increases. This provides a very simple and reliable method to monitor PCR reactions in real time. Another advantage of this technique is that unmodified oligonucleotide primers are required which facilitates primer design/synthesis and lowers cost. However, optimization of the reaction conditions for each primer set is required.

Expression of investigated genes was quantitated on an iCycler iQ real time detection system (Bio-Rad) by using SYBR Green I fluorescent dye (Eugene, Oregon, USA) and the OneStep RT-PCR Kit (Qiagen). The Master mix for all reactions was prepared plus one extra reaction by combining the following items on ice in a $0.5-\mathrm{ml}$ microcentrifuge tube: 


\section{$\underline{\text { Per reaction }}$}

$5 \times$ PCR buffer

$3 \mu 1$

$10 \mathrm{x}$ dNTPs mix

$0.5 \mu 1$

5 U RNase inhibitor (Eppendorf, Köln)

$0.1 \mu 1$

OneStep RT-PCR Enzyme Mix

$0.4 \mu 1$

SYBR Green I

$0.2 \mu 1$

Primer mix (forward and reverse, $10 \mathrm{pmol} / \mu \mathrm{l}$ )

$0.4 \mu 1$

$\mathrm{H}_{2} \mathrm{O}$

$8.9 \mu 1$

$1.5 \mu \mathrm{l}(0.1 \mu \mathrm{g} / \mu \mathrm{l})$ of total RNA isolated from tumor and matched normal tissue was added to 13.5 $\mu 1$ of prepared Master mix in a PCR tube, the sample was placed in the thermal iCycler and the RT-PCR program was run according to the user manual.

icycler conditions:

Reverse transcription:

$30 \min \quad 50{ }^{\circ} \mathrm{C}$

Initial PCR activation step:

$15 \min \quad 95^{\circ} \mathrm{C}$

40-50 cycles:

Denaturation:

$30 \mathrm{sec}$

$94{ }^{\circ} \mathrm{C}$

Annealing:

$30 \mathrm{sec}$

56- $60{ }^{\circ} \mathrm{C}$ (depending on primers)

Extension:

$30 \mathrm{sec}$

$72{ }^{\circ} \mathrm{C}$

Acquisition of fluorescence signals was monitored on the iCycler and terminated when all reactions reached an amplification plateau while a template-free control remained at the basement level. Data analysis was done with the iCycler iQ real time detection system software (Bio-Rad). To verify that only specific PCR products evoked fluorescence signals PCR products were analyzed by monitoring melting curves. In addition, the products were run on $2 \%$ agarose gels and then subcloned and sequenced. The expression of investigated genes was normalized to $ß$-actin mRNA expression to compensate for different sample capacities. 


\subsubsection{Real time RT-PCR by using standard dual-labeled probes}

Dual-labeled probes have a fluorescent reporter and a quencher at their 5' and $3^{\prime}$ ends, respectively. These probes can be used in quantitative PCR systems taking advantage of the 5'-3' exonuclease activity of the Taq DNA polymerase. A specific probe for the sequence of interest is used in the PCR reaction together with sequence specific PCR primers. As shown in Figure 4, this probe is designed to anneal between the PCR primers. During the extension phase of the PCR reaction, the 5'-3' exonuclease activity of the Taq DNA polymerase cleaves the fluorescent reporter from the probe. The amount of free reporter accumulates as the number of PCR cycles increases. The fluorescent signal from the free reporter is measured in real time and allows quantification of the amount of target.

\section{Dual-labeled probe principle}

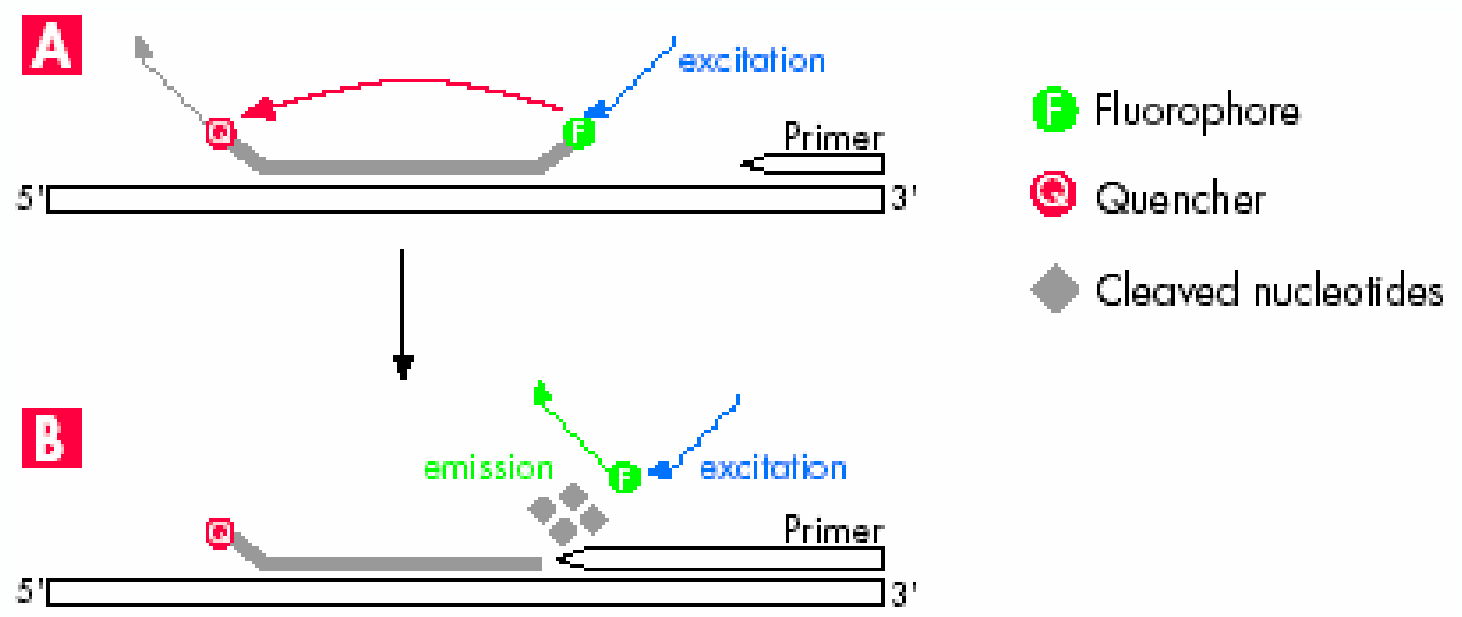

Figure 4. Schematic diagram of the principle of dual labeled probes in real-time PCR.

(modified after 2002 Qiagen Operon protocol)

A) Both the dual-labeled probe and the PCR primers anneal to the target sequence during the PCR annealing step. The proximity of the fluorescent reporter with the quencher prevents the reporter from fluorescing. B) During the PCR extension step, the Taq DNA polymerase extends the primer. When the enzyme reaches the dual-labeled probe, its 5'-3' exonuclease activity cleaves the fluorescent reporter from the probe. The fluorescent signal from the free reporter is measured. 
Total cellular RNA from PC-3 cells and from laser capture micro-dissections were extracted with the RNeasy Mini Kit (Qiagen). Integrity and quantity of total cellular RNA was assessed on an Agilent Bioanalyzer 2100 (Agilent Technologies, Waldbronn) using a RNA 6000 Nano LabChip-Kit for RNA from cultured cells and using a RNA 6000 Pico LabChip-Kit for RNA from micro-dissected samples. Reverse transcription of $500 \mathrm{ng}$ total cellular RNA with random hexamer primers was performed with the Omniscript RT Kit (Qiagen) for RNA from cultured cells and with Sensiscript RT Kit (Qiagen) for RNA from micro-dissections. Expression of $ß$-actin, BI-1, IGFI-R, IGFBP-3 and MMP-2 was quantified on an iCycler iQ real time detection system (Bio-Rad) with HotStar Taq DNA Polymerase Kit (Qiagen). The $20 \mu 1$ reaction from the kit was supplemented with $2 \mu \mathrm{l}$ cDNA, $0.6 \mu \mathrm{M}$ gene-specific primers and $0.2 \mu \mathrm{M}$ dual-labeled fluorescent probes (Qiagen). Primers and probes (Qiagen) were designed using the primer3 on-line primer design program (www-genome.wi.mit.edu/cgibin/primer/primer3_www.cgi). Impairment of optimal PCR conditions due to secondary DNA structure could be avoided after checking the sequences on Dr. Zuker's site (http://bioinfo.math.rpi.edu/mfold/dna/form1.cgi) and optimal choice of non-dimer forming primers was made using the Operon oligo tool kit (http://www.operon.com).

Standard curves for quantitative PCR were generated for IGFI-R, IGFBP-3, MMP-2 and ßactin with standard cRNA ( 0.001 to 1000 attomoles) instead of total cellular RNA. In vitro transcription of gene specific standard cRNA was performed as previously described (Craven et al. 2002). Acquisition of fluorescence signals was monitored on the iCycler and terminated when all reactions reached an amplification plateau while a template-free control remained at basement level. Data analysis was done with an iCycler iQ real time detection system software (Bio-Rad). To verify that only specific PCR products evoked fluorescence signals, PCR products were run on $2 \%$ agarose gels and were analyzed with the E.A.S.Y. Win 32 software (Herolab, Wiesloch). Expression of BI-1, IGFI-R and IGFBP-3 in laser capture micro-dissected samples was normalized to $ß$-actin mRNA expression to compensate for different sample capacities. 


\subsection{Eukaryotic cell culture methods}

\subsubsection{Cell culture conditions}

PC-3 and LNCaP cells were grown in RPMI 1640 medium (PAN-Systems GmbH, Nürnberg) containing 15\% fetal bovine serum (PAN) and 1\% penicillin/streptomycin solution (PAN). Culture medium for stable transfected PC-3 cells was supplemented with hygromycin B (Calbiochem) at $100 \mu \mathrm{g} / \mathrm{ml}$ to maintain selection pressure. NIH3T3 cells were grown in DMEM medium (PAN) containing $15 \%$ fetal bovine serum (PAN) and $1 \%$ penicillin/streptomycin solution (PAN). The cells were cultured at $37^{\circ} \mathrm{C}$ in a humidified incubator with $5 \% \mathrm{CO}_{2}$ and grown to $80 \%$ confluency before treatment with $200 \mu \mathrm{M} \mathrm{ZnSO}$ in medium (if necessary) in the experiments described below.

\subsubsection{Preparation of conditioned medium}

For the preparation of conditioned medium nontransfected and transfected PC-3 cells were cultured as described above up to $70-80 \%$ confluency, then washed and incubated in OPTIMEM I (Invitrogen) serum reduced medium containing $\mathrm{ZnSO}_{4}$ for 20 hours, respectively. The conditioned medium was harvested, $20 \mathrm{x}$ concentrated by standard acetone precipitation and used for Western blot analysis.

\subsubsection{Trypsinization of eukaryotic cells}

Cells were washed twice with sterile PBS and incubated in minimal amount trypsin-EDTA (PAN) (0.5 g/l trypsin, $0.2 \mathrm{~g} / 1$ EDTA) at $37^{\circ} \mathrm{C}$ until they had detached from the dish. The process was controlled under an inverted microscope. Trypsin was inhibited by addition of growth medium in which the cells were subsequently resuspended. Cell counting was performed, when necessary, using an improved Neubauer chamber, and the cells were plated out or harvested for cryoconservation. 


\subsubsection{Cryoconservation and thawing of eukaryotic cells}

Resuspended cells were spun down $\left(1000 \mathrm{~g}\right.$ for $5 \mathrm{~min}$ at $\left.4^{\circ} \mathrm{C}\right)$ in $4 \mathrm{ml}$ growth medium. The supernatant was aspirated and the cells resuspended $\left(1-5 \times 10^{7}\right.$ cells $\left./ \mathrm{ml}\right)$ in ice-cold freezing medium (DMEM or RPMI , 20\% FCS, 10\% DMSO). Cells were kept for 7 days at $-80^{\circ} \mathrm{C}$ and then stored in liquid nitrogen. For revitalization, frozen cells were quickly thawed, gently transferred to disposable Falcon tubes containing $4 \mathrm{ml}$ cold growth medium and spun down as described above. Supernatant was discarded by aspiration, and cells were plated out after being resuspended in a suitable amount of growth medium.

\subsubsection{Stable transfection of PC-3 cells}

The expression vectors $\mathrm{pMT} / \mathrm{EP}$ harboring the $\mathrm{ZnSO}_{4}$-inducible mouse metallothionein-1 (MT-1) promoter produces sense or antisense IGF-IR cRNA of the first 696 bp of the IGF-IR cDNA fragment including the ATG start codon (Burfeind et al. 1996). Transfection of PC-3 cells was accomplished using Lipofectin (Invitrogen $\mathrm{GmbH}$, Karlsruhe) according to the supplier's instructions with either the vectors without insert or containing the IGF-IR cDNA insert in the sense and antisense orientation, respectively. After transfection, the cells were cultured in nonselective OPTI-MEM I (Invitrogen) reduced serum medium for 20 hours. Subsequently, Hygromycin B was added to the culture medium $(100 \mu \mathrm{g} / \mathrm{ml})$ for selection, which was carried out up to the moment when single cell colonies were formed. Established stable transfected PC-3 cellular clones were used for further experiments.

\subsubsection{Matrigel assay}

In vitro cell migration was determined in BioCoat Matrigel Invasion Chambers (Becton Dickinson, Bedford, MA) as described in the user manual. BD BioCoat Matrigel Invasion Chambers provide cells with the conditions that allow assessment of their invasive property in vitro and consist of a BD Falcon ${ }^{\mathrm{TM}}$ TC Companion Plate with Falcon Cell Culture Inserts containing an 8 micron pore size PET membrane with a thin layer of Matrigel Basement Membrane Matrix, which serves as a reconstituted basement membrane in vitro. The layer occludes the pores of the membrane, blocking non-invasive cells from migrating through the 
membrane. In contrast, invasive cells (malignant and non-malignant) are able to detach themselves from and invade through the Matrigel Matrix and the 8 micron membrane pores. The membrane may be processed for light and electron microscopy and can be easily removed after staining. Therefore, Matrigel Invasion Chamber is a convenient, ready-to-use system to study cell invasion in vitro.

Parental PC-3 cells, transfected PC-3 cells and NIH3T3 cells were suspended in the appropriate medium described above at a concentration of $5 \times 10^{4}$ cells $/ \mathrm{ml}$, respectively. Subsequently, $500 \mu \mathrm{l}$ of cell suspension $\left(2.5 \times 10^{4}\right)$ was placed in the upper compartments and incubated for 20 hours at $37^{\circ} \mathrm{C}$ in $5 \% \mathrm{CO}_{2}$ at the presence of $200 \mu \mathrm{M} \mathrm{ZnSO}_{4}$ in the medium. After the incubation step, non-invading cells were removed from the upper surface of the membrane by scrubbing. Cells on the reverse side were stained with the Diff-Quik Staining Set (Dade Behring GmbH, Marburg) and invading cells were counted under a microscope BX60 (Olympus Optical Co. LTD, Japan) at $100 \mathrm{x}$ magnification using the analySIS software (Soft Imaging System GmbH, Münster, Germany). Data are expressed as the percent invasion through the Matrigel Matrix membrane relative to the migration through the control membrane. All experiments were assayed at least in triplicates.

\subsubsection{Cell proliferation assay}

Cell proliferation was determined by using the EZ4U kit (Biozol, Eching) as described in the user manual. This method is based on the finding that living cells are capable to reduce uncolored tetrazolium salts into intensely colored formazan derivatives. This reduction process requires functional mitochondria, which are inactivated within a few minutes after cell death. This method therefore provides an excellent tool for the discrimination of living and death cells.

Approximately 3000 cells/well were cultivated in $200 \mu \mathrm{l}$ cell culture medium as described above with $200 \mu \mathrm{M} \mathrm{ZnSO}_{4}$ in a 96-well plate. After 2 hours, 24 hours and 48 hours of incubation at $37^{\circ} \mathrm{C}$ in a humidified incubator with $5 \% \mathrm{CO}_{2}, 20 \mu 1$ of substrate (EZ4U kit) per well was added and after 2 hours the optical density at $450 \mathrm{~nm}$ and $620 \mathrm{~nm}$ (references) was measured. All experiments were assayed in triplicates. 


\subsection{Gene silencing by RNA interference}

The term RNA interference (RNAi) describes the use of double-stranded RNA to target specific mRNAs for degradation, thereby silencing their expression. RNAi is one manifestation of a broad class of RNA silencing phenomena that are found in plants, animals and fungi (Elbashir et al. 2001, Tuschl 2001, Cogoni and Macino 2000). The discovery of RNAi has changed the understanding of how cells guard their genomes, led to the development of new strategies for blocking gene function, and may yet yield RNA-based drugs to treat human diseases.

\subsubsection{Overview of the RNAi mechanism}

In the initiation step, input dsRNA is digested into 21-23 nucleotide small interfering RNAs (siRNAs), which have also been named "guide RNAs" (Hammond et al. 2001, Sharp 2001). Evidence indicates that siRNAs are produced when the enzyme Dicer, a member of the RNase III family of dsRNA-specific ribonucleases, processively cleaves dsRNA (introduced directly or via a transgene or virus) in an ATP-dependent, processive manner. Successive cleavage events degrade the RNA to 19-21 bp duplexes (siRNAs), each with 2-nucleotide 3' overhangs (Hutvagner et al. 2002, Bernstein et al. 2001). In the effector step, the siRNA duplexes bind to a nuclease complex to form what is known as the RNA-induced silencing complex, or RISC. An ATP-depending unwinding of the siRNA duplex is required for activation of the RISC. The active RISC then targets the homologous transcript by base pairing interactions and cleaves the mRNA $\sim 12$ nucleotides from the $3^{\prime}$ terminus of the siRNA (Hammond et al. 2001, Sharp 2001). 

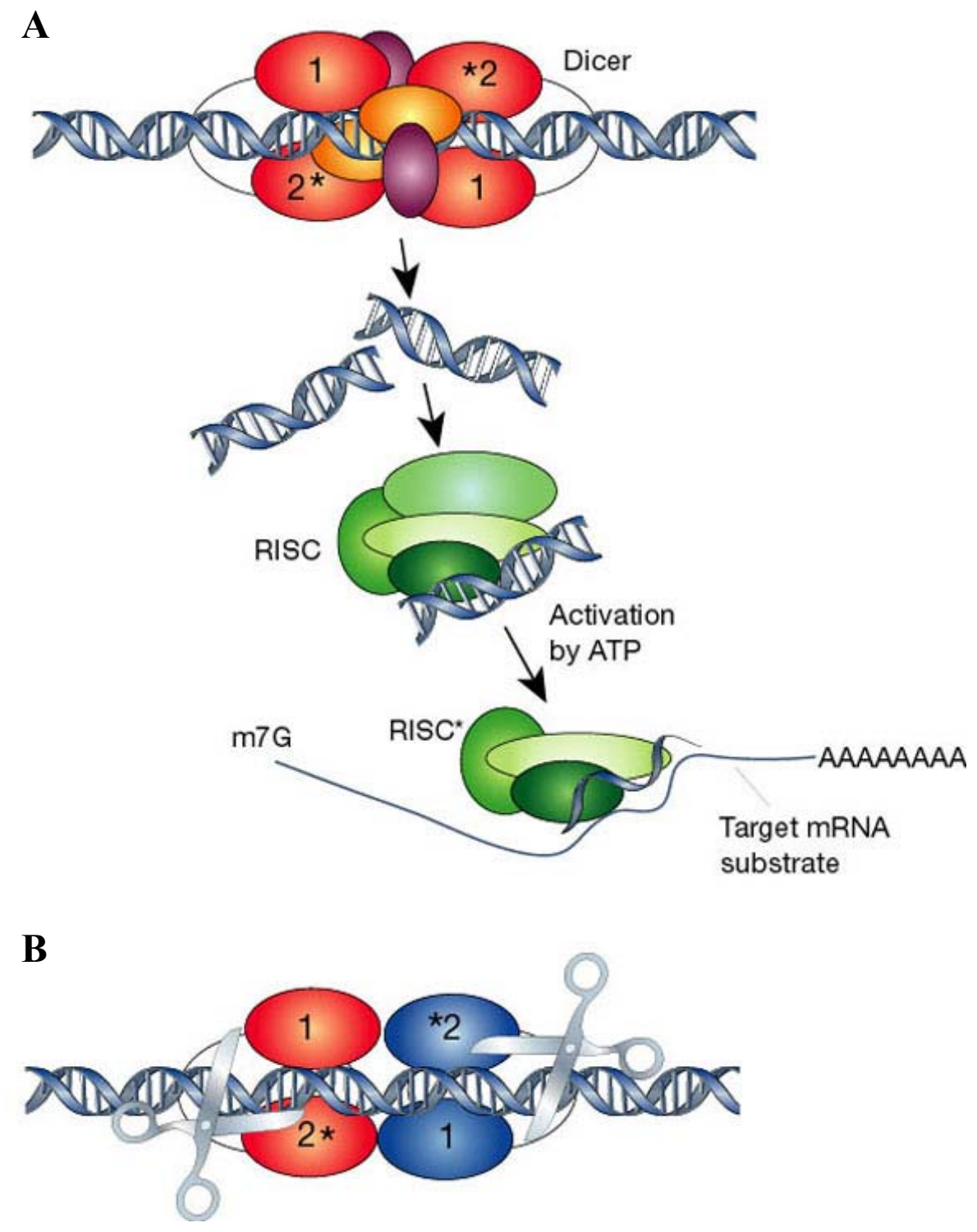

Figure 5. Dicer and RISC (RNA-induced silencing complex). (Hannon 2002)

A) RNAi is initiated by the Dicer enzyme (two Dicer molecules with five domains each are shown), which processes double-stranded RNA into $\sim 22$-nucleotide small interfering RNAs. Based upon the known mechanisms for the RNase III family of enzymes, Dicer is thought to work as a dimeric enzyme. Cleavage into precisely sized fragments is determined by the fact that one of the active sites in each Dicer protein is defective (indicated by an asterisk), shifting the periodicity of cleavage from * 9-11 nucleotides for bacterial RNase III to $\approx 22$ nucleotides for Dicer family members. The siRNAs are incorporated into a multicomponent nuclease, RISC (green). Recent reports suggest that RISC must be activated from a latent form, containing a double-stranded siRNA to an active form, RISC*, by unwinding of siRNAs. RISC* then uses the unwound siRNA as a guide to substrate selection. B) Diagrammatic representation of Dicer binding and cleaving dsRNA (for clarity, not all the Dicer domains are shown, and the two separate Dicer molecules are colored differently). Deviations from the 
consensus RNase III active site in the second RNase III domain inactivate the central catalytic sites, resulting in cleavage at 22-nucleotide intervals.

\subsubsection{Transfection of eukaryotic cells with siRNAs}

The RNAi -based method can be used to target specific mRNAs for degradation, thereby silencing their expression. It was also shown, that sequence-specific single strand RNA oligonuclotides both in sense and antisense orientation can be employed as a negative control for this specific gene silencing, as it has no effect on specific mRNA degradation (Tuschl et al. 1999).

Transfection of both PC-3 and LNCaP cells was accomplished using the Oligofectamine Reagent (Invitrogen $\mathrm{GmbH}$, Karlsruhe) which forms stable complexes between the lipid and oligonucleotides permitting efficient delivery of the RNA molecules into mammalian cells. The transfection procedure was performed according to the supplier's instructions with either BI-1 gene-specific siRNA duplex or with single stranded sense and antisense RNA oligonucleotides (IBA GmbH, Göttingen) at a concentration of $0.66 \mu \mathrm{g}$ per $0.5 \mathrm{ml}$ transfection medium (150 nM).
Target region:
5'- CCCCGUCAACGCAGCAGCA -3'
BI-1 sense RNA:
5'- CCCCGUCAACGCAGCAGCAdTdT -3'
BI-1 antisense RNA:
5'- UGCUGCUGCGUUGACGGGGdTdT -3'

The target region is located 57 nucleotides downstream of the start codon ATG of the human BI-1 gene (GenBank Accession No. X75861). As a further control PC-3 and LNCaP cells were transfected with siRNA duplex oligonucleotides against the firefly luciferase gene (nonrelated sequence).

$\begin{array}{ll}\text { Target region: } & \text { 5'-CGUACGCGGAAUACUUCGA -3' } \\ \text { luc sense RNA: } & \text { 5'- CGUACGCGGAAUACUUCGAdTdT -3' } \\ \text { luc antisense RNA: } & \text { 5'- UCGAAGUAUUCCGCGUACGdTdT -3' }\end{array}$

For the transfection, PC-3 and LNCaP cells were cultured in small flasks $\left(22 \mathrm{~cm}^{2}\right)$ as described above up to $10-20 \%$ and $40-50 \%$ confluency, respectively. The transfection 
procedure described below is calculated for three small flasks. $3 \mu$ of duplex RNA (1.4 $\mu \mathrm{g} / \mu \mathrm{l}), 6 \mu \mathrm{l}$ of sense and $6 \mu \mathrm{l}$ of antisense single strand RNA $(0.7 \mu \mathrm{g} / \mu \mathrm{l})$ were added to $400 \mu \mathrm{l}$ OPTI-MEM I (Invitrogen) in three separate $1.5 \mathrm{ml}$ tubes. Next, $36 \mu$ l Oligofectamine was added to $234 \mu \mathrm{l}$ of OPTI-MEM I in an $1.5 \mathrm{ml}$ tube, mixed by pipetting and incubated $10 \mathrm{~min}$ at RT. After this incubation step, Oligofectamine solution $(90 \mu 1$ per tube) was added to each RNA sample and the tubes were incubated for $20 \mathrm{~min}$ at room temperature. During this time, the cells were washed with PBS and $2 \mathrm{ml}$ OPTI-MEM I medium was added to each flask. After the 20-min incubation step, transfection mixtures (RNA/Oligofectamine in OPTI-MEM) were added to the cells and the cells were incubated at $37^{\circ} \mathrm{C}$ in a humidified incubator with $5 \% \mathrm{CO}_{2}$ for 8 hours. After this time $4 \mathrm{ml}$ of normal medium was added to each flask and the cells were cultured at the same conditions.

At different time points (24, 36 and 45 hours) after transfection both living cells attached to the bottom and cells floating in the medium were collected and used for total RNA and protein isolation, followed by Northern and Western blot analysis to verify silencing of the BI-1 expression and for determination of cell death and apoptosis.

\subsection{Analysis of cell death and apoptosis}

\subsubsection{Trypan blue-staining of eukaryotic cells}

(Freshney 1987)

Cell death was determined by trypan blue exclusion. Trypan Blue is a vital dye. The reactivity of trypan blue is based on the fact that the chromophore is negatively charged and does not interact with the cell unless the membrane is damaged. Therefore, all the cells which exclude the dye are viable. After treatment with siRNA duplex or control oligonuclotides, $100 \mu \mathrm{l}$ of a $0.4 \%$ trypan blue solution (Invitrogen) were added to $0.5 \mathrm{ml}$ of a PC-3 cell suspension (1-2 x $10^{5}$ cells). After 10-15 min of incubation the suspension was applied to a hematocytometer. Both viable and nonviable cells were counted and the percentage of cell death was determined by counting trypan blue-positive cells from three independent experiments. 


\subsubsection{In situ end-labeling (ISEL)}

These studies were performed in cooperation with Dr. Stefan Schweyer from the Department of Pathology, Georg-August-University of Göttingen.

Cleavage of genomic DNA during apoptosis may yield double-stranded, low molecular weight DNA fragments (mono- and oligonucleosomes) as well as single strand breaks ("nicks") in high molecular weight DNA. Those DNA strand breaks can be identified by labeling free 3'-OH termini with modified nucleotides in an enzymatic reaction (Gorczyca et al. 1993). In this method, terminal deoxynucleotidyl transferase (TdT), which catalyzes polymerization of nucleotides to free 3'-OH DNA ends in a template-independent manner, is used to label DNA strand breaks.

PC-3 cells $\left(10^{5}\right.$ cells $\left./ \mathrm{ml}\right)$ were cytocentrifuged on glass slides, dried, fixed in acetone and incubated with TBS containing $10 \%$ FCS and $0.3 \% \mathrm{H}_{2} \mathrm{O}_{2}$ to block endogenous peroxidase activity. Cells were incubated for $60 \mathrm{~min}$ at $37^{\circ} \mathrm{C}$ with $50 \mu \mathrm{l}$ of the labeling mix $(250 \mathrm{U} / \mathrm{ml}$ terminal transferase, $20 \mu \mathrm{l} / \mathrm{ml}$ Dig-DNA labeling mix at $10 \mathrm{x}$ concentration, and $1 \mathrm{mmol} / 1$ $\mathrm{CoCl}_{2}$ in reaction buffer for terminal transferase (Roche, Mannheim). Labeled DNA nicks were detected with a rabbit horseradish peroxidase (HRP)-conjugated $\mathrm{F}(\mathrm{ab})_{2}$ fragment against digoxigenin (Dako, Hamburg) at a working dilution of 1:200. Incubation with 3,3'Diaminobenzidin revealed brown nuclear signals. Controls were stained as above, omitting terminal transferase. As positive controls, lymph nodes with reactive follicular hyperplasia were used. Positive stained cells were counted under a microscope BX60 (Olympus Optical Co. LTD, Japan) at $100 \mathrm{x}$ magnification in five different fields using the analySIS software (Soft Imaging System GmbH, Munster).

\subsubsection{DAPI staining of eukaryotic cells}

Cells undergoing apoptosis display typical features, namely cell shrinkage, membrane blebbing, chromatin condensation and nuclear fragmentation. Dramatic changes occur within the nucleus during apoptotic death. Later, the nucleolus disintegrates, nuclear membrane develops deep invaginations and, ultimately, the nucleus fragments into dense granular

particles (apoptotic bodies). Chromatin condensation, nuclear shrinkage and formation of apoptotic bodies can easily be observed by fluorescence microscopy after appropriate staining 
of nuclei with DNA-specific fluorochromes (DAPI) (Collins et al. 1997, Feldkamp et al. 1999).

For DAPI staining PC-3 and LNCaP cells $\left(10^{5}\right.$ cells $\left./ \mathrm{ml}\right)$ were cytocentrifuged on glass slides, dried overnight and fixed for $10 \mathrm{~min}$ in $100 \%$ acetone. Thereafter, cells were incubated with Vectashield Mounting Medium with DAPI (Vector Laboratories Ltd., Peterborough, England). Stained cells were analyzed and counted under a fluorescent microscope BX60 (Olympus Optical Co. LTD, Japan) at $200 \mathrm{x}$ magnification in five different fields using the analySIS software (Soft Imaging System GmbH, Münster).

\subsubsection{Immunocytochemical staining of eukaryotic cells (Caspase-3)}

These studies were performed in cooperation with Dr. Stefan Schweyer from the Department of Pathology, Georg-August-University of Göttingen.

Diverse groups of molecules are involved in the apoptosis pathway. One set of mediators implicated in apoptosis belong to the asparate-specific cysteinyl proteases or caspases. A member of this family, caspase-3 (CPP32, apopain, YAMA), has been identified as being a key mediator of apoptosis of mammalian cells (Kothakota et al. 1997).

To determine caspase- 3 activity, cytocentrifugated PC-3 cells $\left(10^{5}\right.$ cells $\left./ \mathrm{ml}\right)$ were dried, fixed in acetone and incubated with the polyclonal rabbit anti-human antibody against the active caspase-3 (clone AF835, R\&D Systems GmbH, Wiesbaden) followed by incubation with a biotinylated secondary antibody, alkaline phosphatase-conjugated streptavidin (Dako), and by visualization with Fast Red (Dako). Slides were counterstained with hemalaun. Positive cells showed a red cytoplasmic staining around the clearly demarcated nuclei. Controls were stained as above, omitting first or secondary antibody. As a positive control, sections with gout tophi were used, as described previously (Schweyer et al. 2000). 


\section{RESULTS}

\subsection{Inhibition of insulin-like growth factor type I receptor (IGF-IR) expression in human prostate cancer cells}

\subsubsection{Down-regulation of IGF-IR expression in PC-3 cells transfected with the pMT/EP vector containing the IGF-IR cDNA in antisense orientation}

As described previously (Burfeind et al. 1996), the eukaryotic expression vector pMT/EP containing the $\mathrm{ZnSO}_{4}$ - inducible metallothionein promoter MT-1 (Fig. 6A) was used for transfection and expression of both $I G F-I R$ antisense cRNA and sense cRNA (as a control) in human PC-3 cells (Fig. 6C). The subcloned human IGF-IR cDNA fragment covers the first $696 \mathrm{bp}$ including the first ATG start codon of the IGF-IR cDNA. The antisense and sense orientations of the subcloned IGF-IR cDNA insert were confirmed by both restriction analysis (Fig. 6B) and sequencing as described in the materials and methods section.

A

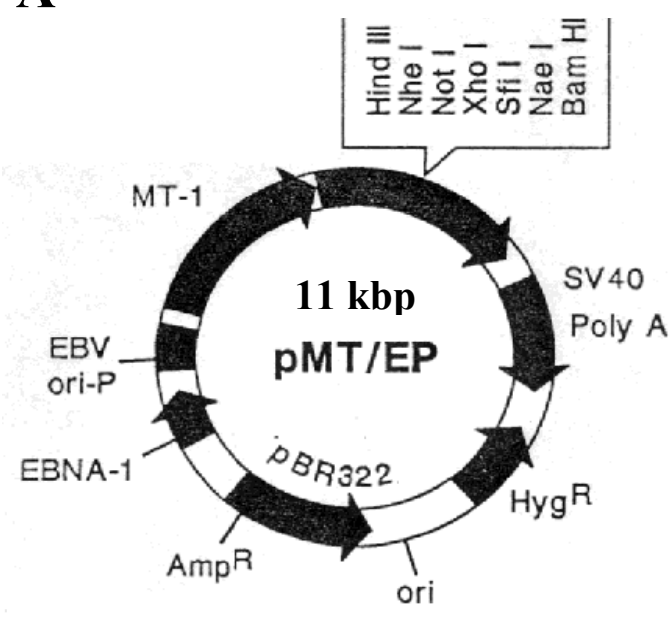

C

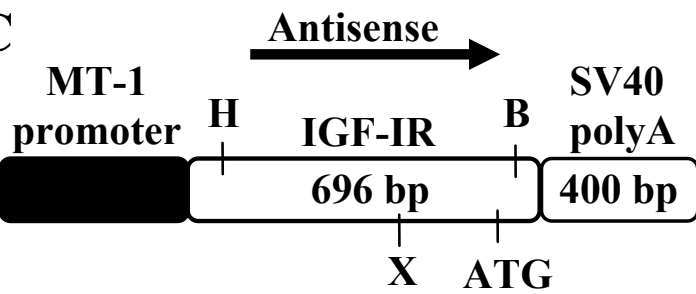

B
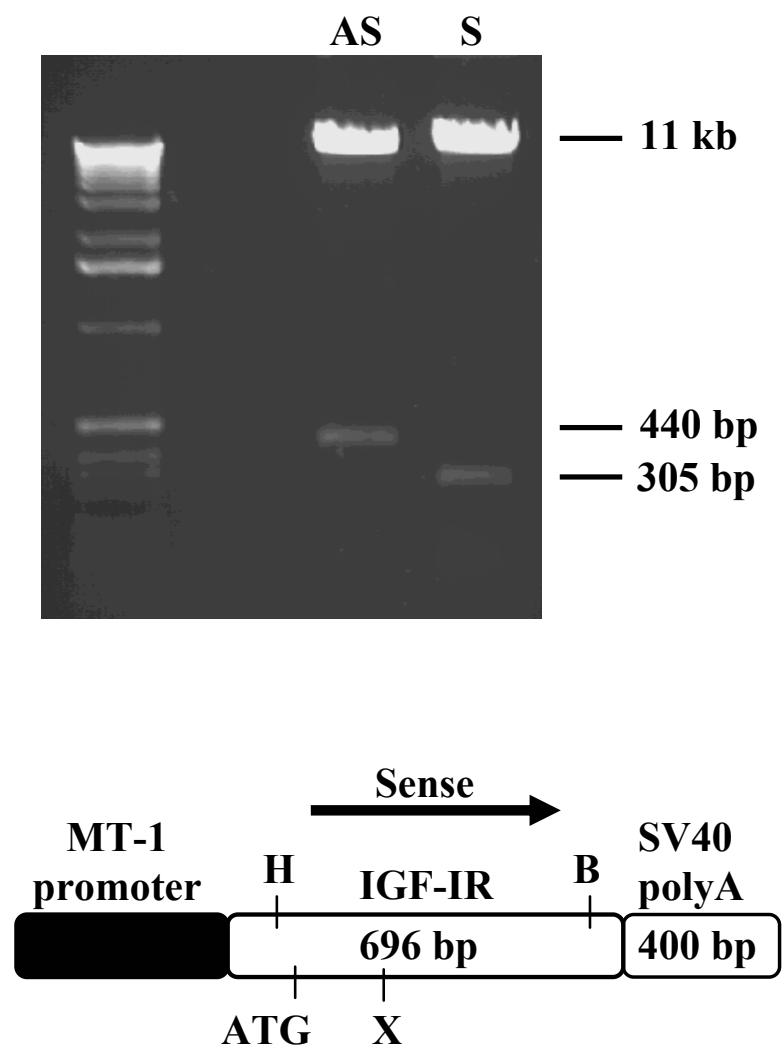

Figure 6. The eukaryotic expression vector pMT/EP used for expression of human IGF-IR cRNA fragments in PC-3 cells. 
A) Schematic representation of the episomal vector $\mathrm{pMT} / \mathrm{EP}$ containing a $\mathrm{ZnSO}_{4}$-inducible metallothionein promoter (MT-1). SV 40, simian virus 40; Amp R, ampicillin resistance gene; Hyg R, hygromycin resistance gene; pBR 322 ori, pBR 322 origin of replication; EBNA-1, EBV-encoded nuclear antigen-1 (EBV, Epstein-Barr virus); EBV oriP, EBV origin of replication. B) Restriction analysis of pMT/EP vectors with enzymes HindIII and XhoI, respectively. Because of an asymetric internal restriction site for XhoI two different DNA fragments 440 bp and 305 bp in length for antisense (AS) and sense (S) constructs, respectively, were obtained. C) The 696-bp-long human IGF$I R$ cDNA fragment was cloned into an episomal vector both in the antisense and sense orientation under the control of the $\mathrm{ZnSO}_{4}$-inducible metallothionein promoter MT-1. H, HindIII; B, Bam HI; X, XhoI; ATG, first ATG start codon.

After transfection, established stably transfected PC-3 cells with the pMT/EP vector containing the $I G F-I R$ cDNA in antisense direction, containing the $I G F-I R$ cDNA in sense orientation (control) or containing the vector without an insert (control) were maintained in culture in the presence of hygromycin B for selection. Non-transfected PC-3 cells were used as an additional control and were cultured without hygromycin. In order to test the induction of $I G F-I R$ antisense and sense cRNA expression in the derived PC-3 cellular transfectants, cells were cultured 20 hours either with or without $\mathrm{ZnSO}_{4}$ in the culture medium. After this induction step total RNA from transfected PC-3 cell clones was isolated and analyzed by Northern blot hybridization using a radioactive labeled human $I G F-I R$ cDNA as a probe. For integrity and equality of the RNA the membrane was subsequently rehybridized with a human $\beta$-actin cDNA probe. As can be seen in Figure 7A strong expression of either sense IGF-IR cRNAs or antisense cRNAs with a transcript size of approximately $1 \mathrm{~kb}$ in transfected PC-3 cells was only obtained after $\mathrm{ZnSO}_{4}$ induction.

In order to determine the down-regulation of endogenous $I G F-I R$ expression in $I G F-I R$ antisense-transfected PC-3 cells, four IGF-IR antisense RNA transfected PC-3 clones (A46, A47, A49, A410), one IGF-IR sense RNA transfected PC-3 clone (S3), one clone carrying an empty plasmid (O) and parental PC-3 cells were analyzed after $\mathrm{ZnSO}_{4}$ induction. Fifty $\mu \mathrm{g}$ of whole-cell lysates were collected and separated on a 4-12\% gradient acrylamide gel, transferred to a membrane and subsequently incubated with an anti-IGF-IR-specific antibody and an anti- $\alpha$-tubulin-specific antibody, respectively (Figure 7B). The endogenous IGF-IR expression in PC-3 cellular transfectants was normalized against the protein level of $\alpha$-tubulin by using Western blot analysis and quantification was performed using the Quantity one software. The down-regulation of endogenous IGF-IR expression in IGF-IR antisense RNA 
transfectants ranged from $30 \%$ (clone A47) up to $70 \%$ (clone A410) as compared to controltransfected (S3 and O) and non-transfected PC-3 cells, respectively.
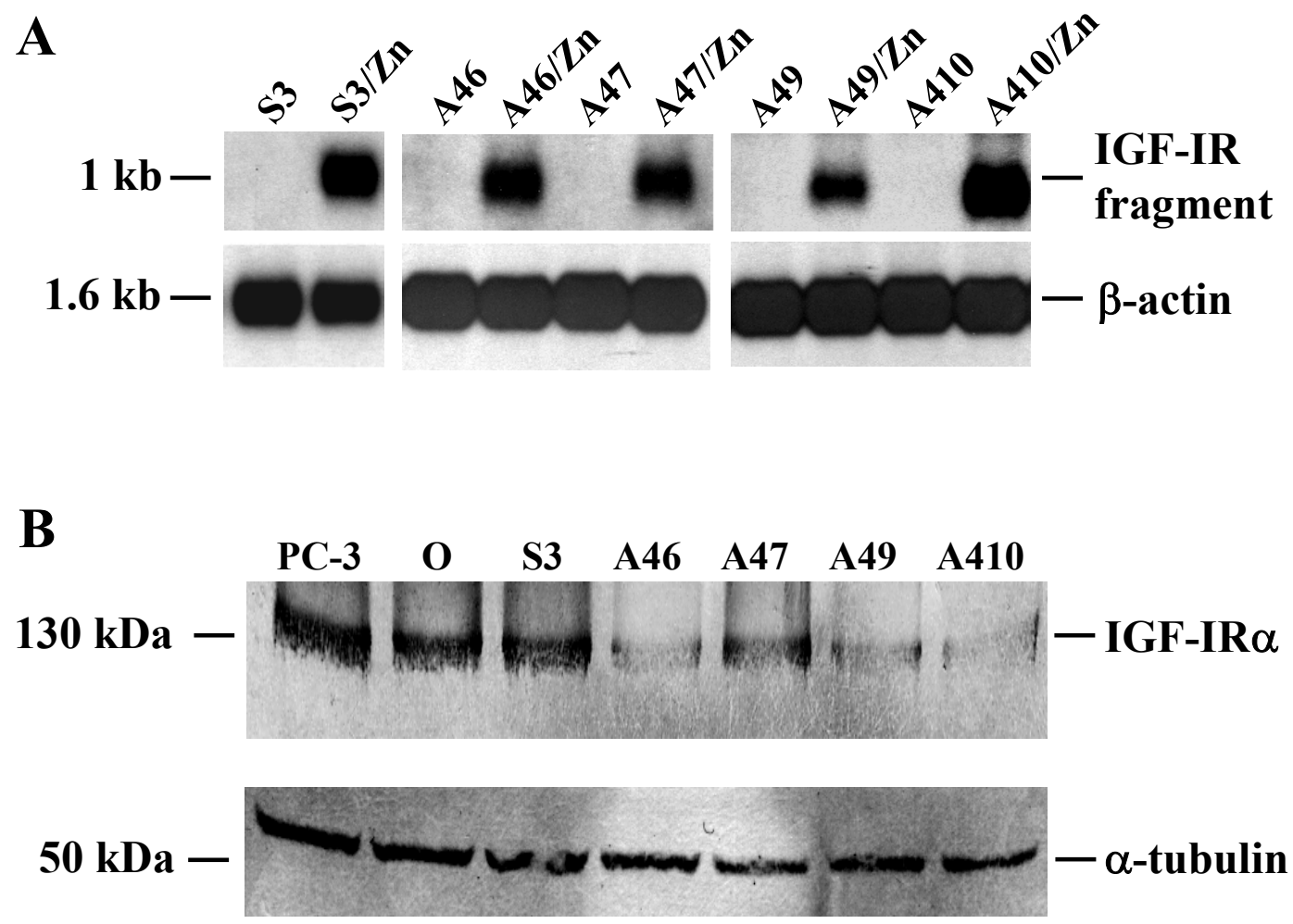

Figure 7. Induction of IGF-IR cRNA expression and down-regulation of endogenous IGF-IR expression in IGF-IR antisense RNA transfected PC-3 cells.

A) Total RNA (6 $\mu \mathrm{g}$ each) was isolated from one sense clone (S3) and four antisense clones (A46, $\mathrm{A} 47, \mathrm{~A} 49$ and A410) and expression of sense and antisense cRNAs for IGF-IR before and after $\mathrm{ZnSO}_{4}$ $(\mathrm{Zn})$ treatment of transfected PC-3 cells was analyzed by Northern blot hybridization by using a ${ }^{32} \mathrm{P}-$ labeled $I G F-I R$ cDNA as a probe. The molecular size $(1 \mathrm{~kb})$ of the $I G F-I R$ cRNAs is shown on the left. For equal loading and integrity of the RNA the Northern blot was rehybridized with a human $\beta$-actin cDNA probe. B) Western blot analysis after $\mathrm{ZnSO}_{4}$ induction of parental PC-3 cells (PC-3), PC-3 cells transfected with the pMT/EP vector alone (clone O), PC-3 cells transfected with the IGF-IR construct in sense orientation (clone S3) and PC-3 cells transfected with the IGF-IR construct in antisense orientation (clones A46, A47, A49 and A410) by using an IGF-IR $\alpha$-specific antibody (upper panel). Inhibition of endogenous IGF-IR expression is observed in all clones treated with the IGF-IR construct in antisense orientation as compared to non-transfected and control-transfected PC-3 cellular clones. The Western blot was stripped and re-probed with an $\alpha$-tubulin-specific antibody to check for equal loading $(50 \mu \mathrm{g})$ of total protein. 


\subsubsection{Inhibition of $I G F-I R$ gene expression leads to reduced cellular invasion of human prostate cancer cells}

To assess the effect of IGF-IR suppression on the invasive capacity of PC-3 cells the in vitro Matrigel invasion system was used. Transfected and non-transfected PC-3 cells were incubated in the upper compartment of the culture chambers for 20 hours in the presence of $\mathrm{ZnSO}_{4}$ in the culture medium and subsequently, PC-3 cells invading through the Matrigelcoated membranes to the lower surface of the filters were stained, counted and compared to the numbers of invaded cells from control inserts as described in materials and methods. As shown in Figure 8 the invasive capacity of four $I G F-I R$ antisense-transfected clones was reduced to levels ranging from 68\% (clone A46) to 17\% (A410) as compared to controltransfected PC-3 cells (clones S and O) and parental PC-3 cells. As an additional control for non-invading cells murine NIH3T3 cells were incubated for 20 hours in the presence of $\mathrm{ZnSO}_{4}$ in the culture medium showing $26 \%$ of invasive capacity.

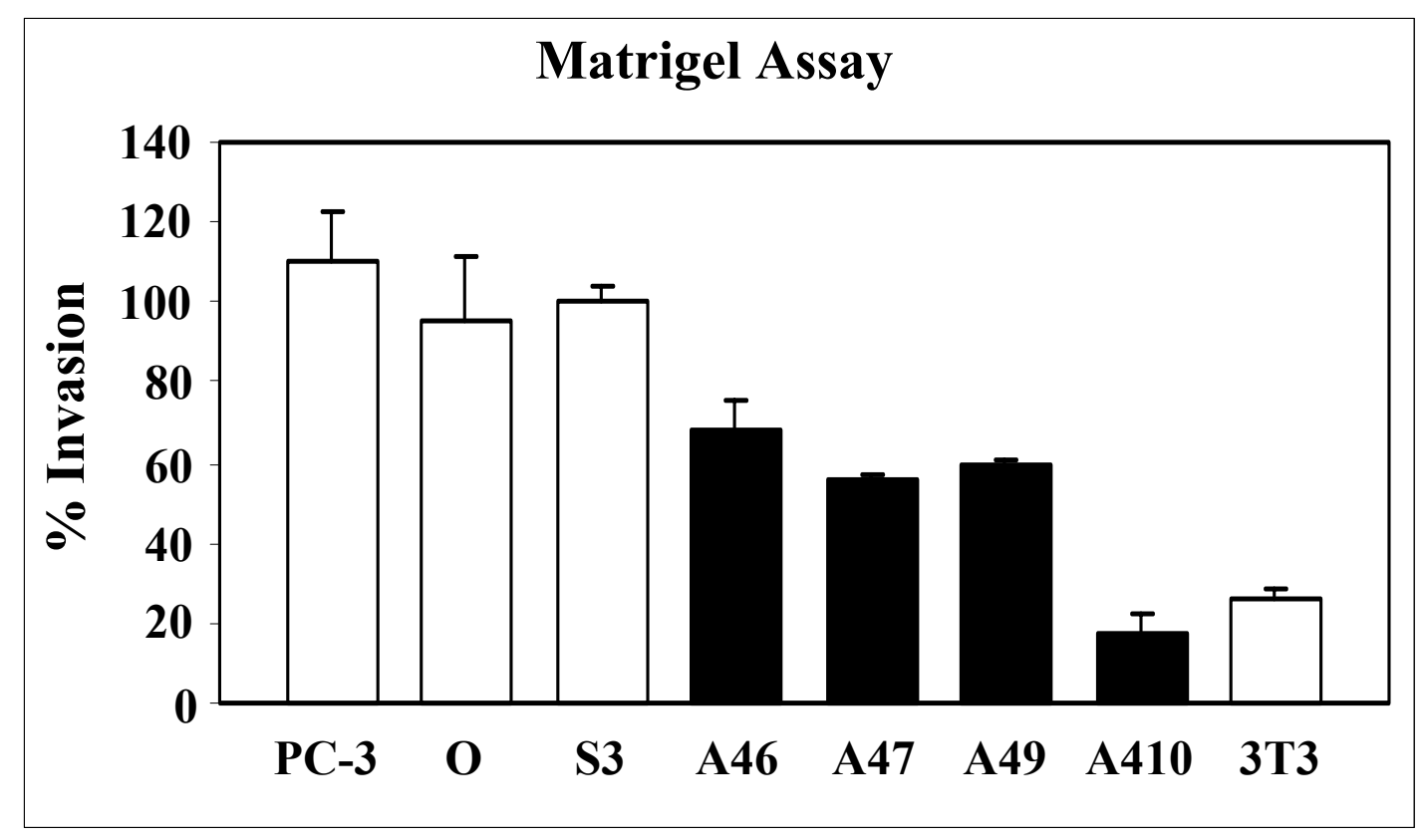

Figure 8. Expression of IGF-IR antisense cRNA in PC-3 cells inhibits cellular invasion in vitro

Non-transfected PC-3 cells (PC-3), control-transfected PC-3 cells (clone O=pMT/EP vector alone; clone $\mathrm{S} 3=I G F-I R$ in sense orientation) and $I G F-I R$ antisense RNA-transfected PC-3 cells (A46, A47, A49 and A410) were placed ( $2 \times 10^{5}$ cells each $)$ in the upper compartments of individual transwell inserts containing $8 \mu \mathrm{m}$ pore polycarbonate membranes precoated with Matrigel. Cells cultured in the presence of $\mathrm{ZnSO}_{4}$, were allowed to invade for 20 hours at $37^{\circ} \mathrm{C}$, and subsequently cells were fixed 
and stained. Cells migrating to the lower side of the membrane were mounted onto a microscope slide and counted under a light microscope. The percentages of invading cells were quantified as described in the materials and methods section and are shown in the bar graph demonstrating an inhibition of invasion of all $I G F-I R$ antisense RNA transfected cellular clones. NIH 3 T3 mouse fibroblast cells (3T3) were used as a control for non-invading cells. Data shown are the mean \pm SD values of at least three separate experiments.

\subsubsection{Inhibition of IGF-IR gene expression leads to reduced cell proliferation of human prostate cancer cells}

To further determine the effect of IGF-IR suppression on PC-3 cell proliferation, four $I G F-I R$ antisense-transfected PC-3 clones (A46, A47, A49 and A410), two control-transfected PC-3 clones (S3 and O) and non-transfected PC-3 cells were analyzed. After an incubation step with $\mathrm{ZnSO}_{4}$ in the cell culture medium over a time period of 48 hours, an MTT-based proliferation assay was performed at different time points ( 2 hours, 24 hours and 48 hours). The 2 hours incubation time was performed as a control point for an equal amount of cell numbers where the optical density at $450 \mathrm{~nm}$ was at a similar level for both $I G F-I R$ antisensetransfected PC-3 clones and control PC-3 cells (Fig. 9). As further shown in Figure 7 after 24 hours a significant inhibition of cell proliferation in IGF-IR antisense RNA transfected PC-3 clones ranging from $43 \%$ to $61 \%$ as compared to control-transfected and parental PC-3 cells was observed. Further incubation (48 hours) revealed similar results in the decrease of cell proliferation in the IGF-IR antisense-transfected PC-3 clones reaching a level of $50 \%$ to $65 \%$ inhibition as compared to control-transfected and non-transfected PC-3 cells. 


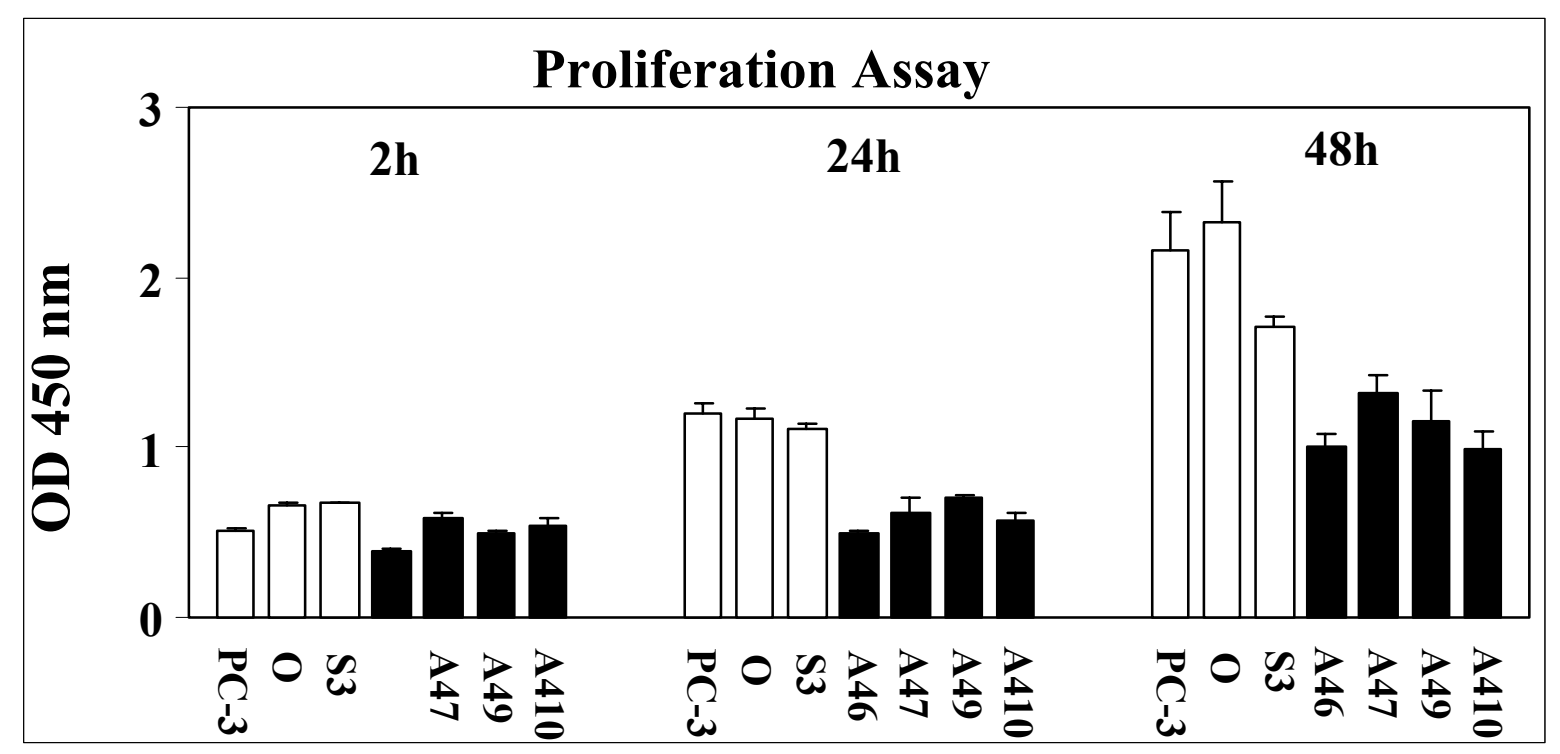

Figure 9. Expression of IGF-IR antisense cRNA in PC-3 cells inhibits cell proliferation in vitro

Effect of treatment with an IGF-IR antisense RNA construct on the proliferation rate of human PC-3 prostate carcinoma cells after $\mathrm{ZnSO}_{4}$ induction. Cell proliferation was measured using an MTT-based assay. The treatment of PC-3 cells with an IGF-IR antisense construct inhibits cell proliferation in four clonal populations (A46, A47, A49 and A410) compared with non-transfected cells (PC-3) and control-transfected cells (O and S3). Results are expressed as means \pm SD of three independent experiments. The clone names correspond to the clone names used in Figure 6. 


\subsubsection{Atlas Array analysis in PC-3 cells showing a reduced level of IGF-IR expression}

To identify genes which are differentially expressed in PC-3 cells showing a reduced level of $I G F-I R$ expression as compared to control-transfected PC-3 cells, total RNA from the IGF-IR antisense RNA transfected PC-3 cell clone A410 and the $I G F-I R$ sense RNA transfected clone $\mathrm{S} 3$ was isolated after incubating the cells with $\mathrm{ZnSO}_{4}$ in the culture medium. Total RNA was prepared from PC-3 transfectants and used to synthesize ${ }^{32} \mathrm{P}$-labeled whole cDNAs by reverse transcription, followed by hybridizations to two identical Atlas Select Human Tumor Arrays (Fig. $10 \mathrm{~A}$ and B) and two identical Atlas Human Cancer 1.2 Arrays (Fig. $10 \mathrm{C}$ and D) from BD Biosciences Clontech as described in the materials and methods section. The signals on the Arrays were scanned after a 3-day exposure by using a Molecular Imager FX and analyzed by using the Quantity one software. In total, 12 differentially expressed genes were identified to be up- or down-regulated in the IGF-IR antisense RNA transfected PC-3 cell clone A410 as compared to the IGF-IR sense RNA transfected clone S3 (Table 4). From these differentially exressed genes, two genes insulin-like growth factor binding protein-3 (IGFBP3) and macrophage inhibitory cytokine 1 (MIC-1) displaying the highest up- and downregulated expression in PC-3 clone A410 were further analyzed. 


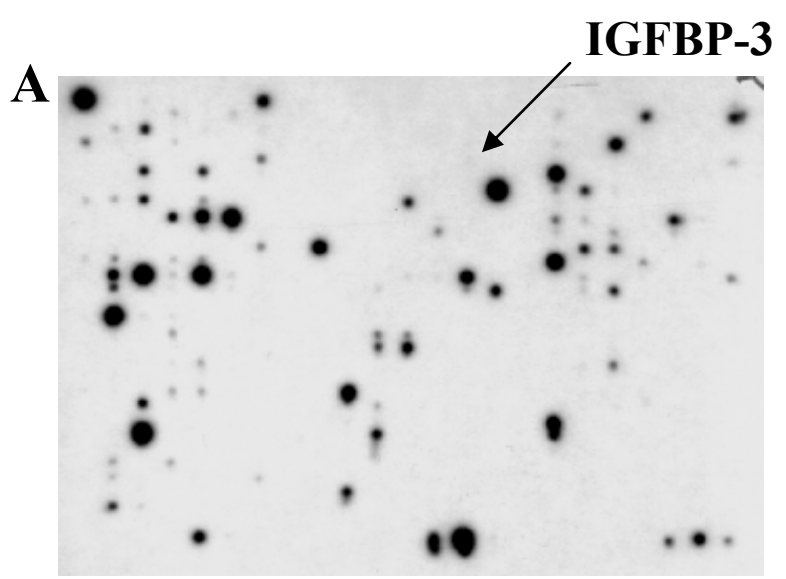

Sense clone S3

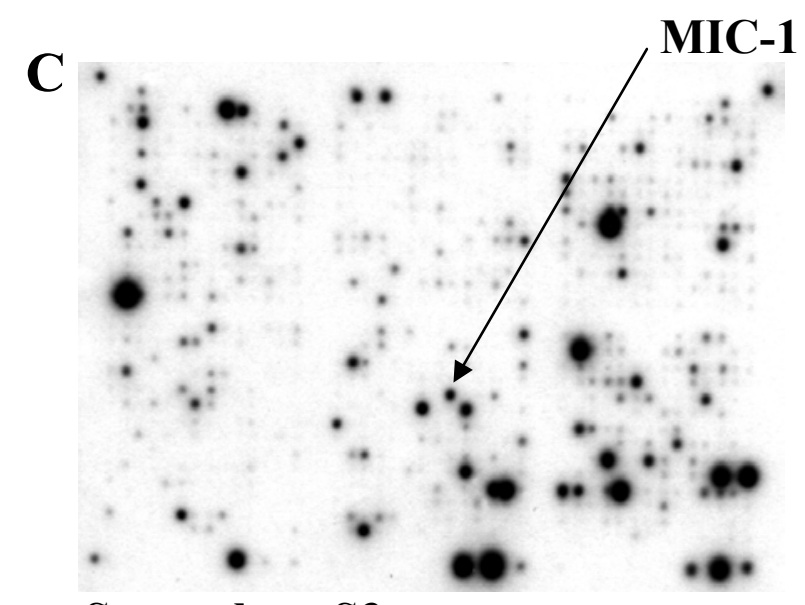

Sense clone S3

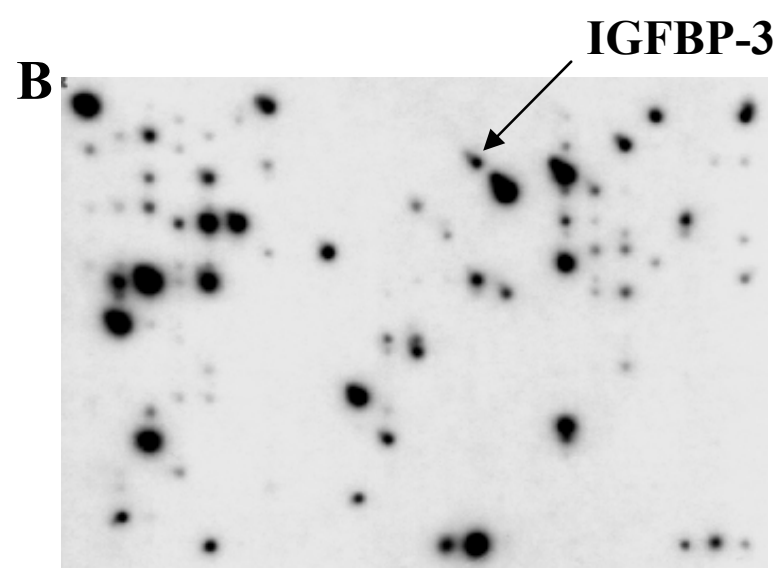

Antisense clone 410

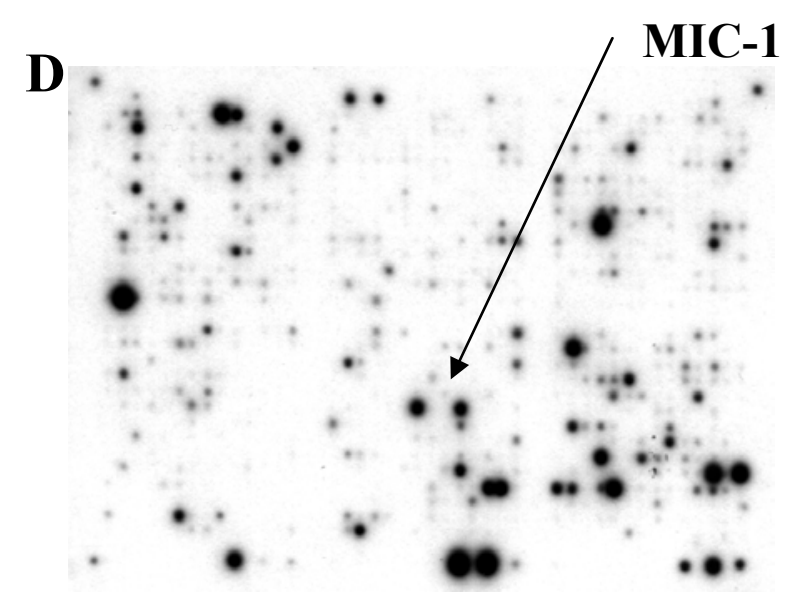

Antisense clone A410

Figure 10. Expression patterns of IGF-IR antisense (A410) and sense (S3) cRNA-treated PC-3 clones

Total RNAs were extracted from either clone A410 or corresponding S3 clone expressing antisense and sense fragment to $I G F-I R$, reverse transcribed into cDNA and used in both hybridization experiments described below. A) Hybridization signals obtained from the Atlas Select Human Tumor Arrays using ${ }^{32} \mathrm{P}$-labeled whole cDNAs as probes. Arrow indicate representative signal for IGFBP-3 cDNA in $I G F-I R$ sense cRNA-treated PC-3 clone S3. B) Hybridization signals obtained from the Atlas Select Human Tumor Arrays using ${ }^{32} \mathrm{P}$-labeled whole cDNAs as probes. Arrow indicate representative signal for $I G F B P-3$ cDNA demonstrating up-regulation of the IGFBP-3 in IGF-IR antisense cRNAtreated PC-3 clone A410. C) Hybridization signals obtained from Atlas Human Cancer 1.2 Arrays using ${ }^{32} \mathrm{P}$-labeled cDNAs as probes. Arrow indicate representative signal for the $M I C-1$ gene in $I G F$ $I R$ sense cRNA-treated PC-3 clone S3. D) Hybridization signals obtained from Atlas Human Cancer 1.2 Arrays using ${ }^{32} \mathrm{P}$-labeled cDNAs as probes. Arrow indicate representative signal for the $M I C-1$ gene demonstrating down-regulation of the MIC-1 in IGF-IR antisense cRNA-treated PC-3 clone A410. 


\begin{tabular}{|c|c|c|}
\hline & GENE NAMES & $\begin{array}{c}\text { GenBank } \\
\text { Accession } \\
\text { No. }\end{array}$ \\
\hline 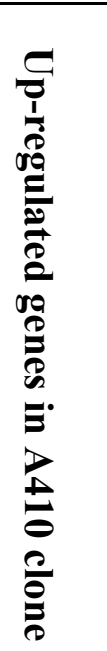 & $\begin{array}{l}\text { insulin-like growth factor binding protein-3 (IGFBP-3) } \\
\text { adenylate kinase } 2 \text { (adk2) } \\
\text { FOS-related antigene } 1 \text { (FRA1), (FOSL1) } \\
\text { ras homolog gene family member A (RHOA, ARHA, ARH12, RHOH12) } \\
\text { erbB3 proto-oncogene, HER3 } \\
\text { 70-kDa heat shock protein (HSPA5, GRP78, BIP) } \\
\text { interleukin } 1 \text { beta (IL1-beta, IL1B), catabolin } \\
\text { interleukin } 6 \text { (IL6), BSF2, IFNB2, HGF }\end{array}$ & $\begin{array}{c}\text { M31159 } \\
\text { AA029438 } \\
\text { X16707 } \\
\text { L25080 } \\
\text { M29366 } \\
\text { M19645 } \\
\text { K02770 } \\
\text { X04602 }\end{array}$ \\
\hline 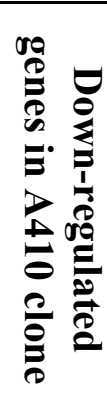 & $\begin{array}{l}\text { macrophage inhibitory cytokine } 1 \text { (MIC-1), prostate differentition } \\
\text { factor (PDF), growth differentiation factor } 15 \text { (GDF 15) } \\
\text { tissue-type plasminogen activator (TPA) } \\
\text { non specific cross reacting antigen } \\
\text { peptidyl-proryl cis-trans isomerase A }\end{array}$ & $\begin{array}{l}\text { AF019770 } \\
\text { M15518 } \\
\text { AA054073 } \\
\text { AA045841 }\end{array}$ \\
\hline
\end{tabular}

Table 4. Results from Atlas Select Human Tumor Array and Atlas Human Cancer 1.2 Array analysis.

Isolated up- and down-regulated genes in the IGF-IR antisense RNA transfected PC-3 cell clone A410 as compared to the IGF-IR sense RNA transfected clone S3. In bold, two genes (IGFBP-3 and MIC1) displaying the highest up- and down-regulated expression in PC-3 clone A410.

\subsubsection{Suppression of IGF-IR expression induces IGFBP-3 expression in PC-3 cells}

One of the genes showing an increased expression in the $I G F-I R$ antisense RNA transfected clone A410 was identified as human IGFBP-3 cDNA. A representative scanned phosphorimage of the arrays displaying IGFBP-3 and $\beta$-actin expression levels in the IGF-IR antisense cRNA tranfected clone (A410) as compared to the $I G F-I R$ sense cRNA transfected clone (S3) is shown in Figure 11A. The intensity of the hybridization signals were quantified with a phosphorimager (Molecular Imager FX) by using the Quantity one software. 
Quantification revealed an 11-fold up-regulation of $I G F B P-3$ expression in the $I G F-I R$ antisense cRNA transfected PC-3 cell clone (A410) as compared to the IGF-IR sense cRNA transfected PC-3 cell clone (S3). In addition, to verify the up-regulated expression of IGFBP3 mRNA in other $I G F-I R$ antisense cRNA transfected PC-3 clones and to determine IGFBP-3 expression in prostate carcinoma (PCa) as compared to the matched normal prostate (P), RNA samples were subjected to Northern blot analysis by using human IGFBP-3 cDNA as a probe (Figure 11B). For integrity and equality of the RNA the same Northern blot was rehybridized with a human $\beta$-actin cDNA probe. Quantification of the Northern blot was performed using a phosphorimager (Figure 11C) demonstrating an up-regulation of IGFBP-3 expression ranging from 8-fold (A49) to 16-fold (A46) in all IGF-IR antisense RNA transfected PC-3 clones as compared to control-transfected PC-3 cells (S3 and O) and parental PC-3 cells. Furthermore, a 2.5-fold down-regulation of IGFBP-3 suppression in cancerous prostate tissue was observed (Gleason score 5, tumor stage pT3aN0) as compared to the matched normal prostate tissue. In addition, an up- regulation of $I G F B P-3$ expression in $I G F-I R$ antisense RNA transfected PC-3 clones could be demonstrated at the protein level by Western blot analysis using a polyclonal antibody against IGFBP-3 on proteins derived from PC-3 cell conditioned media. As shown in Figure 11D, an increased accumulation of IGFBP-3 protein in conditioned media was observed in all IGF-IR antisense RNA transfected PC-3 clones analyzed, whereas controltransfected ( $\mathrm{S} 3$ and $\mathrm{O}$ ) and parental PC-3 cells showed only weak IGFBP-3 signals. 
A

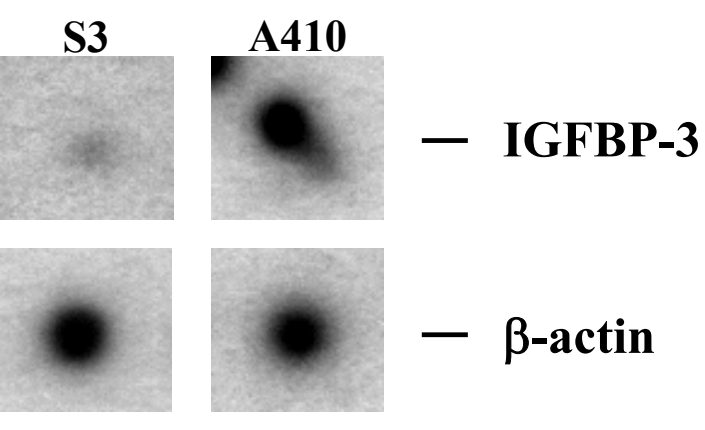

B

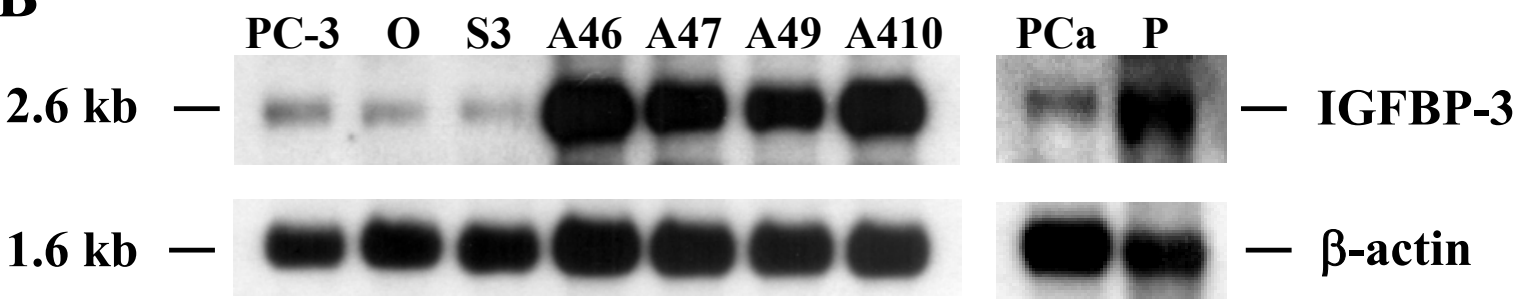

$\mathbf{C}$

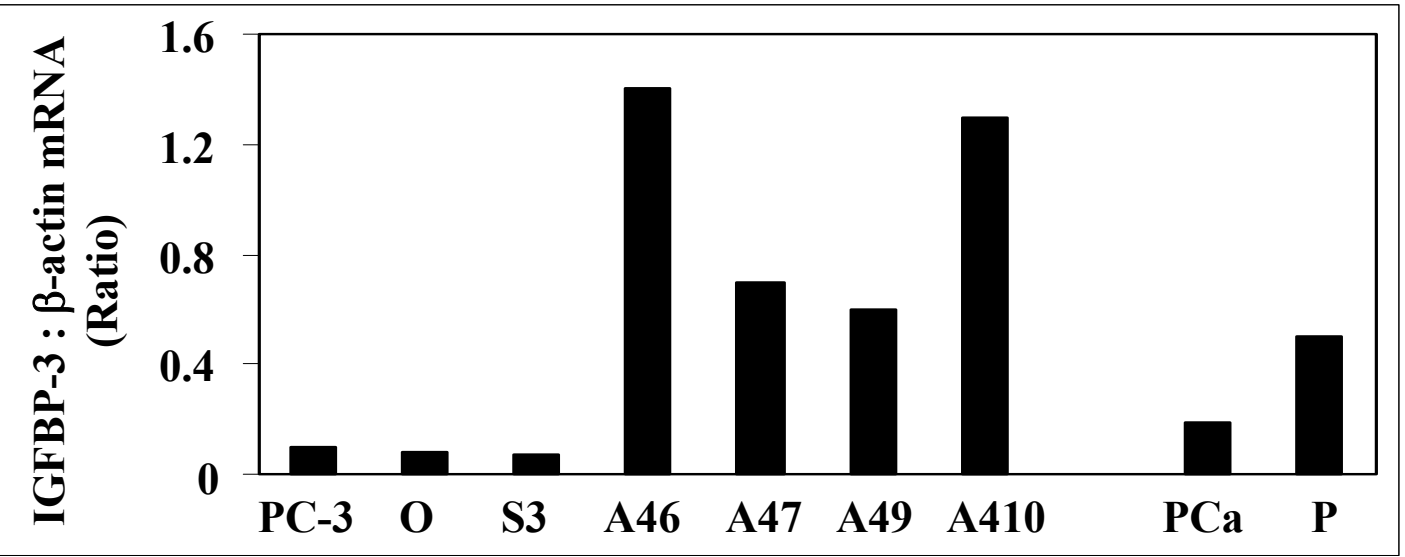

$\mathbf{D}$

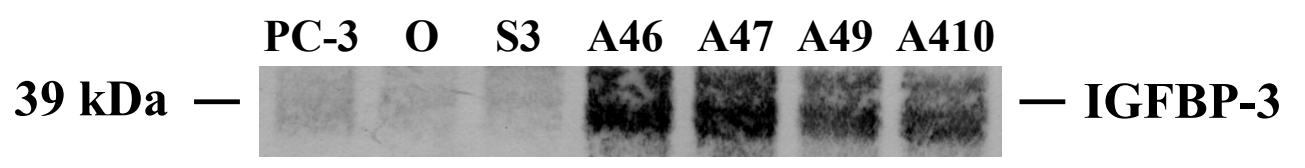

Figure 11. Up-regulation of IGFBP-3 expression in PC-3 cells treated with an IGF-IR antisense RNA construct and reduced $I G F B P-3$ expression in human prostate carcinoma.

A) Representative $I G F B P-3$ and $\beta$-actin hybridization signals obtained from two identical Atlas Select Human Tumor Arrays using ${ }^{32} \mathrm{P}$-labeled whole cDNAs from transfected PC-3 cells (after $\mathrm{ZnSO}_{4}$ induction) as probes. Total RNAs were extracted from the IGF-IR antisense RNA-transfected clone A410 or the control-transfected clone S3 expressing IGF-IR cRNA in the sense orientation, reverse transcribed into cDNA and used in the array hybridization experiments described above. B) Northern blot analysis on total RNA (6 $\mu$ g each) from non-transfected (PC-3), control-transfected (clones $\mathrm{O}$ and 
S3) and IGF-IR antisense RNA transfected PC-3 cells (clones A46, A47, A49 and A410) and from both human prostate carcinoma $(\mathrm{PCa})$ and matched normal prostate $(\mathrm{P})$ by using a human $I G F B P-3$ cDNA fragment as a probe. For integrity and equality of the RNA the Northern blot was rehybridized with a human $\beta$-actin cDNA probe. C) The mRNA signals were scanned using the phosphorimager Molecular Imager FX, and the difference in the expression of IGFBP-3 transcripts was calculated relative to the $\beta$-actin standards. Results of the analysis for IGFBP-3 expression are shown in the bar graphs. The clone names under the bar graphs correspond to the clone names used in B. D) Treatment of PC-3 cells with an IGF-IR construct in antisense orientation increases IGFBP-3 accumulation in PC-3 cell conditioned media. Non-transfected (PC-3), control-transfected (clones $\mathrm{O}$ and S3) and IGFIR antisense RNA-transfected cells (clones A46, A47, A49 and A410) were cultured in RPMI 1640 and after reaching $70-80 \%$ confluency, cells were incubated 22 hours in serum-reduced OPTI-MEM in the presence of $\mathrm{ZnSO}_{4}$. Conditioned media were collected and proteins were concentrated by precipitation. Equal amounts of protein $(50 \mu \mathrm{g}$ each) were loaded on a polyacrylamide gel, blotted and subsequently the Western blot was probed with an IGFBP-3-specific antibody.

\subsubsection{Northern blot analysis of macrophage inhibitory cytokine-1 (MIC-1) expression}

One of the genes showing a decreased expression in the IGF-IR cRNA transfected antisense clone A410 was MIC-1. In order to verify the down-regulated expression of the MIC-1 gene, a MIC-1 cDNA fragment was isolated and subjected to Northern blot analysis to verify the differential expression pattern in other antisense clones as compared to sense clone, parental PC-3 cells and cells transfected with the empty plasmid. For integrity and equality of the RNA the Northern blot was rehybridized with a human $\beta$-actin cDNA probe (Fig. 12). Northern blot analysis revealed an up-regulation of $M I C-1$ expression (1.4 kb transcript size) only in the sense clone S3, but not in parental PC-3 cells and in PC-3 cells transfected with the empty plasmid. 


\section{$\begin{array}{lllllll}\text { PC-3 } & \text { O } & \text { S3 } & \text { A46 } & \text { A47 } & \text { A49 } & \text { A410 }\end{array}$ \\ $1.4 \mathrm{~kb}-$ \\ - MIC-1 \\ $1.6 \mathrm{~kb}-\mathrm{CO}-\beta \mathrm{Cactin}$}

\section{Figure 12. Expression of $M I C-1$ in transfeced PC-3 cells and parental cells}

Northern blot analysis of total RNA (6 $\mu \mathrm{g}$ ) from non-transfected (PC-3), control-transfected (clones O and S3) and $I G F-I R$ antisense RNA transfected PC-3 cells (clones A46, A47, A49 and A410) was carried out with a human $M I C-1$ cDNA fragment that specifically detects endogenous $M I C-1$ mRNA. For integrity and equality of the RNA the Northern blot was rehybridized with a human $\beta$-actin cDNA probe.

\subsubsection{Inhibition of IGF-IR gene expression leads to PC-3 cell death}

In order to study the effect of $I G F-I R$ suppression and $I F G B P-3$ up-regulation on the viability of PC-3 cells, programmed cell death was determined by analyzing the induction of caspase- 3 activity. After 48 hours of incubation with $\mathrm{ZnSO}_{4}$ three clones treated with the $I G F-I R$ antisense RNA construct, control-transfected and non-transfected PC-3 cells were cytocentrifugated, dried, fixed and incubated with a polyclonal rabbit anti-human antibody against the active caspase- 3 followed by visualization as described in the material and methods section. Caspase-3-positive cells displayed a red cytoplasmic staining around the clearly demarcated nuclei as shown in Figure 13A. The appeared caspase-3 activity reached levels from $6.5 \%$ to $8.5 \%$ in the $I G F-I R$ antisense RNA transfected clones, whereas control cells (IGF-IR sense RNA transfected clone S3 and parental PC-3 cells) showed only low levels $(0.5 \%)$ of caspase-3 activity (Figure 13B). 


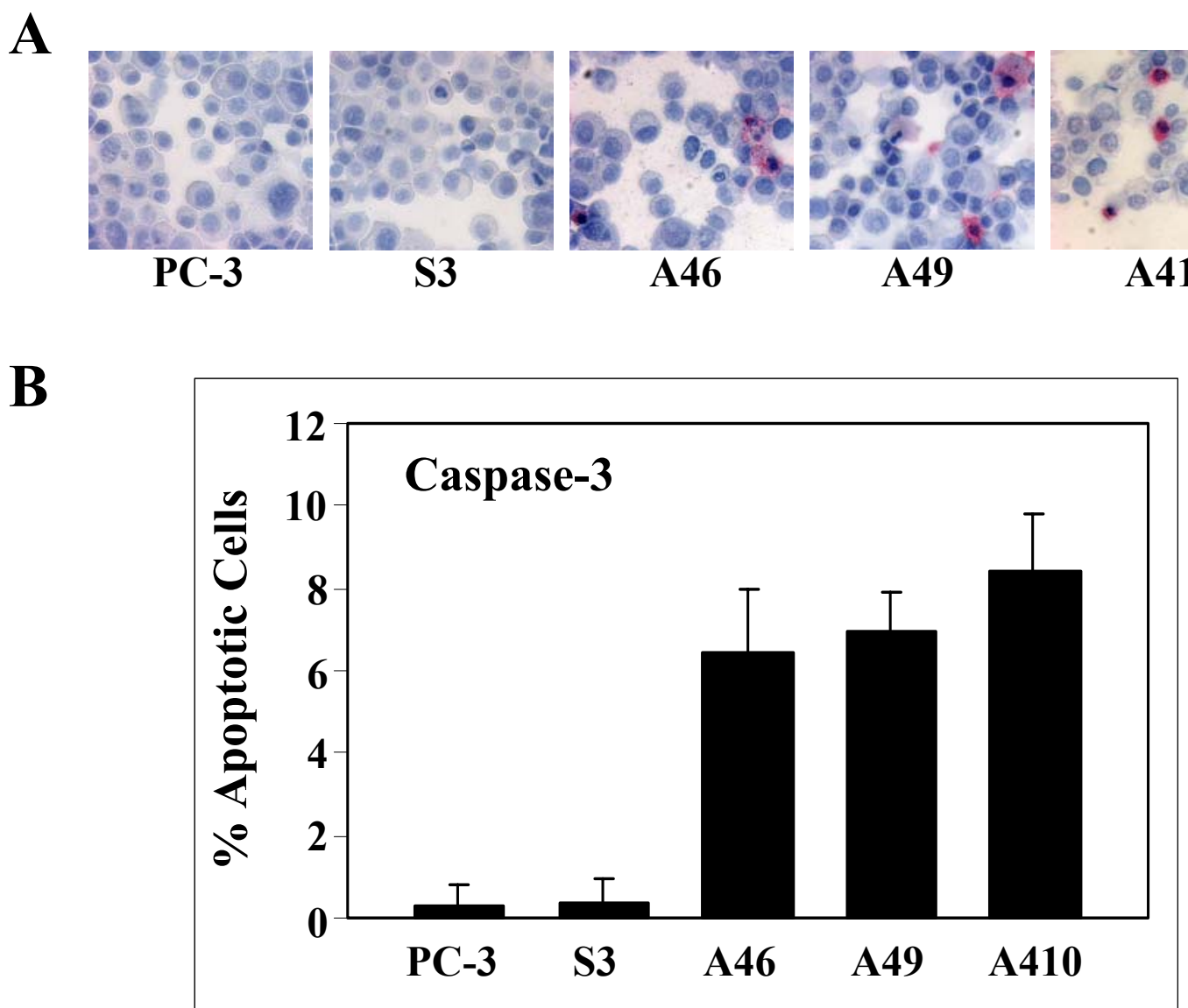

Figure 13. Increase of apoptosis in PC-3 cells treated with the IGF-IR antisense RNA construct.

A) After $\mathrm{ZnSO}_{4}$ induction (48 h) non-transfected (PC-3), control-transfected (clone $\mathrm{S} 3$ ) and $I G F-I R$ antisense RNA transfected PC-3 cells (clones A46, A49 and A410) attached to the bottom and floating in the medium were collected. The percentage of apoptotic cells was assessed by caspase- 3 activation as described in materials and methods. The number of caspase- 3 positive cells was determined by counting labeled cells in 5 randomly chosen high power fields (original magnification x 200). Note the red cytoplasmic staining for caspase-3 around the clearly demarcated nuclei. B) Bar graphs represent the percentage of positively stained PC-3 cells for caspase-3. Data, means of three independent experiments $( \pm \mathrm{SE})$. 


\subsubsection{Inhibition of IGF-IR expression down-regulates MMP-2 expression in human prostate cancer cells}

After analyzing both the endogenous $I G F-I R$ suppression and a decrease in the invasive capacity of $I G F-I R$ antisense RNA transfected PC-3 cells, next the $M M P-2$ expression was investigated in IGF-IR antisense RNA transfected, control-transfected and parental PC-3 cells by real time RT-PCR analysis. Total RNA was isolated from four antisense clones (A46, A47, A49, A410), one sense clone (S3) and parental PC-3 cells previously incubated with $\mathrm{ZnSO}_{4}$ in the culture medium and used for real-time RT-PCR as described in the material and methods section. Silencing of $I G F-I R$ mRNA expression was paralleled by a significant downregulation of $M M P-2$ mRNA expression. As can be seen in Figure 14A moderate $M M P-2$ expression is observed in control-transfected (clone S3) and parental PC-3 cells, whereas $M M P-2$ expression is reduced to almost non-detectable levels in all IGF-IR antisense RNA transfected PC-3 cellular clones (A46, A47, A49 and A410). This all-or-nothing effect between IGF-IR sense RNA transfected (S3) and IGF-IR antisense RNA transfected PC-3 cells (A410) is also evident in agarose gel electrophoresis of $M M P-2$ RT-PCR products after as much as 50 PCR cycles (Fig. 14B). 


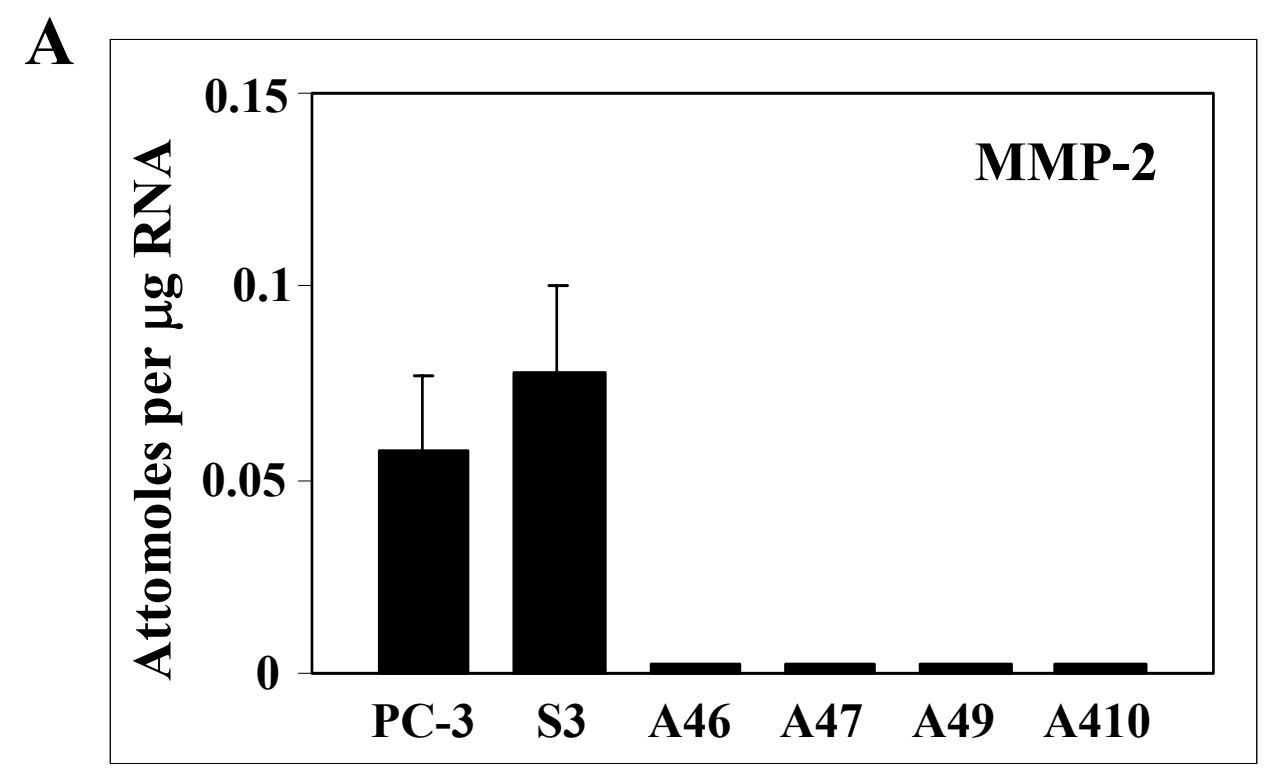

B

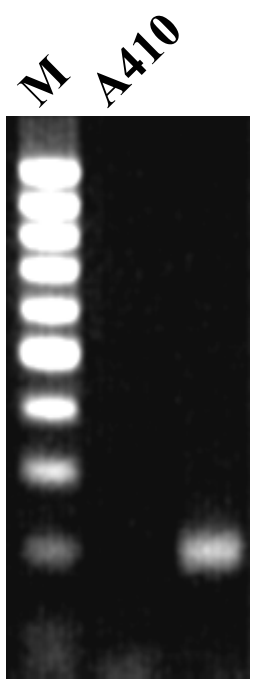

Figure 14. Down-regulation of $M M P-2$ mRNA in IGF-IR suppressed PC-3 cells

A) Quantification of $M M P-2$ expression by using real-time RT-PCR on RNA from non-transfected (PC-3), control-transfected (clone S3) and IGF-IR antisense RNA transfected PC-3 cells (clones A46, A47, A49 and A410) as described in the material and methods section. Means and SD from five parallel experiments are shown. B) Agarose gel electrophoresis of two selected $M M P-2$ PCR runs after 50 PCR cycles: M: 100 bp standard DNA ladder, A410: IGF-IR antisense RNA transfected PC-3 cells, S3: $M M P-2$ RT-PCR product (192 bp) from IGF-IR sense RNA transfected PC-3 cells.

\subsubsection{Laser-capture microdissection and expression of IGF-IR and IGFBP-3 in human prostate cancer}

To further quantify either $I G F-I R$ overexpression or $I G F B P-3$ down-regulation in pure prostate cancer specimens of epithelial origin as compared to the matched normal prostate epithelial tissue, both laser-capture microdissection (LCM) and quantitative RT-PCR analyses were applied. Prior to quantitative RT-PCR, RNA samples isolated from microdissected epithelial cells of matched normal prostate and prostate cancer were checked for RNA integrity and RNA amount by analyzing an RNA aliquot on the Agilent Pico LabChip ${ }^{\circledR}$. Subsequently, both $I G F-I R$ and $I G F B P-3$ mRNA expression were analyzed by quantitative RT-PCR on RNAs (equal amounts) from LCM-derived samples from 12 radical prostatectomies from cancer patients which were prepared as described in the material and methods section. In nine out of twelve cases analyzed, IGF-IR expression was up-regulated up to 28 -fold in LCM samples derived from epithelial cells of tumorous areas as compared to the 
paired normal prostate epithelial tissues (Figure 15A). Furthermore, quantitative RT-PCR studies revealed that $I G F B P-3$ expression was down-regulated from 1.5 -fold to 42 -fold in all prostate cancer samples of epithelial origin as compared to the matched normal prostate epithelial tissues (Figure 15B). Wilcoxon Rank tests for this data set yielded a significance of the up-regulation of $I G F-I R$ expression and the down-regulation of $I G F B P-3$ expression in tumorous tissue with a $\mathrm{p}$ value below 0.01 , respectively. The quantitative RT-PCR analysis did not show a significant correlation with specific clinicopathological features such as pathologic and clinical stage (Table 5).
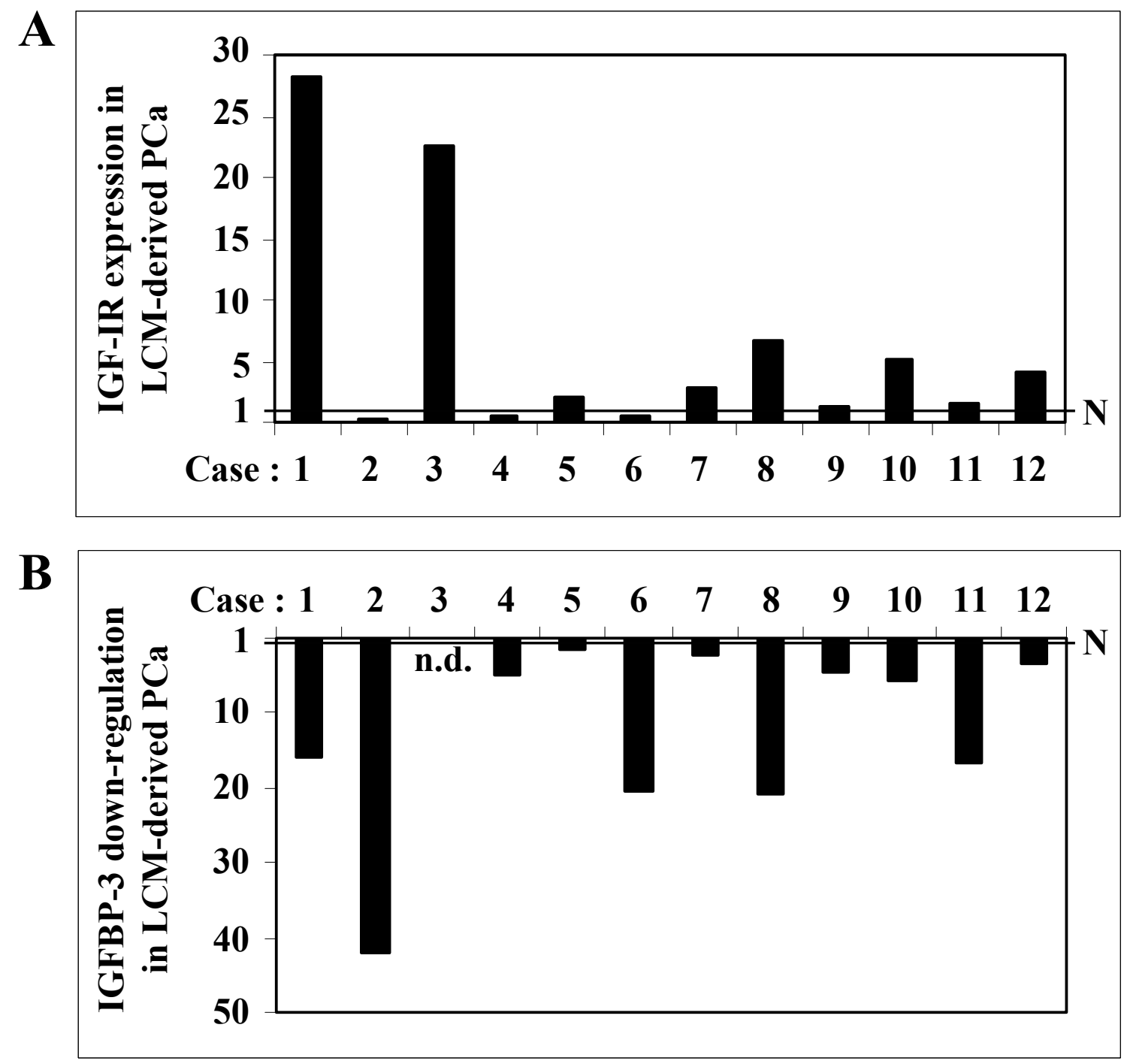

Figure 15. IGF-IR and IGFBP-3 expression in prostate carcinoma (PCa)

Laser captured microdissected (LCM) samples of epithelial origin from twelve radical prostatectomies were analyzed by a two-step real-time RT-PCR for IGF-IR and IGFBP-3 expression, respectively, relative to $\beta$-actin. Factors of up-or down-regulation of $I G F-I R(\mathbf{A})$ and $I G F B P-3$ (B) expression in tumor specimens as compared to matched normal prostate samples are shown. Expression levels in normal prostate tissues samples are set to one $(\mathrm{N}=1)$. 


\begin{tabular}{ccccc}
\hline Case & Gleason score & Tumor stage & IGF-IR* & IGFBP-3* $^{*}$ \\
\hline 1 & 7 & pT3bN1 & 28.3 & 15.8 \\
2 & 6 & pT2aN0 & 0.3 & 42.1 \\
3 & 6 & pT3bN0 & 22.5 & n.d \\
4 & 7 & pT3aN1 & 0.4 & 4.8 \\
5 & 6 & pT2bN0 & 2 & 1.5 \\
6 & 5 & pT2bN0 & 0.5 & 20.5 \\
7 & 8 & pT3bN1 & 2.8 & 2.4 \\
8 & 9 & pT3bN0 & 6.8 & 20.7 \\
9 & 9 & pT3bN0 & 1.2 & 4.6 \\
10 & 7 & pT3aN0 & 5.1 & 5.5 \\
11 & 6 & pT3aN0 & 1.5 & 16.7 \\
12 & 7 & pT2aN0 & 4.2 & 3.4 \\
\hline
\end{tabular}

Table 5. Clinicopathological features of the patients described in Figure 15

* indicates factor of up or down-regulation of IGF-IR and IGFBP-3 expression in comparison to tumor-free tissue normalized against $\beta$-actin. $\mathrm{P}<0.01$; Wilcoxon-Rank-sum-test with comparison of tumor and tumor-free tissue. n.d.= not determined. 


\subsubsection{Cancer Profiling Array analysis of IGFBP-3 expression in different human cancers}

To analyze differential gene expression of IGFBP-3 in different tumors and matched normal samples a cDNA fragment for $I G F B P-3$ was used to synthesize a ${ }^{32} \mathrm{P}$-labeled probe and the labeled probe was hybridized to the Cancer Profiling Array from BD Biosciences Clontech as described in materials and methods. The signals were scanned after a 1-day exposure by using a Molecular Imager FX, as shown in Figure 16 and analyzed by using the Quantity one software. The results are summarized in Table 6. The up-regulation of IGFBP-3 gene was mostly found in the following cancers: kidney cancer (14 patients out of 20), lung cancer (18 patients out of 21), rectum cancer (11 patients out of 18), colon cancer (22 patients out of 34), stomach cancer (18 patients out of 27) and thyroid cancer (4 patients out of 6 ), whereas downregulation was mostly determined in the following cancers: breast cancer ( 34 patients out of 50 ), cancer of the uterus ( 24 patients out of 42 ), and ovarian cancer (9 patients out of 16). The quantification of the representative signals from tumors and corresponding normal tissues from individual patients, using a phosphorimager, revealed the highest up-regulation of IGFBP-3 gene in kidney cancer (up to 7 -fold). In colon and lung cancers the up-regulation of $I G F B P-3$ riched up to 3-fold wheras thyroid, rectum and stomach cancers showed up to 2- fold, 2.3-fold and 2.6-fold up regulation, respectively. Furthermore, the highest down-regulation of IGFBP3 was determined in cancer of the uterus (up to 5.9-fold). In ovarian and breast cancers the down-regulation of IGFBP-3 riched up to 4-fold and 2.5-fold, respectively. 

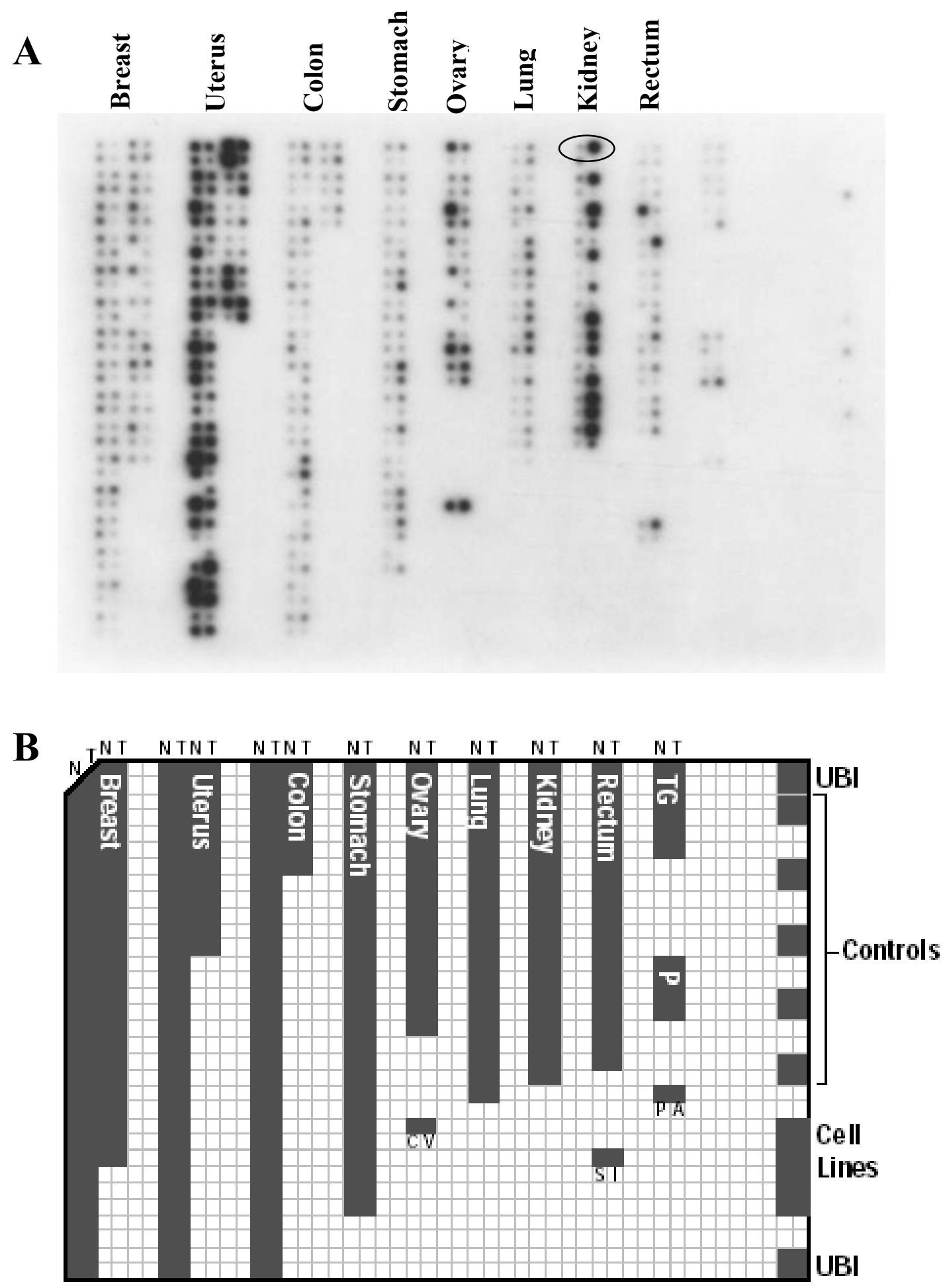

Figure 16. Cancer Profiling Array: representative membrane hybridization pattern.

The cDNA fragment for IGFBP-3 was used to synthesize a ${ }^{32} \mathrm{P}$-labeled probe and the labeled probe was hybridized to the Cancer Profiling Array. A) The representative signals from tumors and corresponding normal tissues from individual patients were scanned after a 1-day exposure by using a Molecular Imager FX. An example of representative signals from one patient (coordinate in kidney section) exhibiting up-regulation of IGFBP-3 is circled. B) Scheme of the Cancer Profiling Array for the cDNA samples localization derived from multiple tumor types, and cancer cell lines. CV $=$ Cervix. 
$\mathrm{SI}=$ Small intestine. $\mathrm{PA}=$ Pancreas. $\mathrm{N}=$ Normal. $\mathrm{T}=$ Tumor. $\mathrm{P}=$ Prostate. $\mathrm{UBI}=$ Ubiquitin $. \mathrm{TG}=$ Thyroid gland. (Modified after CLONTECHniques Catalog 2001)

\begin{tabular}{cccc}
\hline Cancer & $\begin{array}{c}\text { No. of patients with up- } \\
\text { regulated IGFBP-3 } \\
\text { expression }\end{array}$ & $\begin{array}{c}\text { No. of patients with } \\
\text { down-regulated } \\
\text { IGFBP-3 expression }\end{array}$ & $\begin{array}{c}\text { No. of patients with } \\
\text { no difference in } \\
\text { IGFBP-3 expression }\end{array}$ \\
\hline Breast & 7 & $\mathbf{3 4}$ & 9 \\
Uterus & $\mathbf{2 6}$ & $\mathbf{2 4}$ & 10 \\
Colon & $\mathbf{1 8}$ & 7 & 1 \\
Stomach & 4 & 6 & 3 \\
Ovary & $\mathbf{1 8}$ & $\mathbf{9}$ & 3 \\
Lung & $\mathbf{1 4}$ & 2 & 1 \\
Kidney & $\mathbf{1 1}$ & 3 & 3 \\
Rectum & $\mathbf{4}$ & 3 & 1 \\
Thyroid & 1 & 1 & 2 \\
Prostate & & 1 & 4 \\
\hline
\end{tabular}

Table 6. Results from the Cancer Profiling Array analysis for IGFBP-3 expression in different human cancers and the matched normal tissues 


\subsection{Isolation and identification of differentially expressed genes in prostate carcinoma}

\subsubsection{Atlas Array analysis in prostate carcinoma.}

To identify genes which are differentially expressed in normal prostate and prostate carcinoma tissues of epithelial origin total RNA from matched prostate and prostate carcinoma were isolated (case 01, pT3aN0). Total RNA prepared from these tissues was used to synthesize ${ }^{32} \mathrm{P}$-labeled whole cDNAs by reverse transcription, followed by hybridization to two identical Atlas Select Human Tumor Arrays (Fig. 17 A, B and C) from BD Biosciences Clontech as described in materials and methods. In total, 46 differentially expressed genes were identified to be up- or down-regulated in prostate carcinoma (Table 7). In addition, the known genes showing a differential expression pattern in prostate tumor samples included transcription factors, protooncogenes, and other proteins, e.g. Krox 24, c-jun, spermidyne acetyltransferase, ribosomal proteins, clusterin and prostate secretory protein 94 . From these differentially exressed genes, seven genes displaying an up-regulated expression in human prostate carcinoma and which were not described previously to be differentially expressed in prostate cancer were further analyzed (Table 8). 


\begin{tabular}{|c|c|c|c|}
\hline & GENE NAMES & $\begin{array}{l}\text { GenBank } \\
\text { Accession }\end{array}$ & $\begin{array}{c}\text { Gene } \\
\text { Regulation in } \\
\text { cancer* }\end{array}$ \\
\hline 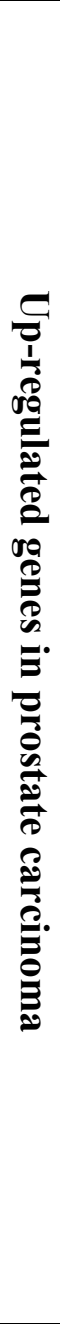 & $\begin{array}{l}\text { clone ZD55G12 (Soares library NbHH19W from IMAGE Consortium) } \\
\text { 60S ribosomal protein L27a (RPL27A) } \\
\text { novel gene (SC69) } \\
\text { 40S ribosomal protein S2 (RPS2); LLrep3 mRNA/protein; RPS4 } \\
\text { ferritin light chain; ferratin L subunit (FLT) } \\
\text { vacuolar ATP synthase subunit F (V-ATPase F subunit; VATF) } \\
\text { inter-alpha-trypsin inhibitor family heavy chain related protein (IHRP) } \\
\text { complement component C1s } \\
\text { ribosomal protein L32 } \\
\text { RNA-binding protein regulatory subunit DJ-1 protein } \\
\text { ribosomal protein S8 } \\
\text { ribosomal protein S11 } \\
\text { poly A binding protein } \\
\text { 40S ribosomal protein S2 (RPS2); RPS4; LLREP3 protein } \\
\text { membrane-associated phospholipase A2 precursor (PLA2G2A) } \\
\text { spermidyne acetyltransferase } \\
\text { cytochrome C oxidase subunit II } \\
\text { 12S ribosomal RNA; } 16 \mathrm{~S} \text { ribosomal RNA; ribosomal RNA } \\
\text { 60S ribosomal protein L7A (RPL7A); surfeit locus protein } 3 \text { (SURF3) } \\
\text { 40S ribosomal protein/mRNA S26 (RPS26) } \\
\text { 40S ribosomal protein S25 (RPS25) } \\
\text { prostatic acid phosphatase precursor (ACPP) } \\
\text { smooth muscle myosin alkali light chain (MLC3SM); LC17B } \\
\text { H. sapiens H2B/I gene } \\
\text { MAT8 protein } \\
\text { ATPase homolog } \\
\text { Peptidyl-proryl cis-trans isomerase A } \\
\text { ferritin heavy chain } \\
\text { ribosomal protein L19 } \\
\text { Nm23 protein } \\
\text { testis enhanced gene transcript (TEGT), Bax inhibitor-1 (BI-1) } \\
\text { c-jun protoncogen; trascription factor AP-1 } \\
\text { early growth response protein 1(hEGR1); KROX24 } \\
\text { (M) }\end{array}$ & $\begin{array}{c}\text { X17206 } \\
\text { M11147 } \\
\text { D49400 } \\
\text { D38595 } \\
\text { X06596 } \\
\text { X03342 } \\
\text { AF021819 } \\
\text { X67247 } \\
\text { X06617 } \\
\text { Y00345 } \\
\text { X17206 } \\
\text { M22430 } \\
\text { M55580 } \\
\text { X55654 } \\
\text { V00710 } \\
\text { M36072 } \\
\text { X69654 } \\
\text { M64716 } \\
\text { X52174 } \\
\text { M22918 } \\
\text { H70744 } \\
\text { AA0535 } \\
\text { W73368 } \\
\text { AA045841 } \\
\text { M97164 } \\
\text { S56985 } \\
\text { X17620 } \\
\text { X75861 } \\
\text { J04111 } \\
\text { X52541 }\end{array}$ & $\begin{array}{c}\text { Up Liver } \\
\text { Up Liver } \\
\text { Up Liver } \\
\text { Up Liver } \\
\text { Up Liver } \\
\text { Up Liver } \\
\text { Down Liver } \\
\text { Down Liver } \\
\text { Down Lung } \\
\text { Down Lung } \\
\text { Down Lung } \\
\text { Down Lung } \\
\text { Up Prostate } \\
\text { Up Prostate } \\
\text { Up Prostate } \\
\text { Up Prostate } \\
\text { Up Prostate } \\
\text { Up Prostate } \\
\text { Up Prostate } \\
\text { Up Prostate } \\
\text { Up Prostate } \\
\text { Down Prost. } \\
\text { Down Prost. } \\
\text { Up Bladder } \\
\text { Up Bladder } \\
\text { Up Bladder } \\
\text { Up Bladder } \\
\text { Up Breast } \\
\text { Up Breast } \\
\text { Up Breast } \\
\text { Up Breast } \\
\text { Non-differ ex. } \\
\text { Non-differ ex. }\end{array}$ \\
\hline 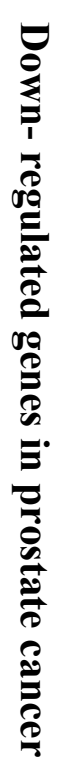 & $\begin{array}{l}\text { 40S ribosomal protein S4 X isoform (RPS4X) } \\
\text { cytoplasmic actin 2; gamma-actin (ACTG) } \\
\text { cytochrome oxidase subunit I (COI) \& subunit II (COII) pseudogenes } \\
\text { novel gene (SC151) } \\
\text { anti-carcinoma surface nomoclonal antibody CR4E8 } \\
\text { chromosome } 2 \text { cosmids cos } 111 \text { and cos } 607 / 6 \text { containing } \\
\text { immunoglobulin Vk-JkCk region } \\
\text { lactotransferrin precursor (LTF); lactoferrin (LF) } \\
\text { aortic smooth actin (ACTSA); vascular smooth muscle actin } \\
\text { (ACTVS); alpha -actin } 2 \text { (ACTA2) } \\
\text { enteric smooth muscle gamma-actin (ACTG2; ACTSG); alpha actin } 3 \\
\text { prostate secreted seminal plasma protein precursor (PRSP) } \\
\text { immunoglobulin binding factor (IGBF); prostate secretory protein } 94 \\
\text { (PSP94); PN44 } \\
\text { squalene epoxidase } \\
\text { metallothionein-le (hMT-le) } \\
\text { clusterin (complement lysis inhibitor; testosterone-repressed prostate } \\
\text { message 2; apolipoprotein J) }\end{array}$ & $\begin{array}{c}\text { M22146 } \\
\text { X04098 } \\
\text { AF035429 } \\
\text { S77601 } \\
\text { AF017732 } \\
\text { M83202 } \\
\text { X13839 } \\
\text { X16940 } \\
\text { M15855 } \\
\text { W80742 } \\
\\
\text { W73154 } \\
\text { AA046041 } \\
\text { AA041549 }\end{array}$ & $\begin{array}{c}\text { Up Liver } \\
\text { Up Liver } \\
\text { Down Liver } \\
\text { Up Lung } \\
\text { Up Lung } \\
\text { Up Lung } \\
\text { Down Prost. } \\
\text { Down Prost. } \\
\text { Down Prost. } \\
\text { Down Prost. } \\
\text { Up Bladder } \\
\text { Up Bladder } \\
\text { Down Bladd. } \\
\text { Down Bladd. }\end{array}$ \\
\hline
\end{tabular}

Table 7. Results from Atlas Select Human Tumor Array analysis. Isolated up- and down-

regulated genes in prostate carcinoma. (* Gene regulation in cancer determined by CLONTECH). 
A

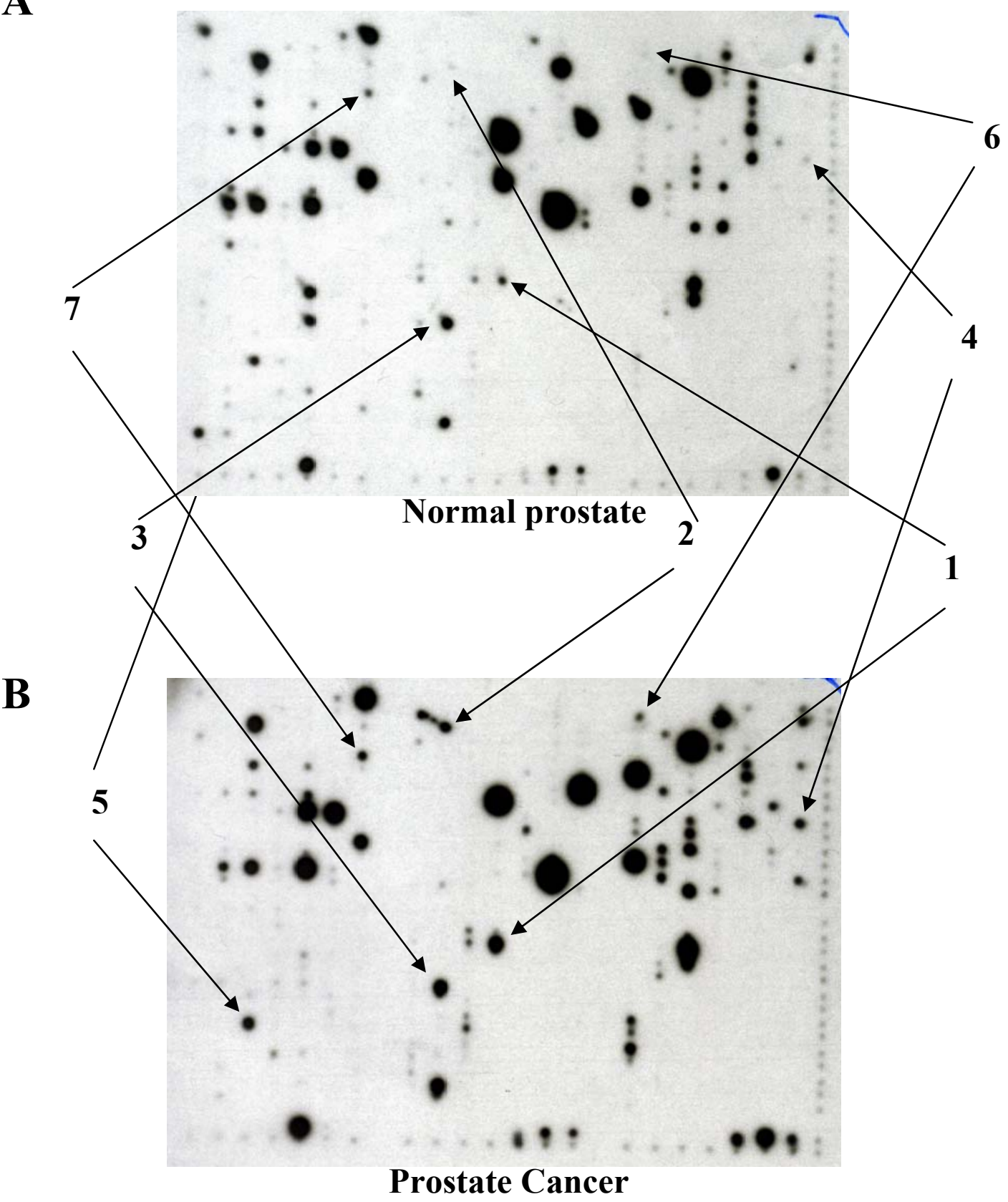

C

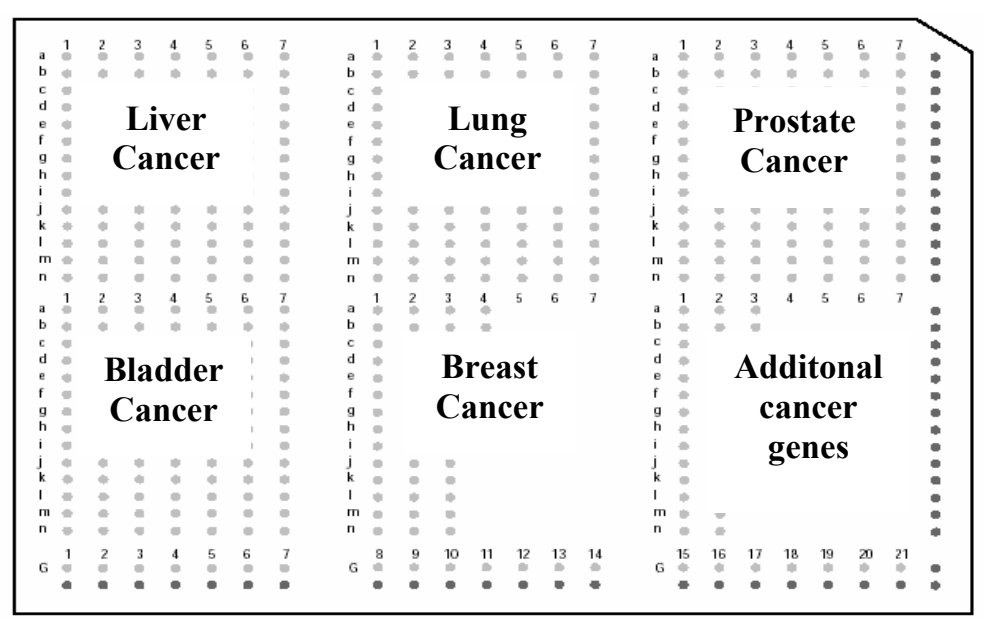


Figure 17. Screening of differentially expressed genes in prostate carcinoma as compared to normal prostate tissue

A ,B) Expression patterns of corresponding normal prostate and prostate carcinoma tissue. Typical phosphorimages are shown after a five-day exposure time. Total RNAs were extracted from either prostate carcinoma (case 01, Gleason score 5, pT3aN0) or corresponding normal prostate tissue, reverse transcribed into cDNA and used in both hybridization experiments with two identical Atlas Select Human Tumor Arrays. Arrows indicate seven genes displaying an up-regulated expression in human prostate carcinoma descriebed in Table 6. C) Scheme of cDNAs and controls immobilized on the Atlas Select Human Tumor Array. Dark gray dots represent orientation marks to determine the coordinates of hybridization signals.(Modyfied after CLONTECH Catalog 2000).

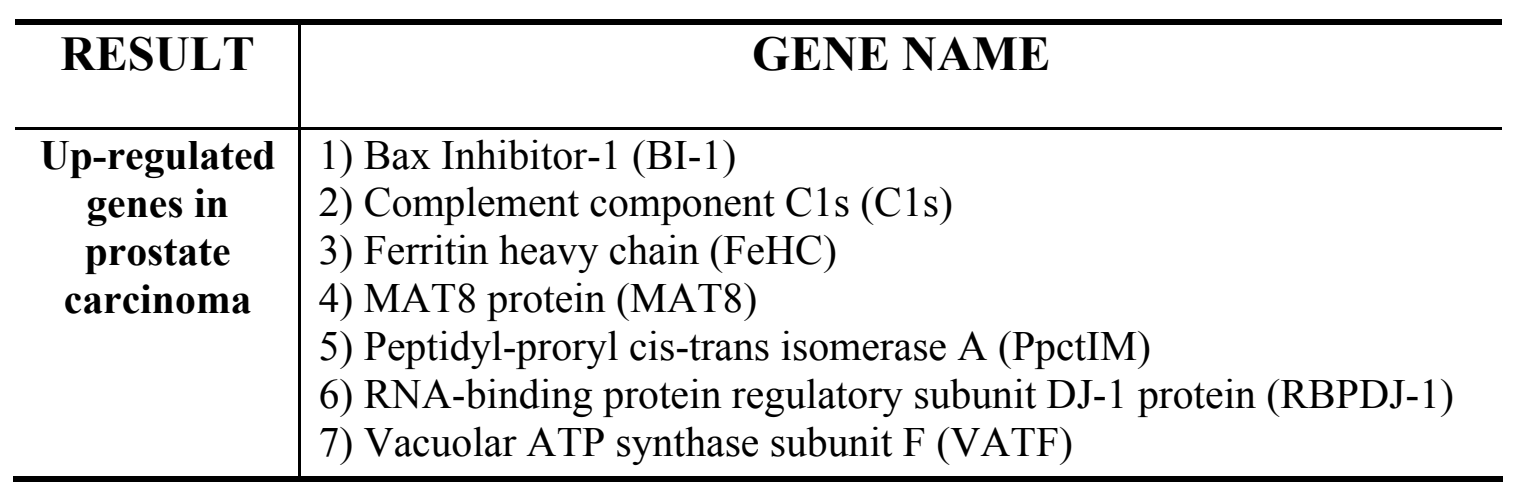

Table 8. Seven genes displaying an up-regulated expression in human prostate carcinoma Genes were isolated by comparing representative signals between prostate carcinoma and corresponding normal prostate tissue. Numbers correspond to numbers used in Figure 17 A and B. 


\subsubsection{Quantitative RT-PCR analysis of the isolated genes on RNA from normal prostate and prostate cancer tissue}

To confirm the overexpression of the seven genes detected by Atlas array analysis in prostate carcinoma, total RNA isolated from matched normal prostate and prostate carcinoma (case 01, pT3aN0) was used for quantitative RT-PCR. Prior to quantitative RT-PCR, total RNA samples were checked for RNA integrity and RNA amount by analyzing an RNA aliquot on the Agilent Nano LabChip (data not shown). Subsequently, mRNA expression of the newly isolated genes (BI-1, C1s, FeHC, MAT-8, PpctIM, RBDJ-1 and VATF) was analyzed by quantitative RT-PCR by using SYBR Green I dye as described in the material and methods section. The expression of the investigated genes was normalized to $\beta$-actin mRNA expression to compensate for different sample capacities. In all cases the expression of the isolated genes was up-regulated, as shown in Figure $18 \mathrm{~A}$ and B, from 3-fold up to 9-fold in the tumor samples as compared to the paired normal prostate tissues. Furthermore, to confirm that only specific PCR products evoked fluorescence signals, PCR products were subcloned into pGEMT vectors (Fig. 18C) and sequenced as described in the material and methods section. 


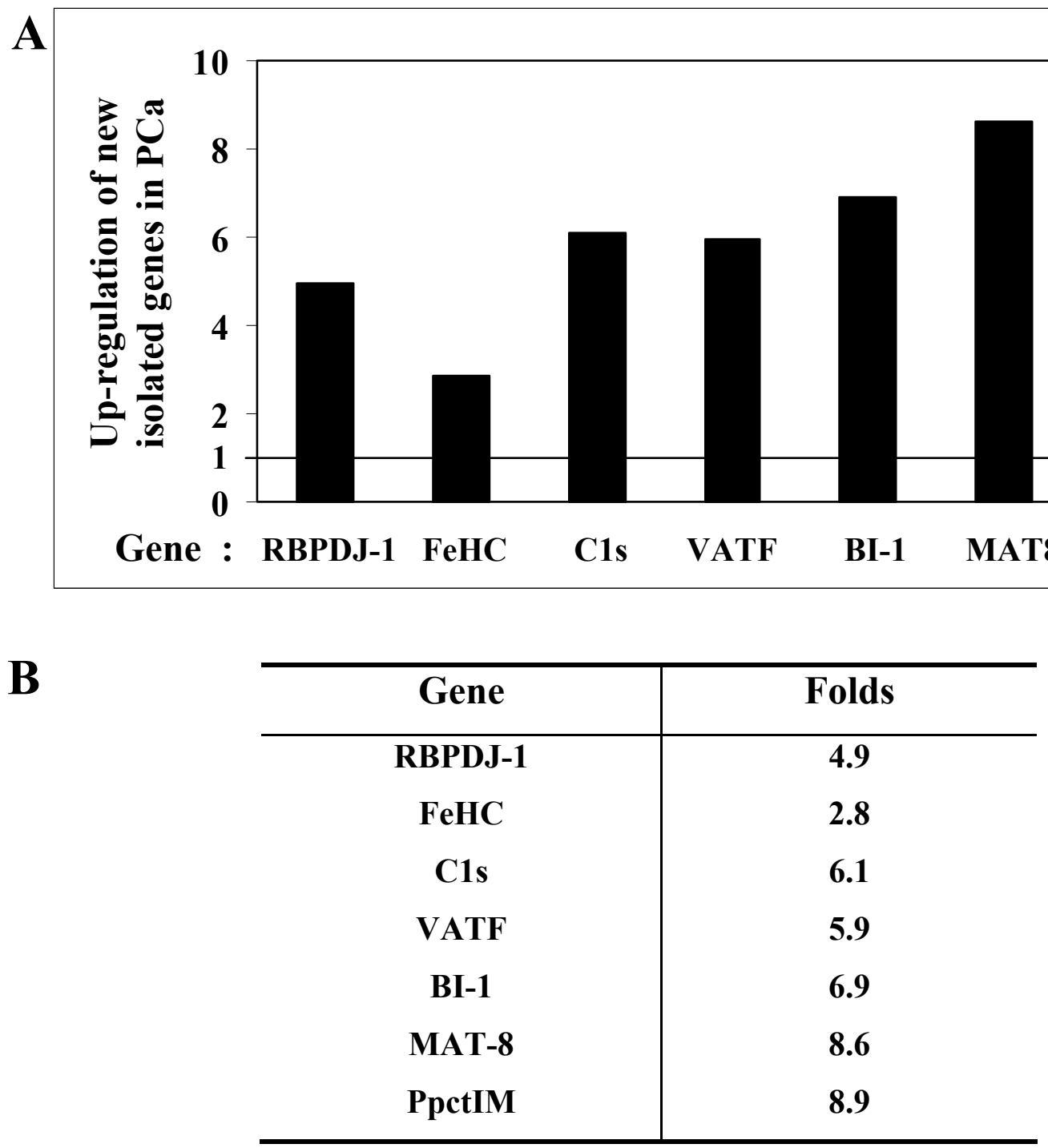

C

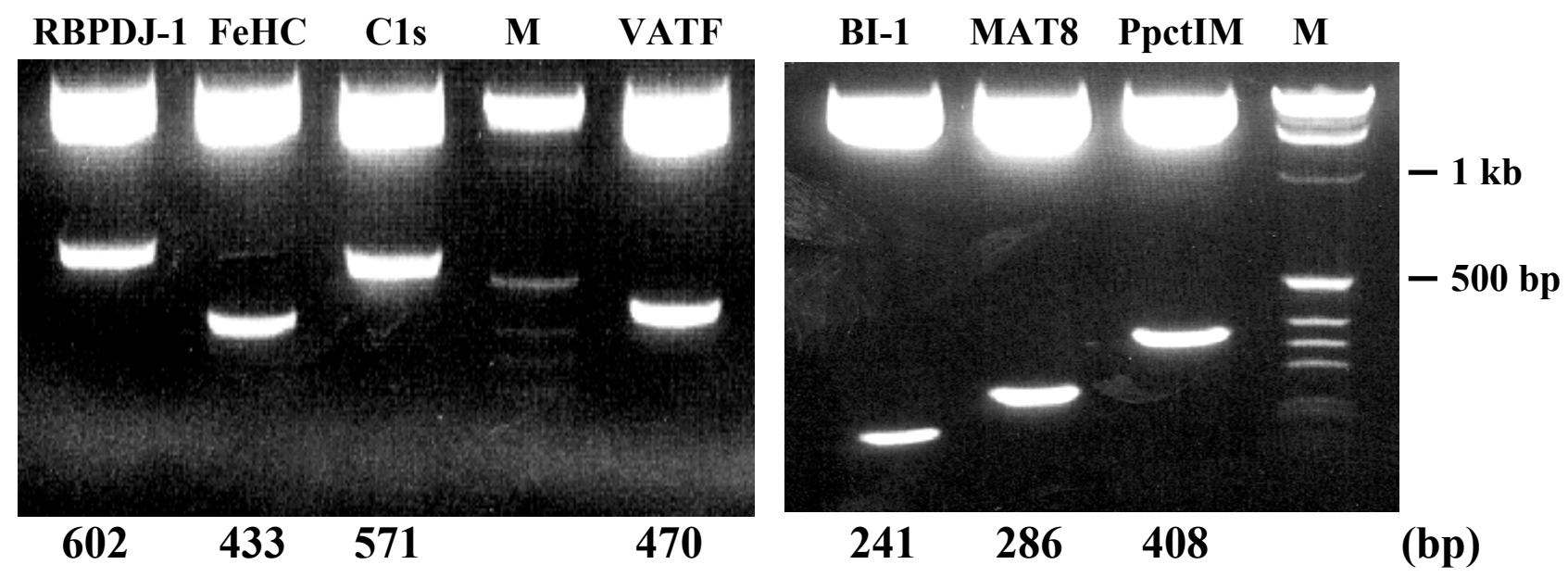

Figure 18. Quantitative RT-PCR analysis for seven genes on RNA from normal prostate and prostate carcinoma (PCa) 
A) Total RNAs isolated from normal prostate and prostate tumor tissue (case 01, pT3aN0) were analyzed by a two-step real-time RT-PCR for BI-1, C1s, FeHC, MAT8, PpctIM, RBDJ-1 and VATF expression relative to $\beta$-actin expression. Expression levels in normal prostate tissue sample $(\mathrm{N})$ for each gene are set to 1. B) Factors of up-regulation in tumor samples as compared to matched normal prostate tissues are shown. C) Restriction analysis with Pst I and Apa I of the subcloned into pGEMTvectors specific for each gene PCR products. The expected sizes of the cDNA inserts are indicated below. M, 1 kb Ladder.

\subsubsection{Array and Northern blot analysis of BI-1 expression in human prostate cancer}

One of the genes showing an increased expression in prostate carcinoma is termed Bax inhibitor-1 (BI-1). A typical scanned phosphorimage of the arrays representing $B I-1$ and $\beta$ actin expression levels in prostate carcinoma as compared to normal prostate tissue is shown in Figure 19A. In addition, the isolated $B I-1$ cDNA was subjected to Northern blot analysis to verify the differential expression pattern in prostate carcinoma as compared to the matched normal prostate and for integrity and equality of the RNA the Northern blot was rehybridized with a human $\beta$-actin cDNA probe (Fig. 19B). Quantification of the Northern blot using a phosphorimager revealed a 4-fold up-regulation of both $B I-1$ transcripts $(2.7 \mathrm{~kb}$ and $1.2 \mathrm{~kb})$ in cancerous specimen as compared to the matched normal tissue. Furthermore, using $B I-1$ cDNA as a probe Northern blot analysis on RNA isolated from both the androgen-dependent cell line LNCaP and the androgen-independent prostate cancer cell line PC-3 revealed that $B I$ $l$ is highly expressed in both prostate cancer cell lines as compared to the normal prostate tissue (Figure 19B). 
A

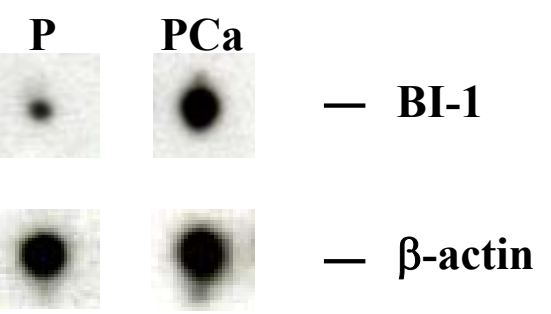

B

P PCa LNCaP PC-3

$2.7 \mathrm{~kb}$

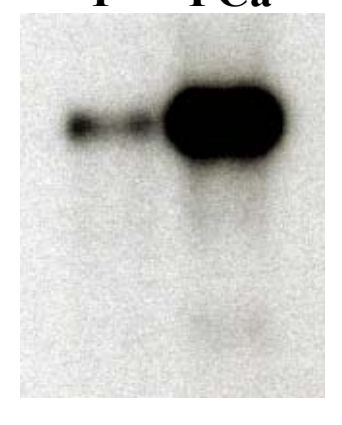

LNCaP PC-3
- BI-1

$1.2 \mathrm{~kb}-$

$1.6 \mathrm{~kb}-$
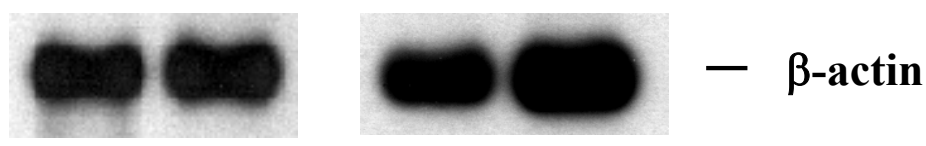

Figure 19. Up-regulation of BI-1 expression in prostate carcinoma (PCa) compared with the benign counterpart $(P)$ from the same gland.

Total RNAs were extracted from either prostate carcinoma (case 01, Gleason score 5, pT3aN0) or corresponding normal prostate tissue, reverse transcribed into cDNA and used in both hybridization experiments described below. A) Representative $B I-1$ and $\beta$-actin hybridization signals obtained from two identical Atlas Select Human Tumor Arrays using ${ }^{32} \mathrm{P}$-labelled cDNAs as probes. B) In the left panel a Northern blot analysis on total RNA ( $5 \mu \mathrm{g}$ each) from both prostate carcinoma (PCa) and matched normal prostate $(\mathrm{P})$ from the same patient is shown which was carried out using a human $B I$ 1 cDNA fragment as a hybridization probe. The right panel shows a Northern blot on total RNA (5 $\mu \mathrm{g}$ each) from LNCaP and PC-3 cells using the same BI- 1 cDNA as a probe For integrity and equality of the RNA Northern blots were rehybridized with a human $\beta$-actin cDNA probe. Hybridization signals for both $B I-1$ and $\beta$-actin were scanned and analyzed using the phosphorimager Molecular Imager FX. 


\subsubsection{Laser-capture microdissection and BI-1 expression analysis in human prostate cancer}

To confirm BI-1 overexpression detected by array and Northern blot analyses on RNA from bulk tumor tissues, prostate cancer specimens were subjected to both laser-capture microdissection and quantitative RT-PCR analysis. Prior to quantitative RT-PCR, RNA samples isolated from matched normal prostate and prostate cancer were checked for RNA integrity and RNA amount by analyzing an RNA aliquot on the Agilent Pico LabChip (Fig. 20). Subsequently, BI-1 mRNA expression was analyzed by quantitative RT-PCR on RNAs (equal amounts) from laser-capture microdissected (LCM)-derived samples from thirteen radical prostatectomies from cancer patients which were prepared as described in the material and methods section. In all cases BI-1 expression was up-regulated up to 7.4-fold in LCMsamples derived from tumorous areas as compared to the paired normal prostate tissues (Fig. 21). A Wilcoxon Rank test for this data set yielded a significance of the up-regulation in tumorous tissue with a $\mathrm{p}$ value of $=0.0078$. The quantitative RT-PCR analysis did not show a significant correlation with specific clinicopathological features such as pathologic and clinical stage (Table 9).

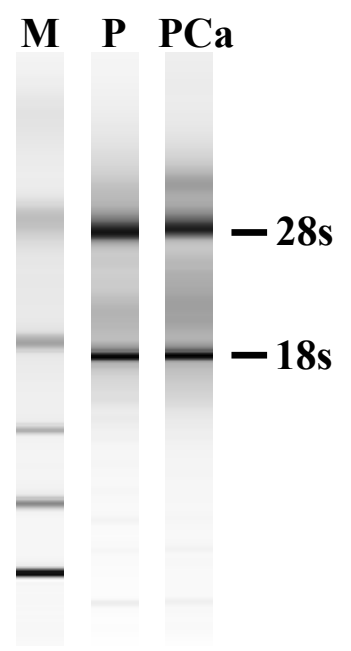

\section{Figure 20. Amount and integrity of LCM-derived total RNAs}

Prior to quantitative RT-PCR the amount and integrity of total RNAs derived from paired laser captured microdissected (LCM) samples were analyzed on an Agilent Pico LabChip. The bands for 28s rRNA and 18s rRNA are indicated $(\mathrm{M}=$ Ambion RNA 6000 ladder, $\mathrm{P}=$ normal prostate, $\mathrm{PCa}=$ prostate carcinoma). 


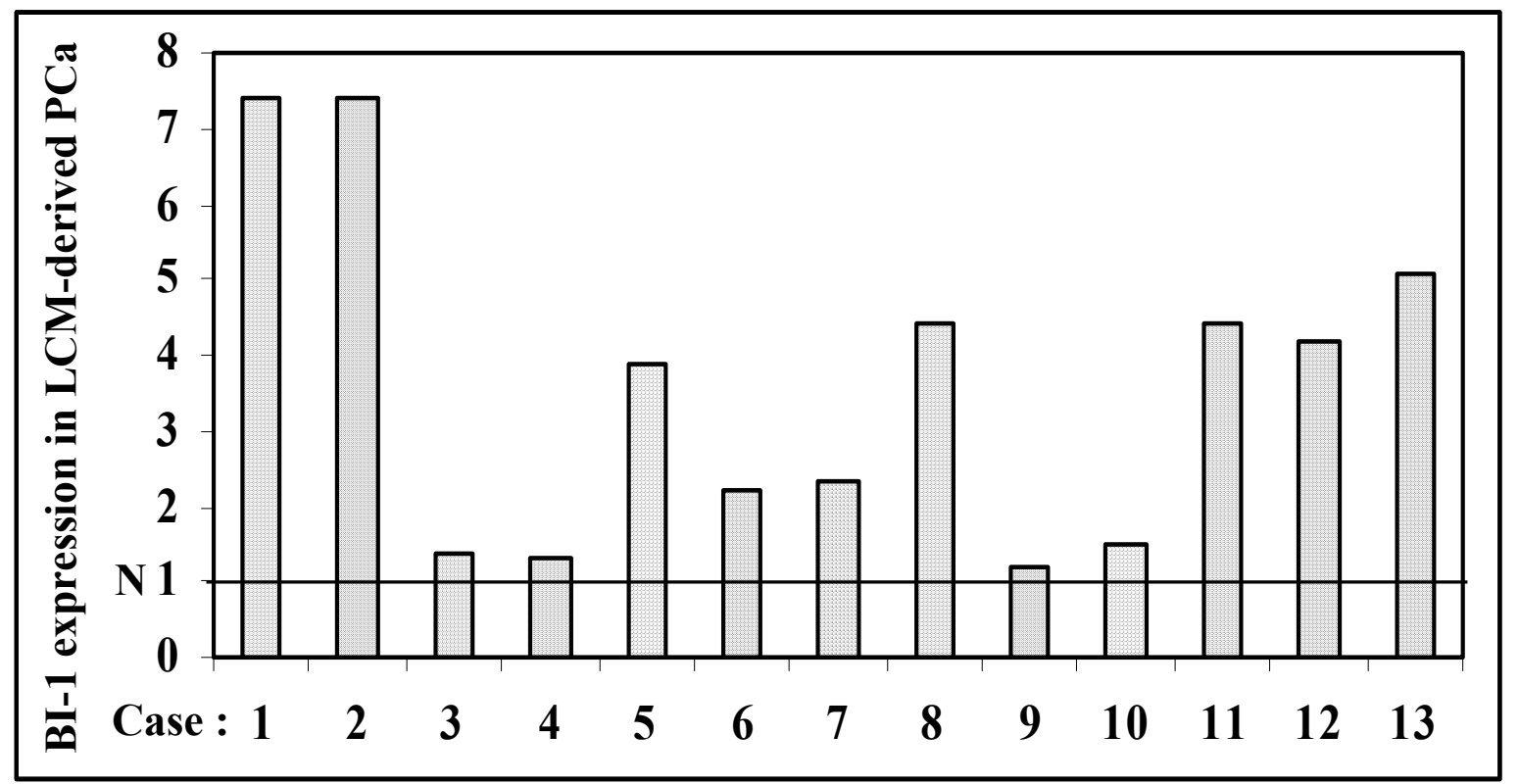

Figure 21. BI-1 expression in prostate carcinoma (PCa).

Prescreened total RNAs isolated from LCM paired normal prostates and prostate tumors from thirteen radical prostatectomies were analyzed by a two-step real-time RT-PCR for BI- 1 expression relative to $\beta$-actin. Factors of up-regulation of BI-1 expression in tumor specimens as compared to matched normal prostate tissues are shown. Expression levels in normal prostate tissues samples $(\mathrm{N})$ are set to 1 . 


\begin{tabular}{cccc}
\hline Case & $\begin{array}{c}\text { Gleason } \\
\text { score }\end{array}$ & $\begin{array}{c}\text { Tumor } \\
\text { stage }\end{array}$ & BI-1* \\
\hline 1 & 7 & pT3bN1 & 7.4 \\
2 & 6 & pT2aN0 & 7.4 \\
3 & 6 & pT2bN0 & 1.4 \\
4 & 6 & pT3aN0 & 1.3 \\
5 & 7 & pT3aN0 & 3.9 \\
6 & 5 & pT2bN0 & 2.2 \\
7 & 8 & pT3bN1 & 2.3 \\
8 & 9 & pT3bN1 & 4.4 \\
9 & 9 & pT3bN0 & 1.2 \\
10 & 6 & pT3aN0 & 1.5 \\
11 & 9 & pT3bN0 & 4.4 \\
12 & 7 & pT2aN0 & 4.2 \\
13 & 7 & pT3aN0 & 5.1 \\
\hline
\end{tabular}

Table 9. BI-1 expression and clinicopathological features of the patients described in Figure 21

* indicates factor of up-regulation of $B I-1$ expression in comparison to tumor-free tissue normalized against $\beta$-actin. $\mathrm{P}=0.0078$; Wilcoxon-Rank-sum-test for comparison of tumor and tumor-free tissue.

\subsubsection{Cancer Profiling Array analysis of BI-1 expression in different human cancers}

To analyze differential gene expression of $B I-1$ across different tumors and matched normal samples a cDNA fragment for $B I-1$ was used to synthesize a ${ }^{32} \mathrm{P}$-labeled probe. The labeled probe was hybridized to the Cancer Profiling Array from BD Biosciences Clontech as described in materials and methods. The signals were scanned after a 1-day exposure by using a Molecular Imager FX, as shown in Figure 22 and analyzed by using the Quantity one software. The results are summarized in Table 10. The up-regulation of the $B I-1$ gene was mostly found in the following cancers: ovarian cancer (13 patients out of 16), cancer of the uterus (30 patients out fo 42 ), prostate cancer ( 3 patients out of 4 ) and breast cancer (25 patients out of 50), whereas down-regulation was mostly determined in the following cancers : kidney cancer (16 patients out of 20), lung cancer (13 patients out of 21), colon cancer (25 
patients out of 38), stomach cancer (17 patients out of 27) and rectum cancer (9 patients out of 18). The quantification of the representative signals from tumors and corresponding normal tissues from individual patients, using a phosphorimager, revealed the highest up-regulation of $B I-1$ gene in ovarian cancer (up to 4.8 -fold). In breast cancer and cancer of the uterus the upregulation of $B I-1$ riched up to 3-fold and 3.3-fold, respectively, wheras prostate cancer showed up to 1.6- fold up-regulation. Furthermore, the highest down-regulation of BI-1 was determined in kidney cancer (up to 4.5 -fold). In stomach and rectum cancers the downregulation of $B I-1$ riched up to 4-fold and 2.5-fold, respectively, wheras colon and lung cancers showed up to 3-fold down regulation. 


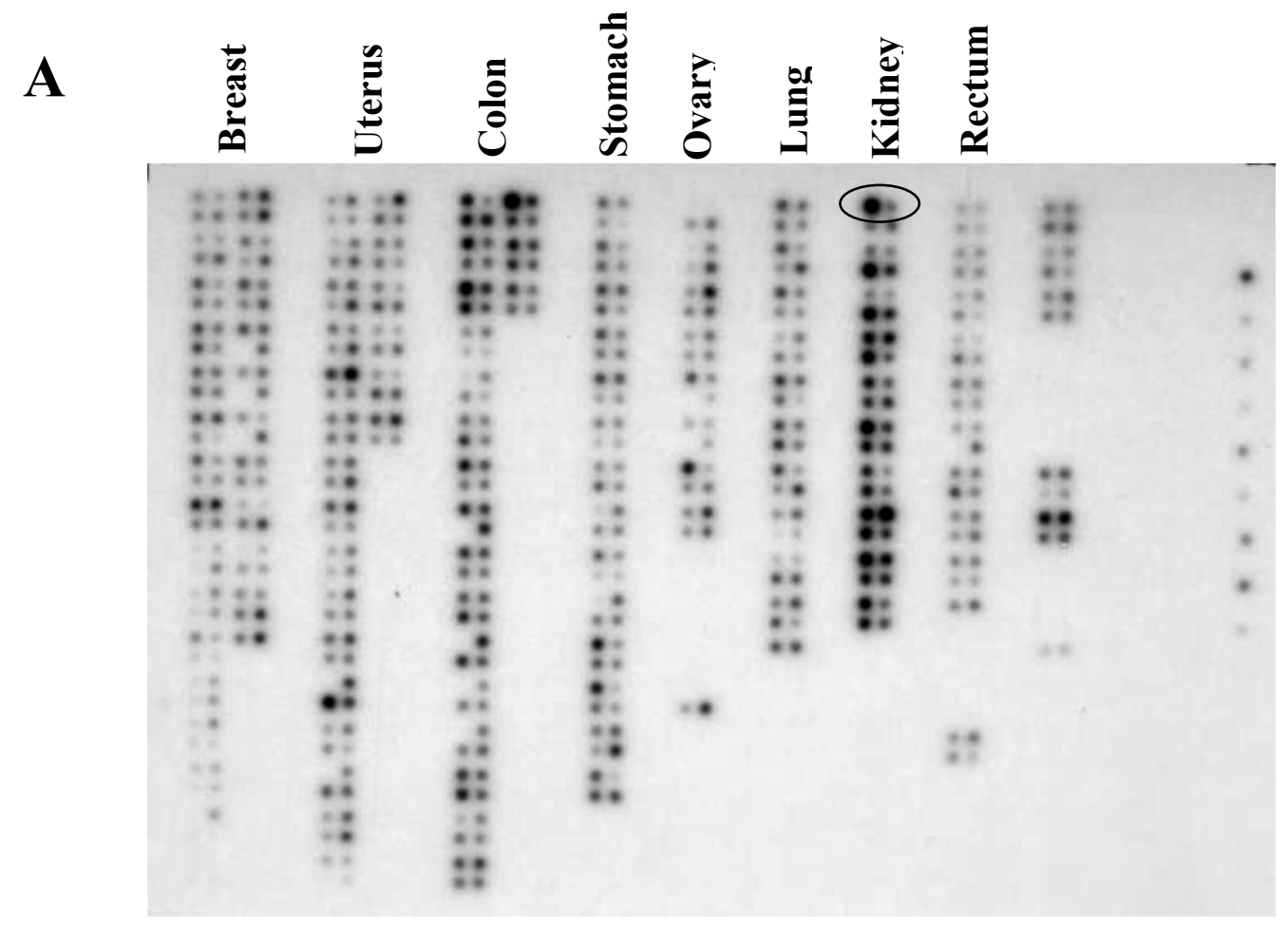

B

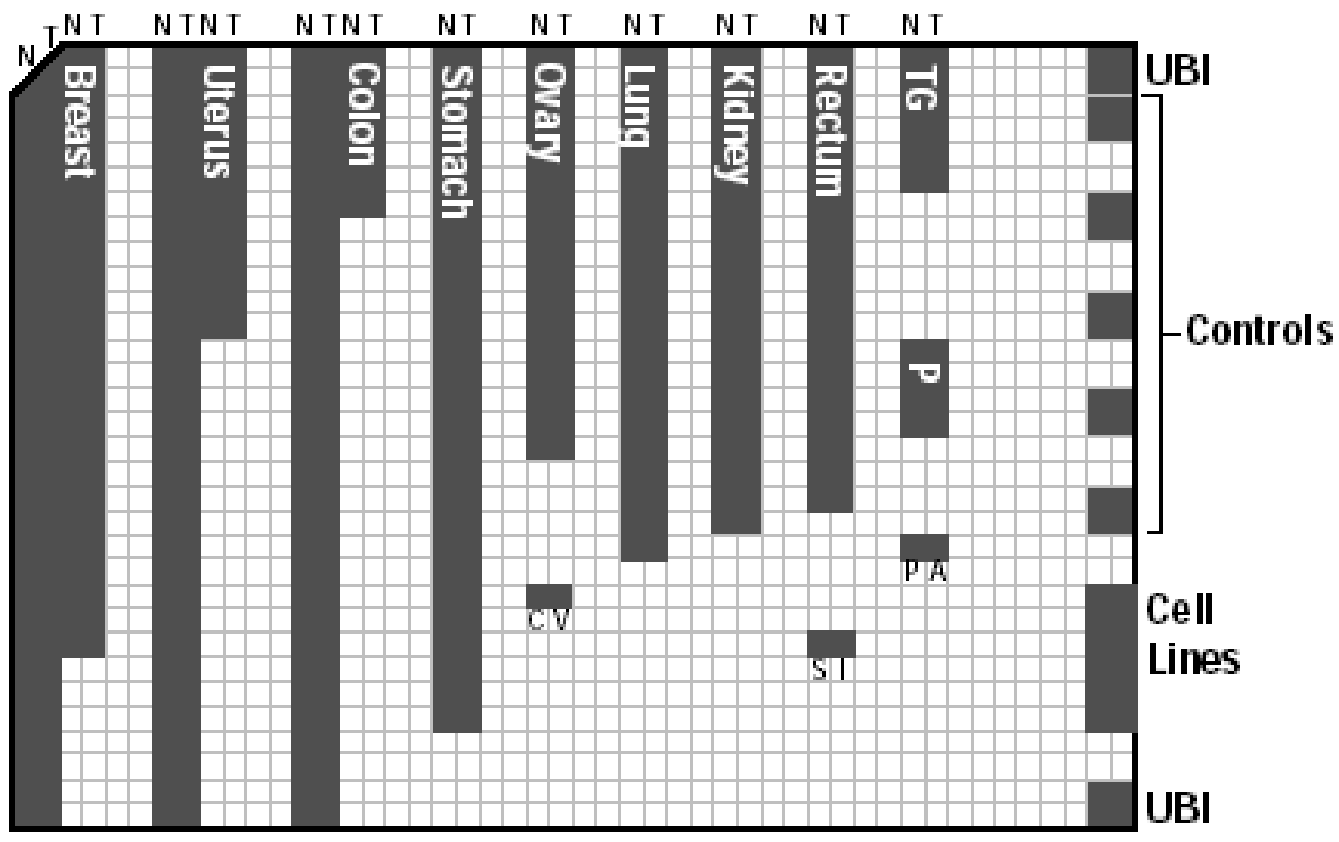

Figure 22. Cancer Profiling Array: representative membrane hybridization pattern

The cDNA fragment for $B I-1$ was used to synthesize a ${ }^{32} \mathrm{P}$-labeled probe and the labeled probe was hybridized to the Cancer Profiling Array. A) The representative signals from tumors and corresponding normal tissues from individual patients were scanned after a 1-day exposure by using a Molecular Imager FX. An example of representative signals from one patient (coordinate in kidney section) exhibiting a down-regulation of $B I-1$ is circled. B) Scheme of the Cancer Profiling Array for the cDNA samples localization derived from multiple tumor types, and cancer cell lines. $\mathrm{CV}=\mathrm{Cervix}$. $\mathrm{SI}=$ Small intestine. $\mathrm{PA}=$ Pancreas. $\mathrm{N}=$ Normal. $\mathrm{T}=$ Tumor. $\mathrm{P}=$ Prostate. $\mathrm{UBI}=$ Ubiquitin. $\mathrm{TG}=$ Thyroid gland. (Modified after CLONTECHniques Catalog 2001) 


\begin{tabular}{cccc}
\hline Cancer & $\begin{array}{c}\text { No. of patients with } \\
\text { up-regulated } B I-1 \\
\text { expression }\end{array}$ & $\begin{array}{c}\text { No. of patients with } \\
\text { down-regulated } B I-1 \\
\text { expression }\end{array}$ & $\begin{array}{c}\text { No. of patients with } \\
\text { no difference in } B I-1 \\
\text { expression }\end{array}$ \\
\hline Breast & $\mathbf{2 5}$ & 18 & 7 \\
Uterus & $\mathbf{3 0}$ & 11 & 1 \\
Colon & 10 & $\mathbf{2 5}$ & 3 \\
Stomach & 8 & $\mathbf{1 7}$ & 2 \\
Ovary & $\mathbf{1 3}$ & 3 & 0 \\
Lung & 6 & $\mathbf{1 3}$ & 2 \\
Kidney & 3 & $\mathbf{1 6}$ & 3 \\
Rectum & 6 & $\mathbf{9}$ & 3 \\
Thyroid & 2 & 1 & 1 \\
Prostate & $\mathbf{3}$ & 0 & 3 \\
\hline
\end{tabular}

Table 10. Results from the Cancer Profiling Array analysis for BI-1 expression in different human cancers and the matched normal tissues 


\subsubsection{Down-regulation of BI-1 expression in PC-3 cells by using the RNAi technique}

In order to evaluate the function of $B I-1$ in human PC-3 prostate carcinoma cells the novel approach of gene silencing through RNA interference (RNAi) was applied. Transfection of PC-3 cells was accomplished with either BI-1 sequence-specific small interfering RNA (siRNA) duplex oligonucleotides or with single-stranded sense (S) and antisense (A) RNA oligonucleotides against the $B I-1$ gene as a control. At different time points after transfection (24hours, 36hours and 45hours) both PC-3 cells attached to the bottom and cells floating in the medium were collected and used for the determination of down-regulation of $B I-1$ expression. To test whether transfection of PC-3 cells with BI-1 duplex siRNA could affect the expression of endogenous BI-1 mRNA, we analyzed RNA from duplex siRNAtransfected PC-3 cells with RNA from PC-3 cells transfected with control oligonucleotides by Northern blot hybridization. It was found that the expression of $B I-1$ in duplex siRNAtransfected (D) PC-3 cells was reduced by $50 \%$ to $70 \%$ relative to the control-transfected (S and A) cells (Fig. $23 \mathrm{~A}$ and B). The same membranes were rehybridized with a cDNA probe for human $\beta$-actin to verify the integrity and amount of RNA in the samples (Fig. $23 \mathrm{~A}$ and B). To investigate the knockdown of BI-1 expression in duplex siRNA-transfected PC-3 cells at the protein level Western blot analysis using a polyclonal antibody against BI-1 was performed. As shown in Figure $23 \mathrm{C}$, the expression of BI-1 (45 hours after transfection) was specifically reduced by the cognate duplex siRNA (D), but not when single stranded sense (S) or antisense (A) oligonucleotides were used. The expression of a non-targeted housekeeping gene, $\alpha$-tubulin was unaffected and the reduction in BI-1 protein was more than $50 \%$ complete as quantified by Western blotting. 


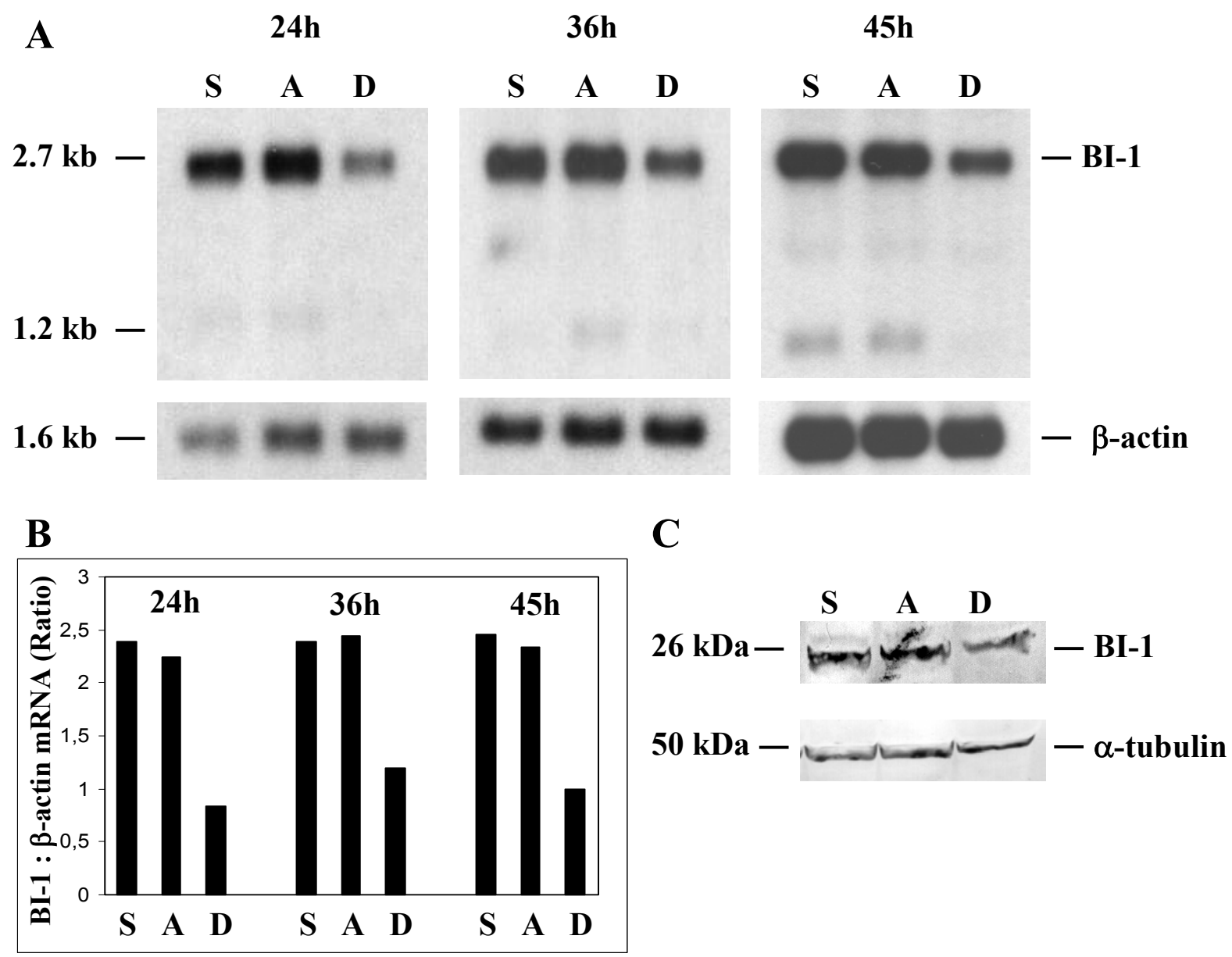

Figure 23. Down-regulation of BI-1 expression in PC-3 cells transfected with sequence-specific duplex siRNA oligonucleotides (D) against $B I-1$

As negative controls, BI-1-specific sense (S) and antisense (A) RNA oligonucleotides were used for transfection experiments. Twenty-four hours, 36 hours and 45 hours after transfection both attached and floating PC-3 cells were collected and used for both RNA and protein isolation. A) Northern blot analysis of total RNA ( $5 \mu \mathrm{g})$ derived from siRNA-transfected (D) and control-transfected (lanes S and A) PC-3 cells was performed using a human BI- 1 cDNA fragment as a probe. Rehybridization of the same filter was carried out with a cDNA probe for $\beta$-actin. B) The mRNA signals were scanned using the phosphorimager Molecular Imager FX, and the difference in the expression of BI-1 transcripts was calculated relative to the $\beta$-actin standards. Results of the analysis for BI-1 are shown in the bar graphs. The letters under the bar graphs correspond to the letters used in A. C) Western blot analysis of transfected PC-3 cells using BI-1- (upper panel) or $\alpha$-tubulin-specific (lower panel) antibodies. The Western blot was stripped and re-probed with $\alpha$-tubulin antibody to check for equal loading (50 $\mu \mathrm{g})$ of total protein. 


\subsubsection{Induction of PC-3 cell death by using siRNAs against the human BI-1 gene}

To assess the effect of BI-1 suppression on viability of PC-3 cells, cell death was studied using four different methods: (a) trypan blue exclusion to detect cell death attributable to membrane damage; (b) analysis of induced caspase-3 activity; (c) ISEL staining to detect DNA fragmentation and (d) DAPI staining to detect nuclear changes such as fragmentation and condensation. After treatment of PC-3 cells with duplex siRNA oligonucleotides against $B I-1$, trypan blue exclusion test was applied where both viable and nonviable cells were counted. The amount of PC-3 cell death was analyzed by comparing the number of trypan blue-positive cells to the number of unstained cells from three independent experiments. As shown in Fig. 24 A, induction of PC-3 cell death by duplex siRNA (D) oligonucleotides occurred 24 hours after transfection (13\% positively stained cells), increased at 36 hours after transfection ( $43 \%$ positively stained cells) and peaked at $45 \mathrm{~h}$ after treatment (59\% positively stained cells). In contrast, neither sense (S) nor antisense (A)-transfected PC-3 cells (negative controls) showed an increase in cell death over the indicated time period, but remained at a constant level of $4 \%$ to $5 \%$ dead cells (Fig. 24 A).

Next, it was determined whether duplex siRNA oligonucleotides against $B I-1$ were capable of inducing caspase-3 activity and/or apoptosis in human PC-3 prostate carcinoma cells. Again, induction of caspase-3 activity and measurement of apoptosis were investigated over a period of 45 hours. As can be seen in Figure 24 B and C, transfection of PC-3 cells with duplex siRNA oligonucleotides (D) caused a time-dependent increase in the activity of caspase-3-like protease in PC-3 cells. The caspase-3 activity appeared at 24 hours (10\% caspase-3-positive cells) and reached its maximum at 45 hours after treatment (38\% caspase-3-positive cells), whereas control-transfected PC-3 cells (S and A) showed only low levels (1\% to $2 \%$ ) of caspase-3 activity over the whole time period. Apoptosis in duplex siRNA (D) and controltransfected (S and A) PC-3 cells was determined by both ISEL and DAPI staining at various time intervals, apoptotic cells being recognized either by brown staining of the nucleus or condensed and fragmented nuclei (Fig. 24 B, D and E). In duplex siRNA treated PC-3 cells, the number of apoptotic cells started to increase 24 hours after transfection (10\% to $15 \%$ apoptotic cells) and the number of apoptotic cells continued to rise at subsequent sampling points, up to 45 hours (up to $45 \%$ apoptotic cells). In control-transfected PC-3 cells (S and A) apoptotic cells were barely ( $2 \%$ to $4 \%$ apoptotic cells) observed over the indicated time period (Fig. 24 B, D and E). 
To further test the specificity of this novel RNAi approach, PC-3 cells were transfected with duplex siRNA oligonucleotides against the firefly luciferase gene (Photinus pyralis) and analyzed for cell death by using DAPI and caspase-3 staining. However, apoptotic PC-3 cells were only observed at a basal level comparable with the results of $B I-1$ sense and antisensetransfected PC-3 cells (Table 11). 

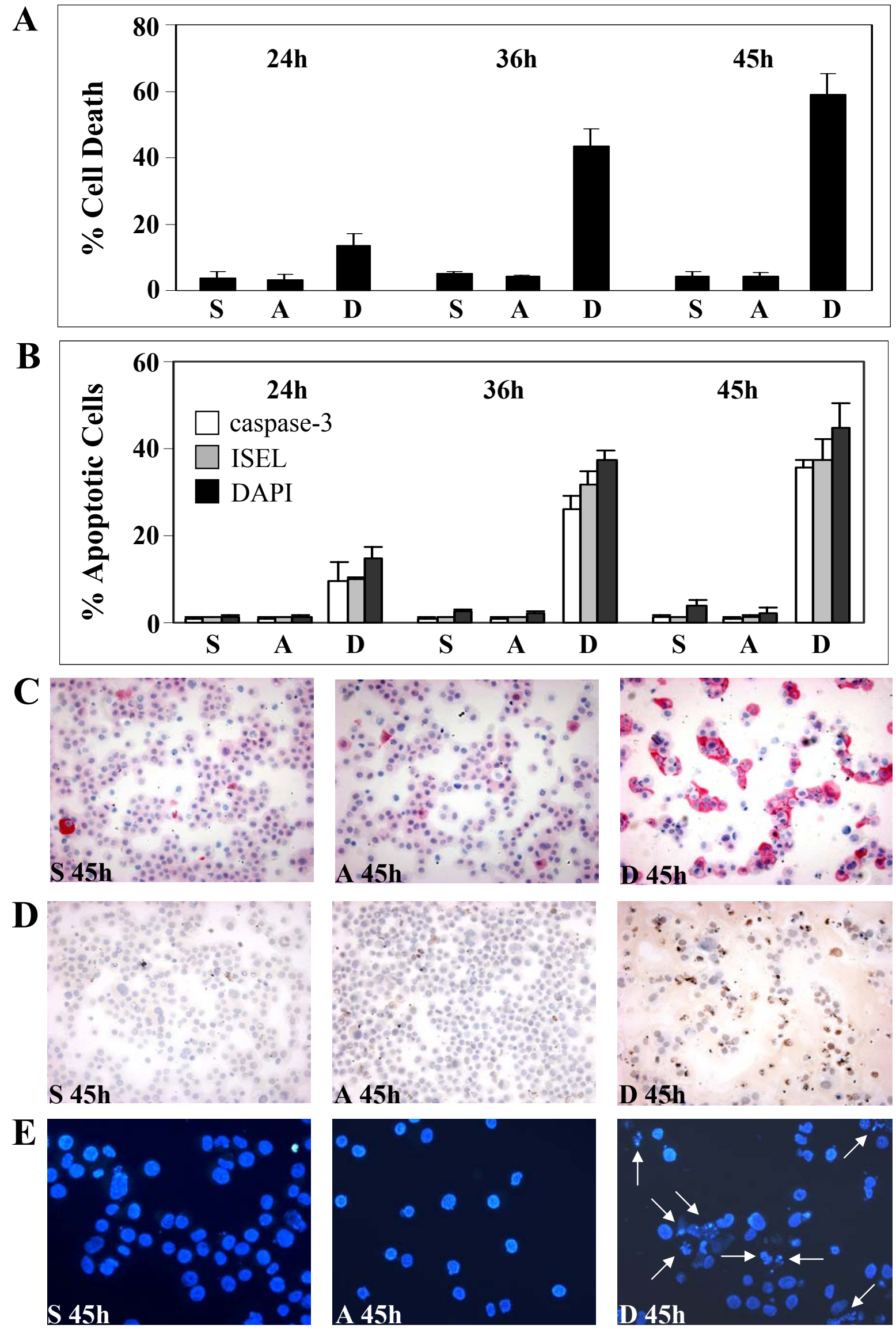

Figure 24. Induction of PC-3 cell death by using siRNAs against the human BI-1 gene 
PC-3 cells were transfected either with $150 \mathrm{nM}$ duplex siRNA oligonucleotides (D) or with $150 \mathrm{nM}$ sense (S) or antisense (A) RNA oligonucleotides as negative controls for various time intervals as indicated. A) After transfection PC-3 cells attached to the bottom and cells floating in the medium were collected and percentage of cell death was assessed by trypan blue-staining as described in "Materials and Methods". Data, means of three independent experiments $( \pm$ SE). B) Activation of caspase-3 and induction of apoptotic PC-3 cell death after transfection of PC-3 cells was analyzed as indicated above and as described in materials and methods. Bar graphs represent the percentage of positively stained PC-3 cells for caspase-3, ISEL-and DAPI-stained apoptotic cells at various time points. Data, means of three independent experiments $( \pm \mathrm{SE})$. The number of both caspase-3 positive cells and apoptotic PC-3 cells was determined by counting labelled cells in 5 randomly chosen high power fields (original magnification x100 and x200 for DAPI-stained cells). C) Caspase-3-stained PC3 cells as described in $\mathrm{B}$ were visualized and photographed under a microscope. Note the red cytoplasmic staining for caspase-3 around the clearly demarcated nuclei. D) ISEL-positive cells of duplex (D) siRNA-transfected and control-transfected (S and A) PC-3 cells at $45 \mathrm{~h}$ after transfection. E) DAPI-stained PC-3 cells as described in B were visualized and photographed under a UVmicroscope. High numbers of apoptotic cells (arrows) were observed in duplex siRNA-transfected PC3 cells, whereas only low numbers of apoptotic cells were detectable in control-transfected cells. 


\subsubsection{Down-regulation of BI-1 expression in LNCaP cells by using the RNAi technique}

In order to evaluate the function of $B I-1$ in human $\mathrm{LNCaP}$ prostate carcinoma cells the novel approach of gene silencing through RNA interference (RNAi) was applied. Transfection of LNCaP cells was accomplished with either $B I-1$ sequence-specific small interfering RNA (siRNA) duplex oligonucleotides or with control duplex siRNA olignucleotides against the firefly luciferase gene (luc) as described in material and methods. Forty five hours after transfection both LNCaP cells attached to the bottom and cells floating in the medium were collected and used for the determination of down-regulation of BI-1 expression. To test whether transfection of LNCaP cells with BI-1 duplex siRNA could again affect the expression of endogenous BI-1 mRNA, we analyzed RNA from duplex siRNA-transfected LNCaP cells with RNA from LNCaP cells transfected with control oligonucleotides by Northern blot hybridization. We found that the expression of $B I-1$ in duplex siRNAtransfected (D) LNCaP cells was reduced $50 \%$ relative to the control-transfected (luc) cells (Fig. $25 \mathrm{~A}$ and B). The same membranes were rehybridized with a cDNA probe for human $\beta$ actin to verify the integrity and amount of RNA in the samples (Fig. 25 A and B). To investigate the knockdown of BI-1 expression in duplex siRNA-transfected LNCaP cells at the protein level Western blot analysis using a polyclonal antibody against BI-1 was performed. As shown in Figure $25 \mathrm{C}$, the expression of BI-1 was specifically reduced by the cognate duplex siRNA (D), but not when control olignucleotides against the firefly luciferase gene (luc) were used. The expression of a non-targeted housekeeping gene, $\alpha$-tubulin was unaffected and the reduction in BI-1 protein was more than $50 \%$ complete as quantified by Western blotting. 
A

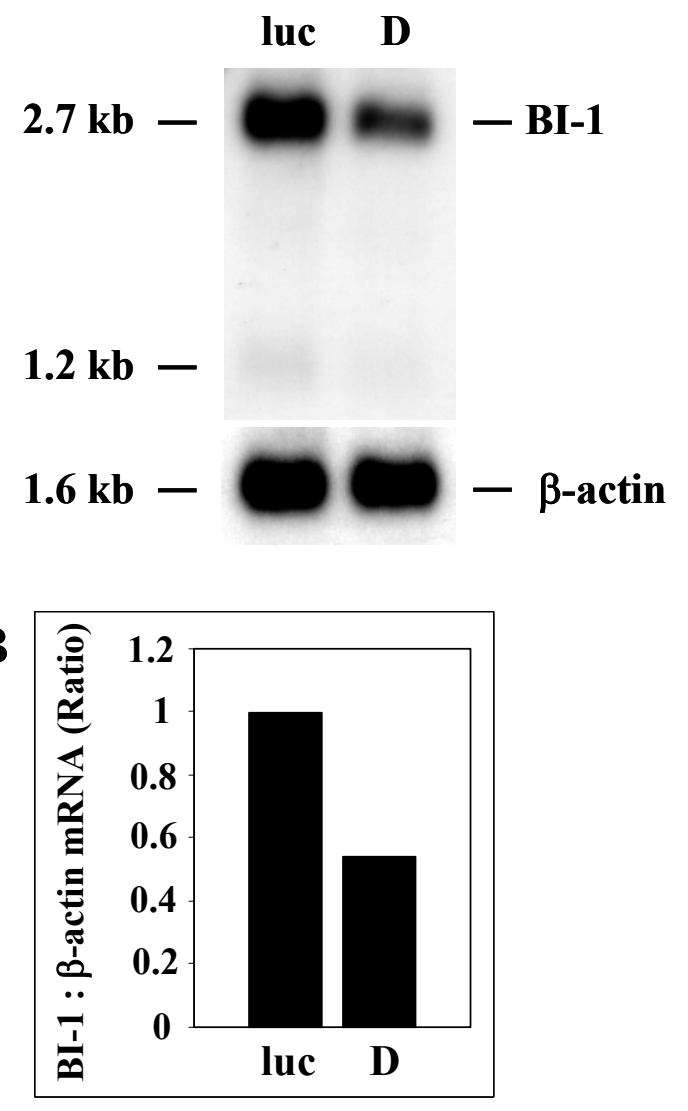

C

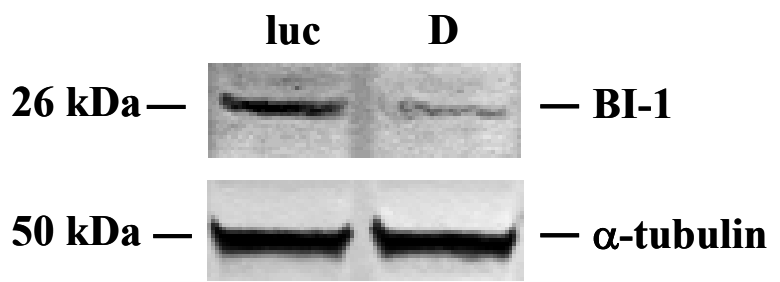

Figure 25. Down-regulation of BI-1 expression in LNCaP cells transfected with sequence-specific duplex siRNA oligonucleotides (D) against BI-1

Twenty-four hours after transfection both attached and floating PC-3 cells were collected and used for both RNA and protein isolation. As negative control, duplex siRNA olignucleotides against the firefly luciferase gene (luc) was used for transfection experiments. A) Northern blot analysis of total RNA (5 $\mu \mathrm{g}$ ) derived from siRNA-transfected (D) and control-transfected (luc) LNCaP cells was performed using a human BI-1 cDNA fragment as a probe. Rehybridization of the same filter was carried out with a cDNA probe for $\beta$-actin. B) The mRNA signals were scanned using the phosphorimager Molecular Imager FX, and the difference in the expression of BI-1 transcripts was calculated relative to the $\beta$-actin standards. Results of the analysis for BI- 1 are shown in the bar graphs. The letters under the bar graphs correspond to the letters used in A. C) Western blot analysis of transfected LNCaP cells using BI-1 (upper panel) or $\alpha$-tubulin-specific (lower panel) antibodies. The Western blot was stripped and re-probed with $\alpha$-tubulin antibody to check for equal loading (50 $\mu \mathrm{g})$ of total protein. 


\subsubsection{Induction of apoptosis in LNCaP cells by using siRNAs against the human BI-1 gene}

To assess the effect of BI-1 suppression on apoptosis of LNCaP cells, DAPI staining was employed to detect nuclear changes such as fragmentation and condensation. LNCaP cells were treated either with duplex (D) siRNA oligonucleotides against BI-1 or with control duplex siRNA olignucleotides against the firefly luciferase gene (luc) as described in material and methods. At different time points after transfection (24 hours, 36 hours, 45 hours and 5 days) both cells attached to the bottom and cells floating in the medium were collected and used for DAPI staining. In duplex siRNA against BI-1 treated LNCaP cells, the number of apoptotic cells started to increase 24 hours after transfection (3.5\% apoptotic cells) and the number of apoptotic cells continued to rise at subsequent sampling points, up to 5 days (up to $39 \%$ apoptotic cells). In control-transfected LNCaP cells (luc) apoptotic cells were barely (1\% to $1.8 \%$ apoptotic cells) observed over the indicated time period (Fig. $26 \mathrm{~A}$ and B). 

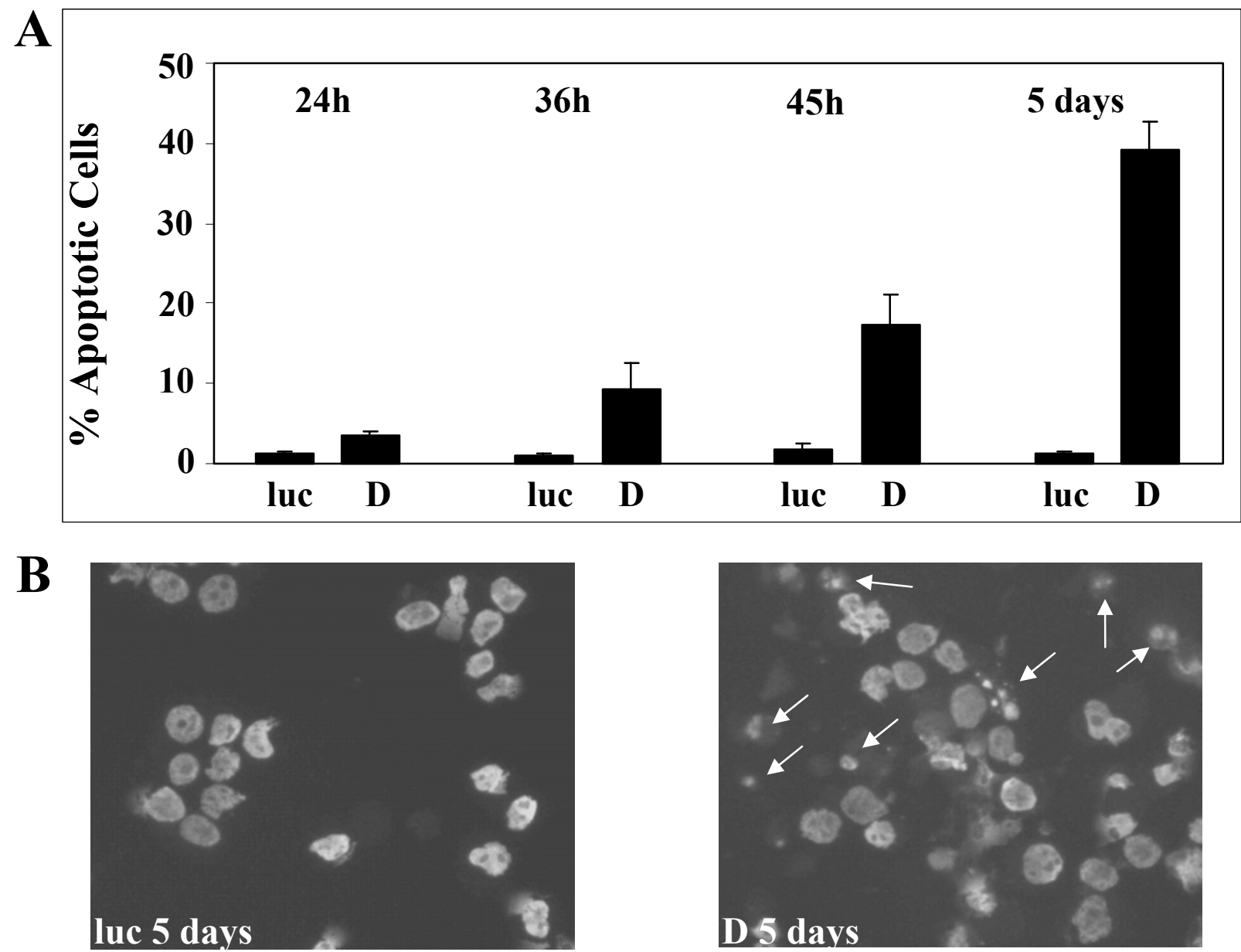

Figure 26. Induction of apoptosis in LNCaP cells by using siRNAs against the human BI-1 gene

LNCaP cells were transfected either with $150 \mathrm{nM}$ duplex siRNA oligonucleotides (D) or with $150 \mathrm{nM}$ duplex siRNA oligonucleotides against the firefly luciferase gene (luc) as a negative control for various time intervals as indicated. A) After transfection, $\mathrm{LNCaP}$ cells attached to the bottom and cells floating in the medium were collected and percentage of cell death was assessed by DAPI staining as described in materials and methods. Bar graphs represent the percentage of DAPI-stained apoptotic cells at various time points. Data, means of three independent experiments $( \pm$ SE). The number of apoptotic LNCaP was determined by counting cells in 5 randomly chosen high power fields (original magnification x 200). B) DAPI-stained LNCaP cells were visualized and photographed under a UVmicroscope. High numbers of apoptotic cells (arrows) were observed in duplex siRNA-transfected PC3 cells, whereas only low numbers of apoptotic cells were detectable in control-transfected cells. 


\subsubsection{Induction of apoptosis in LNCaP and PC-3 cells by using RNA interference technique}

The summary of the induction of apoptosis in both LNCaP and PC -3 cells by using siRNAs against the human BI-1 gene is shown in Table 7. After treatment of PC-3 cells with duplex siRNA oligonucleotides against BI-1, the number of apoptotic PC-3 cells reached its maximum at 45 hours after treatment ( $35 \%$ to $44 \%$ ), whereas the similar effect in LNCaP (39\% of apoptotic cells) was determined at 5 days after treatment (Table 7 A). In addition, both control-transfected PC-3 and LNCaP cells either with single-stranded sense (S) and antisense (A) RNA oligonucleotides against the BI-1 gene or control duplex siRNA olignucleotides against the firefly luciferase gene (luc) showed only low levels ( $1 \%$ to $4 \%$ ) of the apoptotic cells over the whole time period of the treatment ( 24 hours, 36 hours, 45 hours and 5 days) (Table $7 \mathrm{~B}$ and $\mathrm{C}$ ). 


\begin{tabular}{|c|c|c|c|c|c|c|c|}
\hline \multirow{2}{*}{$\begin{array}{c}\text { A } \\
\text { Method: }\end{array}$} & \multicolumn{3}{|c|}{$\begin{array}{l}\% \text { of cell death and apoptotic cells } \\
\text { after treatment of PC- } 3 \text { cells with } \\
\text { duplex siRNAs against } B I-1 \text { gene }\end{array}$} & \multicolumn{4}{|c|}{$\begin{array}{c}\% \text { of apoptotic cells after } \\
\text { treatment of LNCaP cells with } \\
\text { duplex siRNAs against } B I \text {-1gene }\end{array}$} \\
\hline & $24 \mathrm{~h}$ & $36 \mathrm{~h}$ & $45 \mathrm{~h}$ & $24 \mathrm{~h}$ & $36 \mathrm{~h}$ & $45 \mathrm{~h}$ & 5 days \\
\hline Trypan blue & 13.49 & 43.48 & 59.07 & n.d. & n.d. & n.d. & n.d. \\
\hline Caspase-3 & 9.58 & 26.15 & 35.85 & n.d. & n.d. & n.d. & n.d. \\
\hline DAPI & 14.93 & 37.25 & 44.6 & 3.58 & 9.41 & 17.46 & 39.12 \\
\hline ISEL & 10.06 & 31.74 & 37.42 & n.d. & n.d. & n.d & n.d. \\
\hline
\end{tabular}

\begin{tabular}{|c|c|c|c|c|c|c|}
\hline B & \multicolumn{3}{|c|}{$\begin{array}{l}\% \text { of cell death and apoptotic cells } \\
\text { after treatment of PC- } 3 \text { with } \\
\text { single-strand sense RNA } \\
\text { oligonuclotides against } B I-1 \text { gene }\end{array}$} & \multicolumn{3}{|c|}{$\begin{array}{l}\% \text { of cell death and apoptotic cells } \\
\text { after treatment of PC- } 3 \text { with } \\
\text { single-strand antisense RNA } \\
\text { oligonuclotides against } B I-1 \text { gene }\end{array}$} \\
\hline Method: & $24 \mathrm{~h}$ & $36 \mathrm{~h}$ & $45 \mathrm{~h}$ & $24 \mathrm{~h}$ & $36 \mathrm{~h}$ & $45 \mathrm{~h}$ \\
\hline Trypan blue & 3.89 & 5.17 & 4.26 & 3.31 & 4.23 & 4.37 \\
\hline Caspase-3 & 0.91 & 1.02 & 1.25 & 0.76 & 0.97 & 0.94 \\
\hline DAPI & 1.37 & 2.68 & 3.82 & 1.15 & 2.14 & 2.38 \\
\hline ISEL & 1.19 & 1.26 & 1.11 & 1.3 & 1.17 & 1.37 \\
\hline
\end{tabular}

\begin{tabular}{c|ccccccc}
\hline \multirow{2}{*}{$\mathbf{C}$} & \multicolumn{3}{|c}{$\begin{array}{c}\text { \% of apoptotic cells after } \\
\text { treatment of PC-3 cells with } \\
\text { duplex siRNAs against luc gene }\end{array}$} & \multicolumn{3}{c}{$\begin{array}{c}\text { \% of apoptotic cells after treatment } \\
\text { of LNCaP cells with duplex } \\
\text { siRNAs against luc gene }\end{array}$} \\
\hline Method: & $\mathbf{2 4} \mathbf{h}$ & $\mathbf{3 6} \mathbf{h}$ & $\mathbf{4 5 ~ h}$ & $\mathbf{2 4} \mathbf{h}$ & $\mathbf{3 6 ~ h}$ & $\mathbf{4 5} \mathbf{h}$ & $\mathbf{5}$ days \\
Caspase-3 & 0.2 & 0.48 & 0.46 & n.d. & n.d. & n.d. & n.d. \\
DAPI & 0.19 & 0.36 & 0.42 & 1.2 & 1.08 & 1.78 & 1.34 \\
\hline
\end{tabular}

Table 11. Summary of the induction of apoptosis in LNCaP and PC-3 cells by using siRNAs against the human $B I-1$ gene

Transfection of PC-3 and LNCaP cells was accomplished with either BI-1 sequence-specific siRNA duplex oligonucleotides (A) or with single-stranded sense, antisense RNA oligonucleotides against the BI-1 gene (B) and with duplex siRNA oligonucleotides against the firefly luciferase gene (luc) as a control (C). At different time points after transfection ( $24 \mathrm{~h}, 36 \mathrm{~h}, 45 \mathrm{~h}$ and 5 days) both cells attached to the bottom and cells floating in the medium were collected and used for the determination of cell death and apoptosis as described in the material and method section. (n.d.= not-determined) 


\section{DISCUSSION}

\subsection{Summary of the results}

The present work can be divided into two parts: in the first part the role of IGF-IR in prostate cancer cells was evaluated. In the second part differentially expressed genes in prostate carcinoma cells were isolated and further characterized.

A. In the first part of the present study the following results were obtained:

1. The endogenous $I G F-I R$ gene expression is reduced in stably transfected prostate carcinoma PC-3 cells by employing the antisense RNA strategy.

2. A significant suppression of PC-3 cell invasion and proliferation as well as an increase in PC-3 cell apoptosis are found in $I G F-I R$ antisense-RNA transfected PC-3 cells.

3. An up-regulation of $I G F B P-3$ and down-regulation of $M M P-2$ expression is found in $I G F-I R$ antisense-RNA transfected PC-3 cells.

4. Further, direct correlation was demonstrated between the inhibition of $I G F-I R$ gene expression and either an up-regulation of $I G F B P-3$ or a down-regulation of $M M P-2$ expression in PC-3 cells.

5. Furthermore, the expression of both $I G F-I R$ and $I G F B P-3$ was investigated by quantitative real time RT-PCR analyses on RNA from LCM-derived matched normal prostate and prostate tumor epithelial tissue samples of 12 patients demonstrating that the $I G F-I R$ expression is up-regulated in 9 prostate cancers and that $I G F B P-3$ expression is down-regulated in all prostate carcinomas.

6. In addition, by using the cancer profiling array an up-regulation of IGFBP-3 gene expression was determined in the following cancers: kidney cancer, lung cancer, rectum cancer, colon cancer, stomach cancer and thyroid cancer, whereas a down-regulation of $I G F B P-3$ gene expression was determined in breast cancer, cancer of the uterus and ovarian cancer. 
B. In the second part of the present study the following results were obtained:

1. In total, 46 differentially expressed genes were identified to be up- or down-regulated in prostate carcinoma (pT3a) using the cDNA array technique in a set of prostate tumor and matched normal prostate tissue.

2. From these differentially expressed genes, seven genes (Bax inhibitor-1, complement component C1s, ferritin heavy chain, MAT8 protein, peptidyl-proryl cis-trans isomerase A, RNA-binding protein regulatory subunit DJ-1 protein and vacuolar ATP synthase subunit F) displaying an up-regulated expression in human prostate carcinoma were further confirmed to be overexpressed in prostate cancer by using real time RT-PCR analysis on whole tumor RNA.

3. The overexpression of Bax inhibitor-1 (BI-1) in prostate carcinoma was confirmed by using both Northern blot analysis on whole tumor RNA and real time RT-PCR on RNA from thirteen laser captured microdissected prostate tumor tissue samples.

4. In addition, by using the cancer profiling array the up-regulated expression of the $B I-I$ gene was determined in the following cancers: ovarian cancer, cancer of the uterus, prostate cancer and breast cancer, whereas down-regulated expression was determined in kidney cancer, lung cancer, colon cancer, stomach cancer and rectum cancer.

5. Further, to determine the function of BI-1 in vitro, human androgen-independent PC-3 and androgen-dependent LNCaP prostate carcinoma cells were transfected with small interfering double-stranded RNA (siRNA) oligonucleotides against the BI-1 gene leading to a specific down-regulation of BI-1 expression.

6. Furthermore, transfection of PC-3 and LNCaP cells with BI-1 sequence-specific siRNAs caused a significant increase both in cellular apoptosis and necrosis. 


\subsection{New technologies in prostate cancer research}

One of the key issues in prostate cancer research is to develop molecular markers that can effectively detect and distinguish the progression and malignancy of prostate tumors as well as provide insights into prostate tumor development or behavior. Progress in identifying such markers has been markedly accelerated by recent advances in molecular biology technologies, such as cDNA array and microarray techniques, which enabled analyzing the expression of thousands of genes in a single experiment and hold great promise for a better understanding of the molecular genetics and biology of prostate cancers (Asamoto et al. 2001, Welsh et al. 2001). In addition, the recent development of laser capture microdissection (LCM), a technique that allows for the reliable and accurate procurement of cells from specific microscopic regions of tissue sections under direct visualization, now affords the opportunity to perform molecular genetic analysis of pure populations of prostate cancer cells in their native tissue environment $(\mathrm{Xu}$ et al. 2001).

In the present study, the cDNA array techniques were employed to identify genes which are differentially expressed between two RNA populations. Using this technique, one simple hybridization experiment provides a visual profile of gene expression in the investigated samples. To further quantify either overexpression or down-regulated expression of isolated genes in pure prostate cancer specimens of epithelial origin as compared to the matched normal prostate epithelial tissue, both laser-capture microdissection (LCM) and quantitative RT-PCR analyses were applied. Prostate cancer, due to its infiltrative nature, with individual tumor acini infiltrating through stroma and directly adjacent to benign prostatic epithelium, makes it extremely difficult to isolate pure cancer cell populations. As shown in Figure 27, this obstacle was overcome by using the LCM technique. The LCM-derived material contains only pure tumor cell populations or pure normal prostate cells of epithelial origin. Next, prior to quantitative RT-PCR, RNA samples isolated from microdissected epithelial cells of matched normal prostate and prostate cancer were checked for RNA integrity and RNA amount by analyzing an RNA aliquot on the Agilent Nano or Pico LabChip ${ }^{\circledR}$. Using this technology it is possible to analyze such small amounts of RNA even in the nanogram or picograms scale, which can normally be isolated from microdissected tissue. 

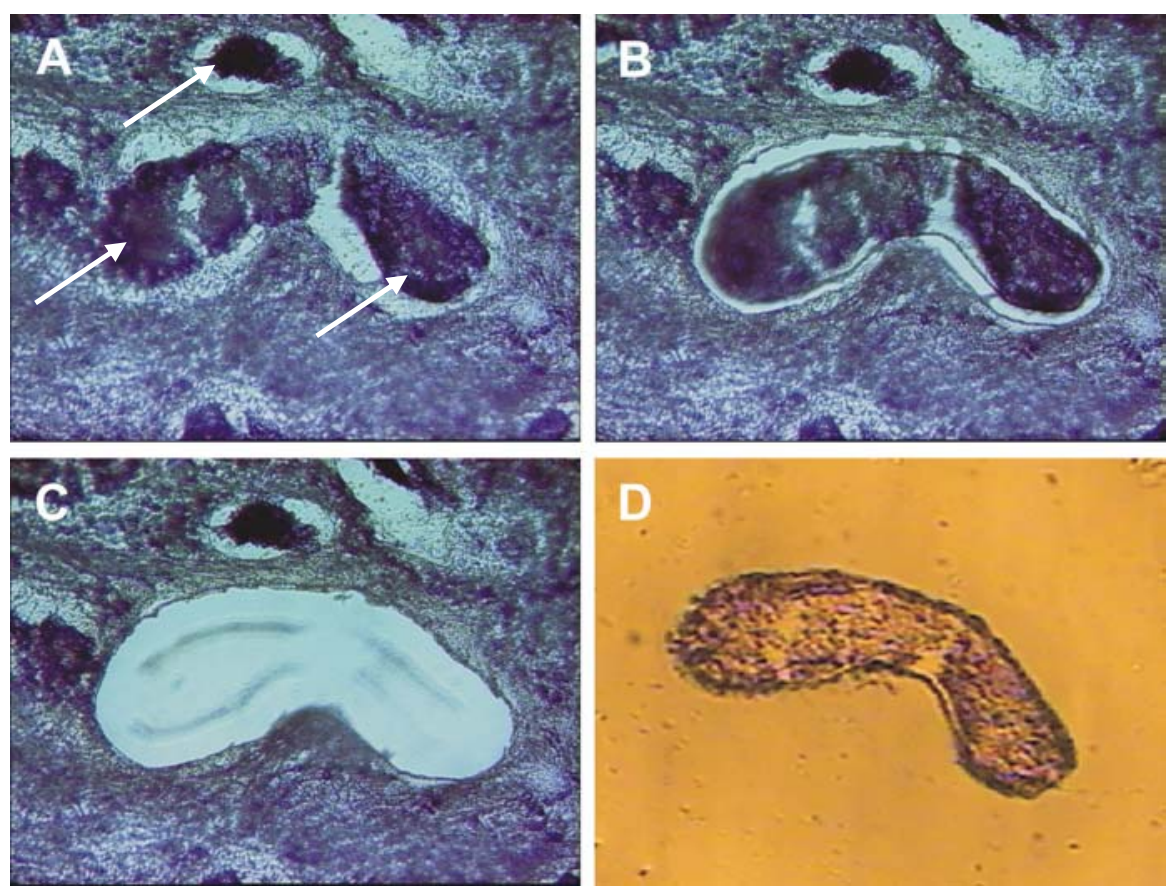

Figure 27. Laser capture microdissection of a prostate cancer glandular formation

A-C) Different stages of microdissection are demonstrated. The arrows indicate tumorous areas. D) The microdissected fragment containing pure prostate cancer specimens of epithelial origin after transfer into the tube lid. 


\subsection{The Insulin-like growth factor (IGF) system in cancer research}

\subsubsection{The Insulin-like growth factor I receptor (IGF-IR) as an anti-cancer target}

As reviewed by Wang and Sun (2002) the insulin-like growth factor I receptor (IGF-IR) is a tetrameric glycoprotein composed of two alpha and two beta subunits (Fig. 28). The alpha subunit localizes extra-cellulary for ligand binding, whereas the beta subunit consists of transmembrane chains and a cytoplasmic tyrosine kinase domain for enzymatic activity. The IGF-IR ligands, IGF-I and IGF-II, are mitogens and survival factors for many cancer cells. Binding of ligands to the IGF-IR initiates a cascade of events leading (mainly MAPK and PI-3K pathways) to stimulate proliferation/mitogenesis, to induce neoplastic transformation, to inhibit apoptosis, and to promote angiogenesis and metastasis. It has been shown that the presence of IGF-IR is required for transformation induced by many oncogenes and overexpression or constitutive activation of IGF-IR give rise to transformed phenotypes. Significantly, overexpression of the IGF-IR was observed in multiple human cancers including carcinomas of breast, lung, colon, and prostate. Patients with IGF-IR positive cancers have a worse prognosis in some cases. Furthermore, down-regulation or functional inactivation of IGF-IR sensitized tumor cells to apoptosis and to a reversed tumor cell phenotype. Thus, the IGF-IR appears to be a promising cancer target. Indeed, a variety of approaches aimed at targeting the IGF-IR have been utilized to prove the concept, or are being developed for potential anticancer therapies. These include targeting functional IGF-IR on cell surface, targeting ligand/receptor interaction, targeting receptor expression and functions, and targeting receptor kinase activity. Cancer patients could eventually benefit from the development of these specific IGF-IR antagonists. 


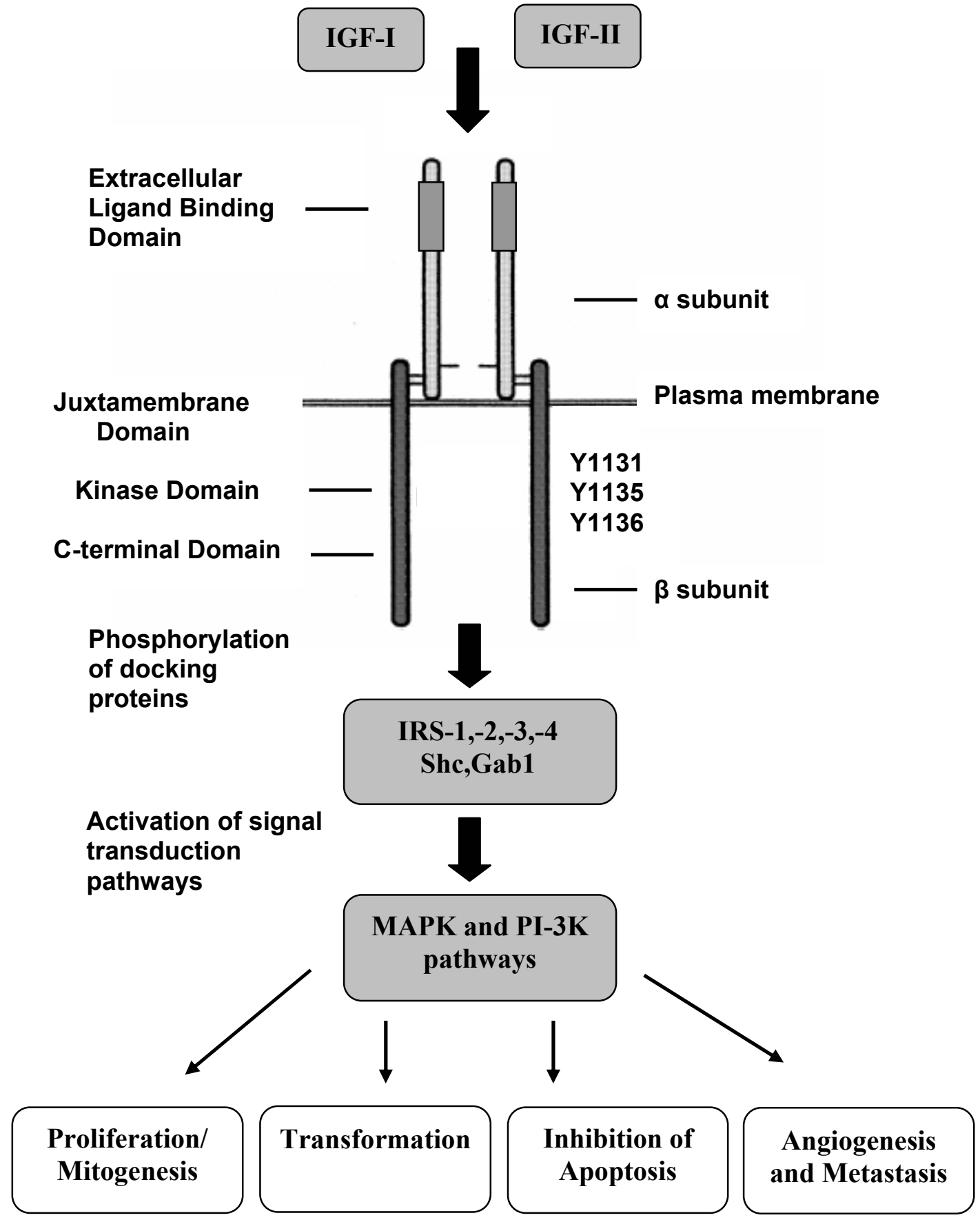

Figure 28. The insulin-like growth factor I receptor (IGF-IR) and IGFs signaling network (modified after Sepp-Lorenzino 1998).

Binding of ligands (IGF-I and IGF-II) leads to the activation of the intracytoplasmic tyrosine kinase in the $\beta$-chain of the protein. This initiates the autophosphorylation of the receptor, in particular, of tyrosine residues 1131, 1135, and 1136 (Kato et al. 1994). This results in the activation of their tyrosine kinase domain enabling the receptor kinase to phosphorylate intermediate docking proteins such as insulin- 
receptor substrate (IRS)-1, $-2,-3$ or -4 , Src homology/a-collagen protein (Shc) and Grb2-associated binder-1 (Gab1), which subsequently recruit various intracellular Src homology 2 (SH2)-domaincontaining proteins. This association, in turn, results in the activation of downstream signaling cascades, most prominently the Ras/Raf/mitogen-activated protein (MAP) kinase/MAP kinase kinase (MEK) and the phosphatidylinositol 3-kinase (PI 3-kinase) pathways, leading to stimulate proliferation/mitogenesis, to induce neoplastic transformation, to inhibit apoptosis, and to promote angiogenesis and metastasis at the cellular level.

\subsubsection{The IGF axis in prostate cancer}

As reviewed by Cohen et al. (1994), the insulin-like growth factor (IGF) axis is a multicomponent network of molecules involved in the regulation of cell growth. The axis includes two major ligands, (IGF-I and IGF-II), cell surface receptors, (the type I IGF receptor family as well as the type II IGF receptor), a family of high affinity binding proteins (IGFBPs) which regulate IGF availability to the receptors and a group of IGFBP proteases which cleave IGFBBPs and modulate IGF action. Human seminal plasma contains IGF-I and -II, IGFBP-2 and -4, as well as IGFBP-3 fragments and IGFBP-3 protease activity.

Prostate cancer preferentially metastasizes to bone where insulin-like growth factors (IGF-I and IGF-II) are two of the most abundant growth factors (Yoneda et al. 1994). The type I insulin-like growth factor receptor (IGF-IR), activated by its ligands, controls the proliferation of cells in a variety of ways, namely: it sends a mitogenic signal, it protects cells from a variety of apoptotic injuries, it promotes growth in cell size (a requirement for cell division) (Blakesley et al. 1999, Baserga et al. 1999).

In the present study, endogenous $I G F-I R$ gene expression was found to be reduced in stably transfected PC-3 prostate carcinoma cells by employing the antisense RNA strategy which resulted in a significant suppression of both PC-3 cell invasion and proliferation. In agreement with our results it has been previously reported (Baserga and Morrione 1999, Grimberg and Cohen 2000, Baserga 2000) that IGF-IR plays a crucial role in the establishment and maintenance of the transformed phenotype and that IGF-IR regulates cell adhesion and cell motility and that the IGF-IR is involved in invasion and metastasis of several cancers: highly invasive murine Lewis lung carcinoma cells (Long et al. 1998), metastatic breast cancer cells (Dunn et al. 1998, 
Chernicky et al. 2000), pancreatic cancer cells (Tanno et al. 2001) and myosarcoma cells (Sciacca et al. 2002). There is considerable evidence from both laboratory and population studies that the IGF axis is relevant to prostate cancer and prostate cancer progression to androgen independence. For example, it has been shown that both normal prostate epithelial cells and prostate cancer cells exhibit IGF responsiveness in vitro (Cohen et al. 1991, Peehl et al. 1996), that IGF-IR suppression inhibits rat prostate tumor cell growth and invasion in vivo (Burfeind et al. 1996), and that overexpression of IGF-I in prostate epithelial cells in a transgenic model leads to transformation (DiGiovanni et al. 2000). In addition, it was demonstrated that IGF-I can directly activate the androgen receptor in the absence of androgens (Culig et al. 1994, Putz et al. 1999) and that in vivo progression of LAPC-9 and LNCaP prostate cancer models to androgen independence is associated with increased expression of IGF-I and IGF-IR (Nickerson et al. 2001). Thus, the results presented in this study confirm the importance of IGF-IR as an anticancer target and provide a further basis for targeting $I G F-I R$ as a potential treatment for prostate carcinoma.

Ligand-receptor interactions are modulated by a family of high affinity specific IGF binding proteins (IGFBPs) and IGFBP-3 is the major serum carrier protein for the IGFs (Pollak et al. 1999, Hwa et al. 1999). More than 90\% of IGFs in the intravascular compartment are found in a ternary complex composed of the IGF, IGFBP-3, and an acid-labile subunit (Hwa et al. 1999). The experiments presented in this work clearly demonstrate that a direct correlation exists between the inhibition of $I G F-I R$ gene expression and an up-regulation of IGFBP-3 in androgenindependent PC-3 cells which results in an increase in cellular apoptosis and suppression of cell proliferation. In addition, both $I G F-I R$ and $I G F B P-3$ expression were investigated by quantitative real time RT-PCR analyses on RNA from LCM-derived matched normal prostate and prostate tumor epithelial tissue samples of 12 patients demonstrating that IGF-IR expression is upregulated in most of the prostate cancers (9 out of 12) and that IGFBP-3 expression is downregulated in all prostate carcinomas. The quantitative RT-PCR analysis did not show a significant correlation with specific clinicopathological features such as pathologic and clinical stage and the further studies are now required to address the correlation between IGF-IR and IGFBP-3 expression in the different stages of prostate cancer. However, in agreement with the presented findings recently the up-regulated expression of the IGF-IR in prostate cancer was demonstrated by immunostaining (Hellawell et al. 2002). Furthermore, similar to the observation presented in this study not all of the primary prostate cancers expressed elevated level of the IGF-IR (8 out of 
12 cases). On the other hand, as reviewed by Djavan et al. (2001), the IGF-IR ligands (IGF-1 and IGF-2) are expressed not only in prostate tumor cells but also in stroma cells, which can act in an autocrine or paracrine manner in prostate carcinoma (Fig. 29). In addition, it was also reported that expression of the IGFs can differ between different prostate cancers specimens and even between stroma cells (Li et al. 1998). On the basis of the present study and previous findings it can be concluded that in prostate carcinomas with normal expression of IGF-IR, the elevated expression of its ligands (IGF-I and IGF-II) in these cancer cells or in stroma cells could lead to tumor growth comparable to this with overexpressed IGF-IR. Therefore, for the better understanding of the expression of IGF-IR in prostate carcinoma it is also very important to investigate not only expression of the IGF-IR but also the expression of IGF-I and IGF-II in cancer cells as well as in stromal cells.

\section{Paracrine action}

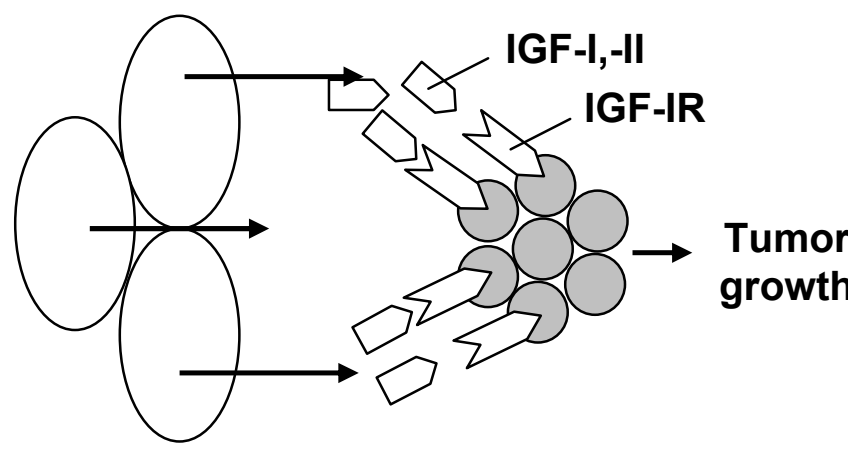

Stromal

cells
Prostate cancer

cells

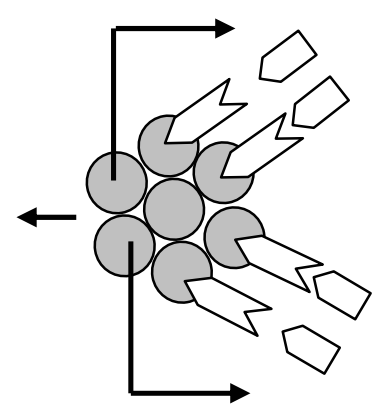

Prostate cancer cells
Autocrine action

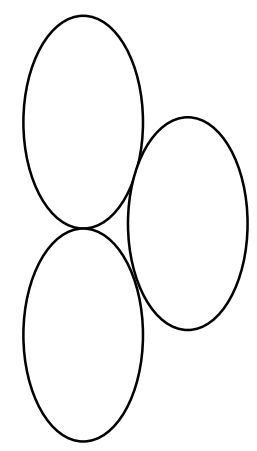

Stromal

cells

Figure 29. Schematic representation of paracrine and autocrine actions of IGF-I and IGF-II in prostate cancer

Paracrine action of IGF-IR in prostate cancer cells is mediated by its ligands (IGF-I and IGF-II) which are produced in non-tumor cells (stroma). In contrast, in the autocrine action the IGF-IR ligands are produced and secreted through the cancer cells, thus activating the IGF-IR pathways.

Moreover, on the basis of the present results, it is suggested that overexpression of $I G F-I R$ negatively regulates $I G F B P-3$ expression leading to both prostate cancer cell growth-activation and prevention from apoptosis of prostate cancer cells (Fig. 30). This hypothesis is supported by the fact that the inhibitory effect of silibinin on prostate cancer PC-3 cells involves increased 
$I G F B P-3$ gene expression and secretion as well as inhibition of IGF-I-induced signaling (Zi et al. 2000). Furthermore, evidence was provided that outside the circulation, IGFBP-3 has been found to be a negative regulator of cell proliferation and an inducer of apoptosis (Fig. 31) in prostatic and other tissues (Angelloz-Nicoud and Binoux 1995, Rajah et al. 1997). However, this growth inhibition has been attributed not only to the reduction of IGF-I and/or IGF-II bioactivity (Hwa et al. 1999), but also to an IGF-independent growth-inhibiting action that appears to involve cell surface receptors for IGFBP-3 (Rajah et al. 1997).

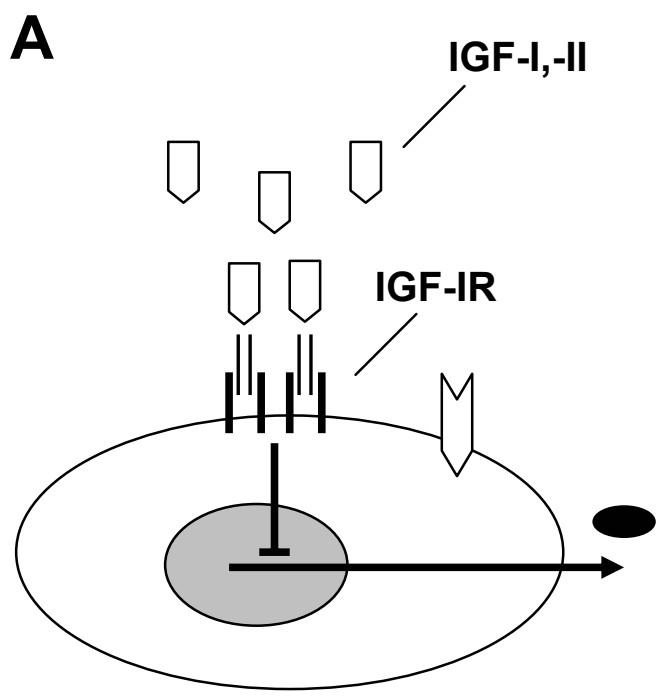

Growth-activation

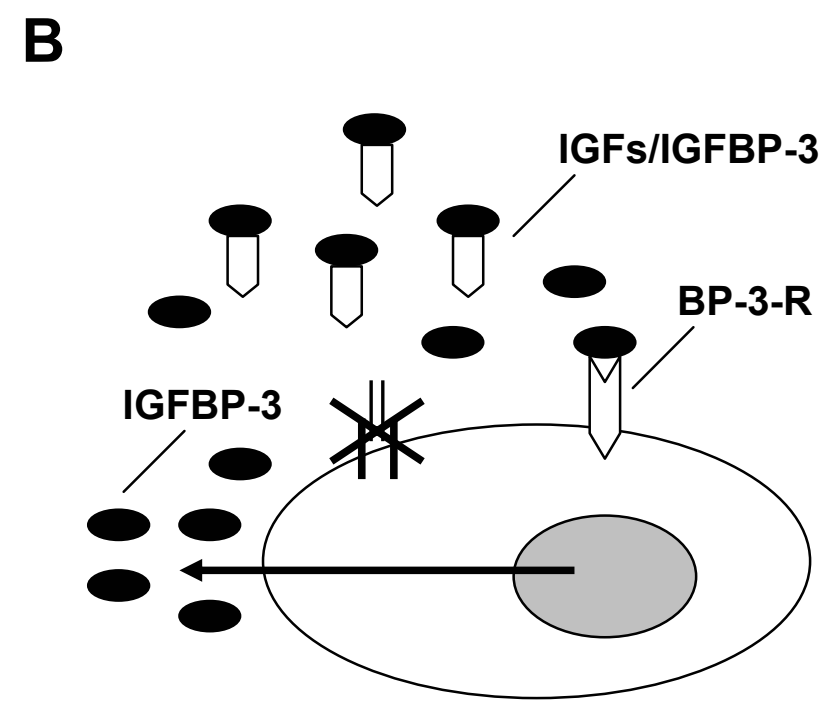

Growth-inhibition/ Apoptosis

Figure 30. Regulation of IGFBP-3 expression through IGF-IR pathways in prostate carcinoma (hypothetical model)

A) Overexpression of IGF-IR decreases an expression of IGFBP-3 leading to growth activation in prostate cancer cells. B) In contrast, reduction of IGF-IR levels leads to an increase in the level of IGFBP-3 expression and secretion resulting in growth-inhibition and apoptosis of prostate carcinoma cells. As reported previously IGFBP-3 is able to cause growth-inhibition by the reduction of IGF-I and/or IGF-II bioactivity and sequestering IGFs away from the IGF-I receptor (Hwa et al. 1999) and to mediate apoptosis via its own receptors (BP-3-R) (Rajah et al. 1997). 


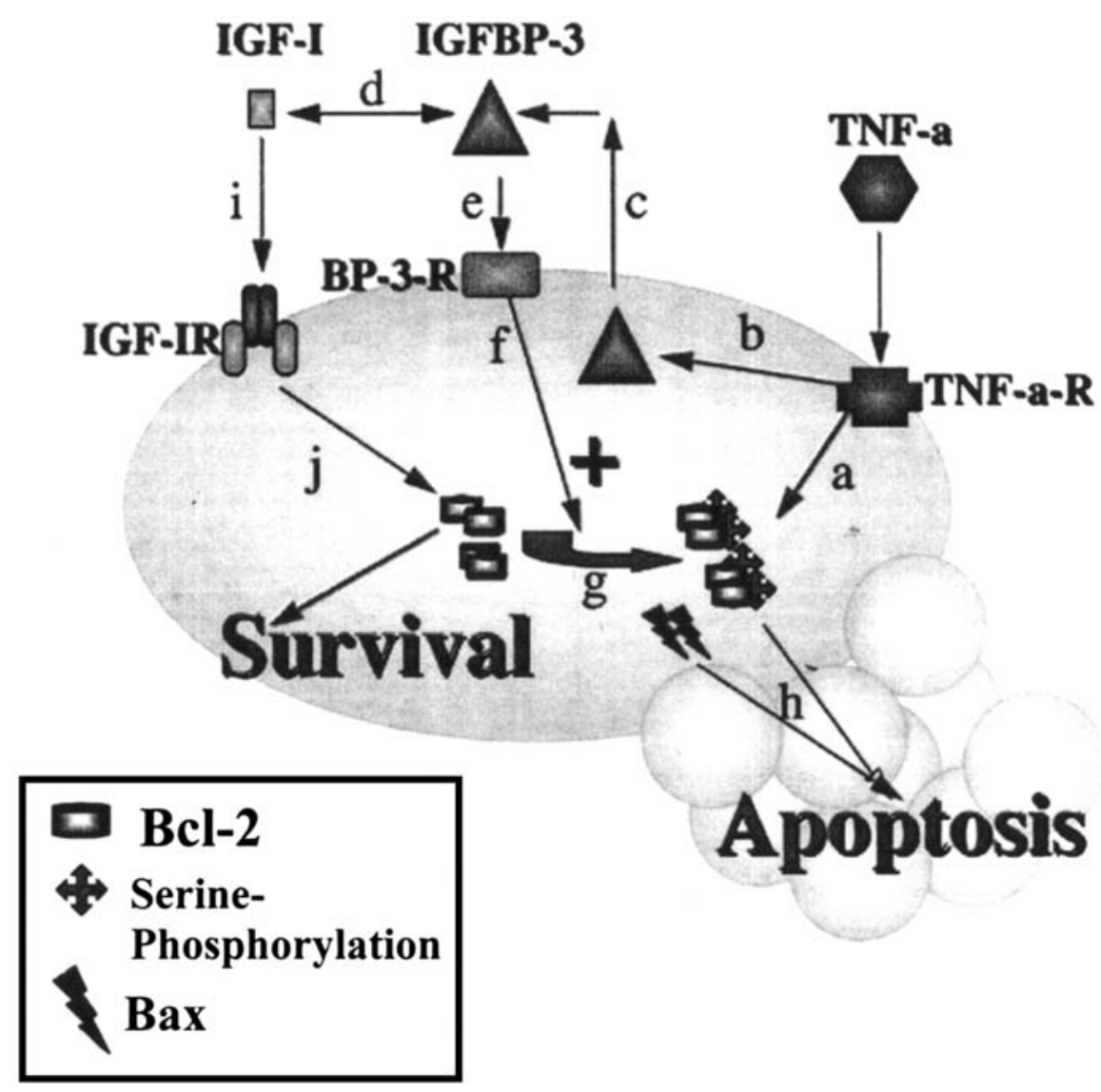

Figure 31. IGF, IGFBP-3, and cytokine-induced apoptosis: a theoretical model (Rajah et al. 2002) TNF- $x$ induces apoptosis directly $(a)$ by binding to its receptor or by inducing IGFBP-3 $(b-h)$. IGFBP-3 induces apoptosis by inducing serine phosphorylation of Bcl-2 $(g)$ and thereby increasing the inactive bcl2 form and targeting the Bcl-2:Bax ratio toward apoptosis induction $(h)$. This apoptosis-inducing effect of IGFBP-3 can be blocked when IGFBP-3 binds to IGFs with high affinity $(d)$. IGFs mediate survival via the IGF-I receptor $(i)$, leading to an increase in Bcl-2 $(j)$ as well as Bcl- $\mathrm{X}_{\mathrm{L}}$ expression. TNF- $\mathrm{a}$-induced IGFBP-3 is able to block this pathway by sequestering IGFs away from the IGF-I receptor $(d)$ and by mediating apoptosis via its own receptors (e). Thus, IGFBP-3 can mediate cell death by both IGFdependent and IGF-independent pathways. Moreover, IGFBP-3 can mediate apoptosis induced by several agents, and this involves the inactivation of Bcl-2 via serine phosphorylation. 
Moreover, recent publications demonstrate that the growth-inhibitory activity of transforming growth factor B1 (Oh et al. 1995), vitamin D-related compounds (Huynh et al. 1998), retinoic acid (Gucev et al. 1996), antiestrogens (Huynh et al. 1996), antiandrogens (Nickerson and Pollak 1999), p53 (Buckbinder et al. 1995), tumor necrosis factor alpha (Rozen et al. 1998) all involve up-regulation of IGFBP-3 gene expression and production indicating that IGFBP-3 may be involved in many growth-inhibiting signaling pathways. The findings presented in this work demonstrate an important role for the IGF-IR and IGFBP-3 expression in cellular homeostasis of prostate carcinoma and provide a basis for better understanding of the $I G F$ - $I R$-activated signaling pathways.

In the present study one of the genes showing an altered expression in $I G F-I R$ antisense-RNA transfected PC-3 cells is termed macrophage inhibitory cytokine $M I C-1$, previously identified to be overexpressed in human prostate tumor tissues (Welsh et al. 2001). However, its altered expression could not be confirmed in other control cellular PC-3 clones and parental PC-3 cells as indicated in the result section. Therefore, it is suggested that this event was observed due to acquired abnormalities which occurred during cellular cloning and culturing.

\subsubsection{IGBP-3 expression in different human cancers}

To determine IGBP-3 expression in different human cancers we used the cancer profiling array. In the present study, the up-regulation of IGFBP-3 expression was determined in the following cancers: kidney, lung, rectum, colon, stomach and thyroid cancer, whereas down-regulation was determined in breast, uterus and ovarian cancer. In agreement with our findings it was previously reported (Hintz et al. 1991) that expression of the IGFBP-3 gene was increased in human renal carcinomas. Recently, the association with elevated IGFBP-3 levels and a higher risk of lung cancer in current smokers was observed by Spitz et al. (2002). Also, it has been shown that an increase in colon cancer risk exists with increasing levels of IGF-I and IGFBP-3 (Palmqvist et al. 2002). Next, levels of IGFBP-3 were found to be elevated in colon cancers as compared with adjacent normal tissue (Kansra et al. 2000). Further, the enhanced expression of IGFBP-3 has been recently demonstrated in gastric cancer cells but not all gastric cancer cells express the 
IGFBP-3. Interestingly, the anticancer drug-induced-growth inhibition was more evident to induce apoptosis in IGFBP-3-expressing gastric cancer cells but not the IGFBP-3 non-expressing cells (Lee et al. 2002). Moreover, as reported by Bachrach et al. (1995) the IGFBP-3 production was increased in human thyroid follicular carcinoma cell lines by dedifferentiation factors such as epithelial growth factor (EGF) and tissue-type plasminogen activator (TPA) and inhibited by thyroid-stimulating hormone (TSH) and forskolin, which enhance differentiated function suggesting a potential role for IGFBP-3 in modulating malignant thyroid growth. On the other hand, in agreement with the present findings regarding the down-regulation of IGFBP-3 in human cancers, IGFBP-3 was reported (Vollenhoven et al. 1993) to be expressed in both fibroids (leiomyomata) and myometrium and those fibroids express less IGFBP-3 mRNA than myometrium. Further, a high IGFBP-3 expression in epithelial ovarian cancer was found (Katsaros et al. 2002) to be associated with a significantly reduced risk for disease progression and it was shown that an inverse dose-dependent relationship exists between IGFBP-3 and disease progression-free survival. Moreover, as reviewed by Martin et al. (2002) IGFBP-3 is inhibitory to the growth of many breast cancer cells in vitro, however, a high level of expression of IGFBP-3 in breast tumors correlates with poor prognosis, suggesting that IGFBP-3 may be associated with growth stimulation in some breast cancers.

On the basis of the observations presented in this study and previous findings it can be concluded that the regulation of IGFBP-3 expression and its function can vary between different human tumors and even between different tumor stages. However, the present study confirms to some extend the expression of IGFBP-3 in different human tumors but to determine the clinical relevance of these findings further studies are strongly required.

\subsection{The role of the IGF-IR in tumor metastasis}

The poor prognosis and survival rate of patients presenting with advanced disease with a clinically detectable metastasis underscores the need to better understand the molecular mechanisms of invasion in these tumors and the new treatments blocking the formation of metastasis will provide greater chances of survival for cancer patients. 
The IGF-IR plays a critical role in the acquisition of the malignant phenotype. As shown in Table 12 , the IGF-IR was reported to be involved in invasion and metastasis of several cancers.

\begin{tabular}{l|l}
\hline \multicolumn{1}{c|}{ CANCER CELLS } & \multicolumn{1}{c}{ References } \\
\hline Human colon cancer cells & Reinmuth et al. 2002 \\
Human myosarcoma cells & Sciacca et al. 2002 \\
Human pancreatic cancer cells & Tanno et al. 2001 \\
Human metastatic breast cancer cells & $\begin{array}{l}\text { Dunn et al. } 1998, \\
\text { Chernicky et al. } 2000 \\
\text { Invasive murine Lewis lung carcinoma cells } \\
\text { Rat prostate adenocarcinoma cells }\end{array}$ \\
\hline
\end{tabular}

Table 12. Reported correlation between IGF-IR expression and metastasis.

Invasiveness of tumor cells is a complex process that requires the proteolytic degradation of extracellular matrix (ECM) barriers (Stetler-Stevenson et al. 1993), coupled with migration of the cells through the modified region (Stracke et al. 1994). Degradation of ECM in malignant tumors is accomplished primarily by members of the MMP (matrix metalloproteinases) family of enzymes, which currently include at least 26 distinct gene products (Nagase and Woessner 1999, Park et al. 2000). MMPs are zinc-dependent endopeptidases, which collectively are capable of degrading virtually all ECM components (Fig. 32) (Birkedal-Hansen et al. 1993). The evidence is particularly compelling for the involvement of the Mr 72,000 type IV collagenase (MMP-2) in the dissolution of basement membrane barriers, a process thought to be required for tumor cell invasion into blood vessels and for tumor extravasation (Stetler-Stevenson et al. 1993). 


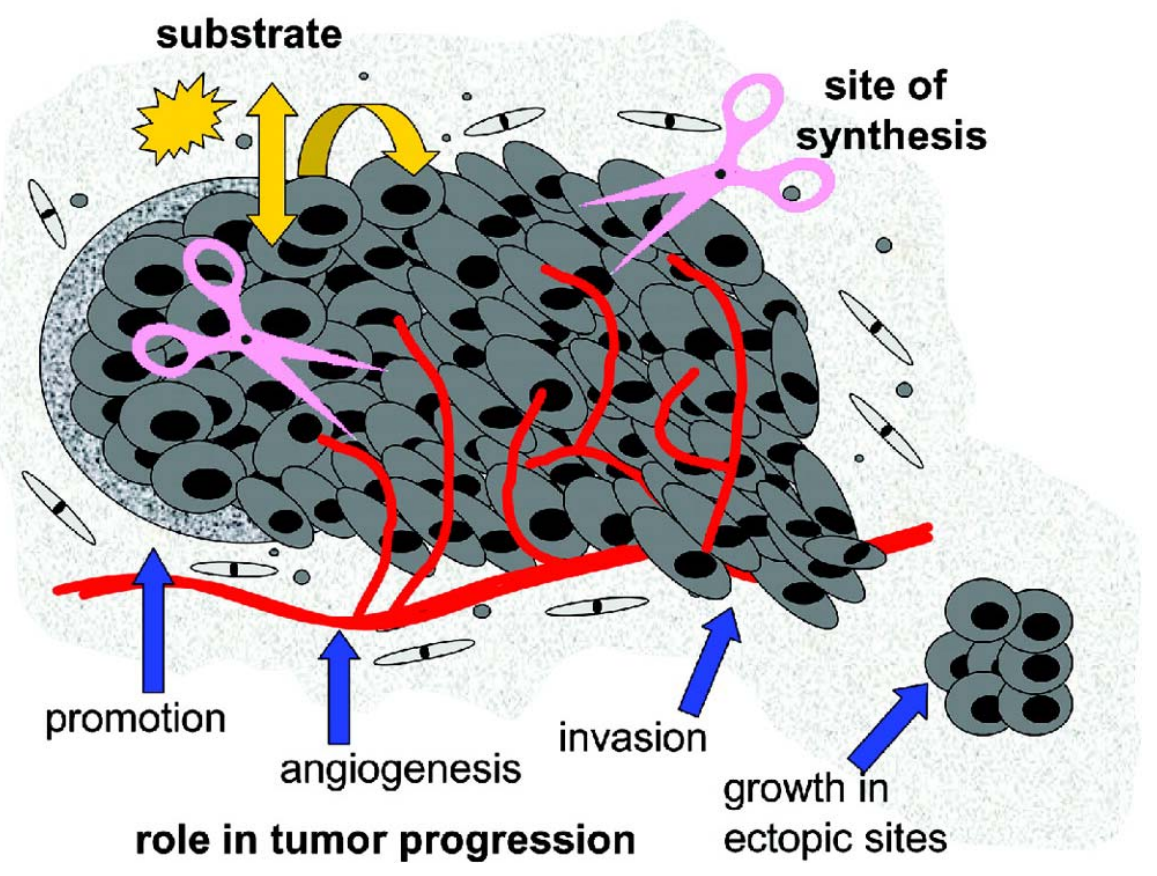

Figure 32. Current view of MMP action in cancer (Coussens et al. 2002)

MMPs (represented by scissors) are now known to contribute to multiple steps of tumor progression in addition to invasion, including tumor promotion, angiogenesis, and the establishment and growth of metastatic lesions in distant organ sites. In addition, it is recognized that MMPs not only can be synthesized by tumor cells but are frequently produced by surrounding stromal cells, including fibroblasts and infiltrating inflammatory cells. Finally, although creating gaps in matrix barriers remains a role for MMP activity, MMPs are also known to solubilize cell surface and matrix-bound factors that can then act in an autocrine or paracrine manner to influence cellular properties such as growth, death, and migration.

In the present study, it was demonstrated for the first time that a direct correlation exists between the inhibition of $I G F-I R$ gene expression and a down-regulation of $M M P-2$ expression in androgen-independent human PC-3 prostate carcinoma cells resulting in a significant suppression of PC-3 cell invasion. In agreement with these results it was documented using two subclones of Lewis lung carcinoma (H-59 and M-27) cells, that a correlation exists between IGF-IR levels and the metastatic potential of these cells. Furthermore, it was reported that a reduction in $I G F-I R$ levels by antisense mRNA leads to the abrogation of the metastatic phenotype and a decrease in the level of MMP-2 mRNA transcripts in the highly invasive carcinoma subline H-59. In contrast, $I G F-I R$ overexpression results in the acquisition of a highly invasive/metastatic phenotype involving increased expression of the $M M P-2$ gene in the poorly invasive carcinoma subline $\mathrm{M}$ - 
27 (Long et al. 1998). In addition, recently it was reported that serum levels of MMP-2 together with PSA increased with prostate carcinoma disease progression and it was suggested that MMP2 may be involved in the invasion and metastasis of prostate cancer (Kanoh et al. 2002). Therefore, on the basis of the results presented in this study and previous findings, it can be concluded (as shown in Figure 33) that the IGF-IR through its pathways positively regulates $M M P-2$ expression leading to invasion and metastasis of prostate cancer.
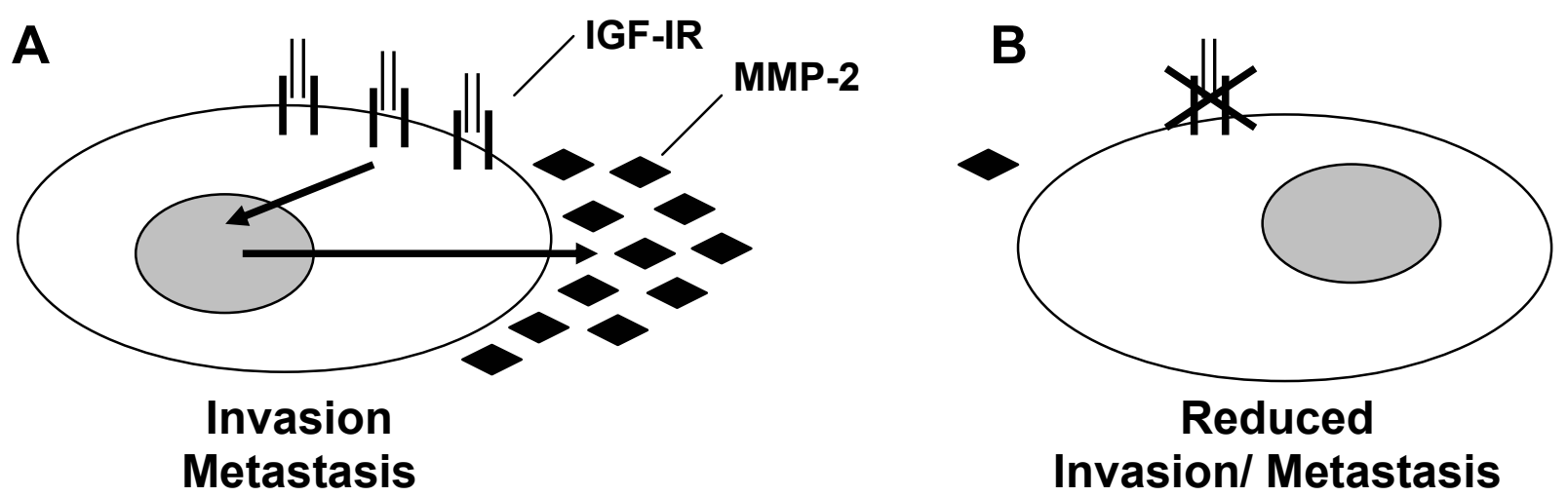

Figure 33. Regulation of MMP-2 expression through IGF-IR pathways in prostate carcinoma cells (hypothetical model)

A) Overexpression of IGF-IR increases expression of MMP-2 leading to invasion and metastasis of prostate cancer. B) On the contrary, reduction of IGF-IR levels leads to a decrease of MMP-2 expression and to the abrogation of the invasive/ metastatic phenotype in prostate carcinoma cells.

\subsection{Isolation of differentially expressed genes in human prostate carcinoma}

As a clear need to identify prostate tumor markers does exist we analyzed differential gene expression of putative prostate tumor markers by comparing the expression levels of more than 400 cancer-related genes using the cDNA array technique in a set of a capsule-invasive prostate tumor and matched normal prostate tissue. In total, 46 differentially expressed genes were identified to be up- or down-regulated in prostate carcinoma. In addition, as reported previously, the known genes showed a differential expression pattern in prostate tumor e.g. Krox 24 (Ahmed et al. 2001), c-jun (Aoyagi et al. 1998), spermidyne acetyltransferase (Fukutome et al. 1999), 
ribosomal proteins (Rinaldy and Steiner 1999), clusterin (Bettuzzi et al. 2000) and prostate secretory protein 94 (Sakai et al. 1999). From these differentially expressed genes, seven genes displaying an up -regulated expression in human prostate carcinoma and which were not described previously to be differentially expressed in prostate cancer (complement component C1s, ferritin heavy chain, MAT-8 protein, peptidyl-proryl cis-trans isomerase A, RNA-binding protein regulatory subunit DJ-1 protein, vacuolar ATP synthase subunit F and Bax inhibitor-1) were further suggested to be potential putative prostate cancer markers. In addition, we confirmed their overexpression in prostate cancer by using real time quantitative PCR analysis. In agreement with our suggestions it has been previously demonstrated that the ferritin heavy chain gene, which is involved in iron metabolism, displayed an elevated expression in metastatic ovarian tumor (Tripathi and Chatterjee 1996) and in breast cancer (Yang et al. 2001). Next, the peptidyl-proryl cis-trans isomerase, which catalyzes cis-trans isomerization of imide bonds in peptides and proteins, was found to be highly expressed in human breast ductal carcinoma (Bini et al. 1997). RNA-binding protein regulatory subunit DJ-1 protein, which is involved in the posttranscriptional control of gene expression, was previously identified (Nagakubo et al. 1997) as a novel oncogene which transforms mouse NIH3T3 cells in cooperation with Ras-related signal transduction pathway. Further, it has been previously shown that non-transformed mouse A31 cells became tumorigenic when they were transfected with hamster C1s cDNA and the possible involvement of $\mathrm{C} 1 \mathrm{~s}$ (which takes part in the immune response against infections) in tumorigenicity is suggested (Sakai et al. 1994, Sakiyama et al. 1996) Recently, elevated expression of F(1)-ATP synthase beta-subunit, which is involved in energizing biomembranes, was identified in hepatocellular carcinoma by proteomic analysis (Naour et al. 2002). Further, the small membrane MAT-8 protein, which plays a role in ion transport regulation, was found to be overexpressed in ras-initiated mammary tumors (Morrison and Leder 1994) and identified as a novel phospholemman-like protein expressed in human breast tumors (Morrison et al.1995). Moreover, recently MAT- 8 has been found to be expressed in benign prostatic hyperplasia (BPH) tissue and in human prostate androgen-dependent LNCaP prostate cancer cells, whereas transcripts encoding MAT-8 were absent in human prostate carcinoma PC-3 cells and in androgen-independent LNCaP cells (Vaarala et al. 2000 ). Although presented preliminary findings and previous observations suggest that these differentially expressed genes (Table 13) could serve as putative human prostate cancer markers, there is a clear need for further studies to 
confirm the overexpression of these genes on RNAs derived from other prostate cancer specimens.

\begin{tabular}{l|l|c}
\hline \multicolumn{1}{c|}{ GENE NAME } & $\begin{array}{l}\text { REPORTED EXPRESSION } \\
\text { IN OTHER CANCERS }\end{array}$ & REFERENCES \\
\hline $\begin{array}{l}\text { Vacuolar ATP synthase subunit } \\
\text { Ferritin heavy chain }\end{array}$ & $\begin{array}{l}\text { hepatocellular carcinoma } \\
\text { breast cancer } \\
\text { metastatic ovarian tumor } \\
\text { benign prostatic hyperplasia } \\
\text { MAT-8 protein }\end{array}$ & $\begin{array}{c}\text { Naour } \text { et al. } 2002 \\
\text { Yang et al. } 2001 \\
\text { Tripathi and Chatterjee } 1996 \\
\text { Vaarala } \text { et al. } 2000\end{array}$ \\
Peptidyl-proryl cis-trans isomerase A & $\begin{array}{l}\text { Vaarala } \text { et al. } 2000 \\
\text { RNA-initiated mammary tumors } \\
\text { subunit DJ-1 protein }\end{array}$ & $\begin{array}{l}\text { Morrison and Leder } 1994 \\
\text { Bini } \text { et al. } 1997\end{array}$ \\
Complement component C1s & a novel oncogene involved in \\
Ras-related signaling pathway & Nagakubo et al. 1997 \\
\hline
\end{tabular}

Table 13. Putative human prostate tumor markers identified in the present study

\subsection{Apoptosis in prostate carcinogenesis (role of Bax inhibitor-1)}

During the past 10 years, interest of basic scientists and clinicians in the influence of programmed cell death, or apoptosis, on the sensitivity of tumors to anticancer treatment has increased and continues to rise dramatically. A major reason for this interest is that apoptosis is a defined program of cell death that is markedly influenced both positively and negatively by a variety of genes, many of which are mutated and/or dysfunctionally regulated in human cancers. Among the most important of these are the tumor suppressor gene $p 53$ and members of the Bcl-2 gene family (Fisher 2001). Compelling evidence suggests that the tumorigenic growth of the prostate depends on the evasion of normal homeostatic control mechanisms, because of an increase in cell proliferation and a decrease in apoptotic death (Berges et al. 1995, Tu et al. 1996). Thus, enhancing the apoptotic process emerges as a significant therapeutic target for the effective elimination of both androgen-dependent and androgen-independent prostate cancer cells (Bruckheimer and Kyprianou 2000). 
Recently, adenovirus-mediated Bax overexpression was reported to induce apoptosis of LNCaP, PC-3 and DU-145 growing in vitro and in vivo (Li et al. 2001). However, the pro-apoptotic protein Bax seems to be expressed in all prostate cancers evaluated, but the expression of several anti-apoptotic members of the Bcl-2 gene family increase during progression of prostate cancers (Krajewska et al. 1996). Therefore, it is important to unravel the mechanisms protecting prostate cancer cells from undergoing apoptosis and to identify new therapeutic targets and to develop new treatments. In a previous study, the novel anti-apoptotic protein Bax inhibitor-1 (BI-1), formerly known as testicular enhanced gene transcript (TEGT) (Walter et al. 1995), was shown to represent a new type of regulator of cell death pathways controlled by Bcl-2 and Bax. It was demonstrated that BI-1 can interact with Bcl-2 and Bcl- $\mathrm{X}_{\mathrm{L}}$ (Fig. 34) but not with Bax and Bad and when overexpressed in mammalian cells, BI-1 suppressed apoptosis induced by Bax, etoposide, staurosporine and growth factor deprivation, but not by Fas (CD95) (Xu et al. 1998).

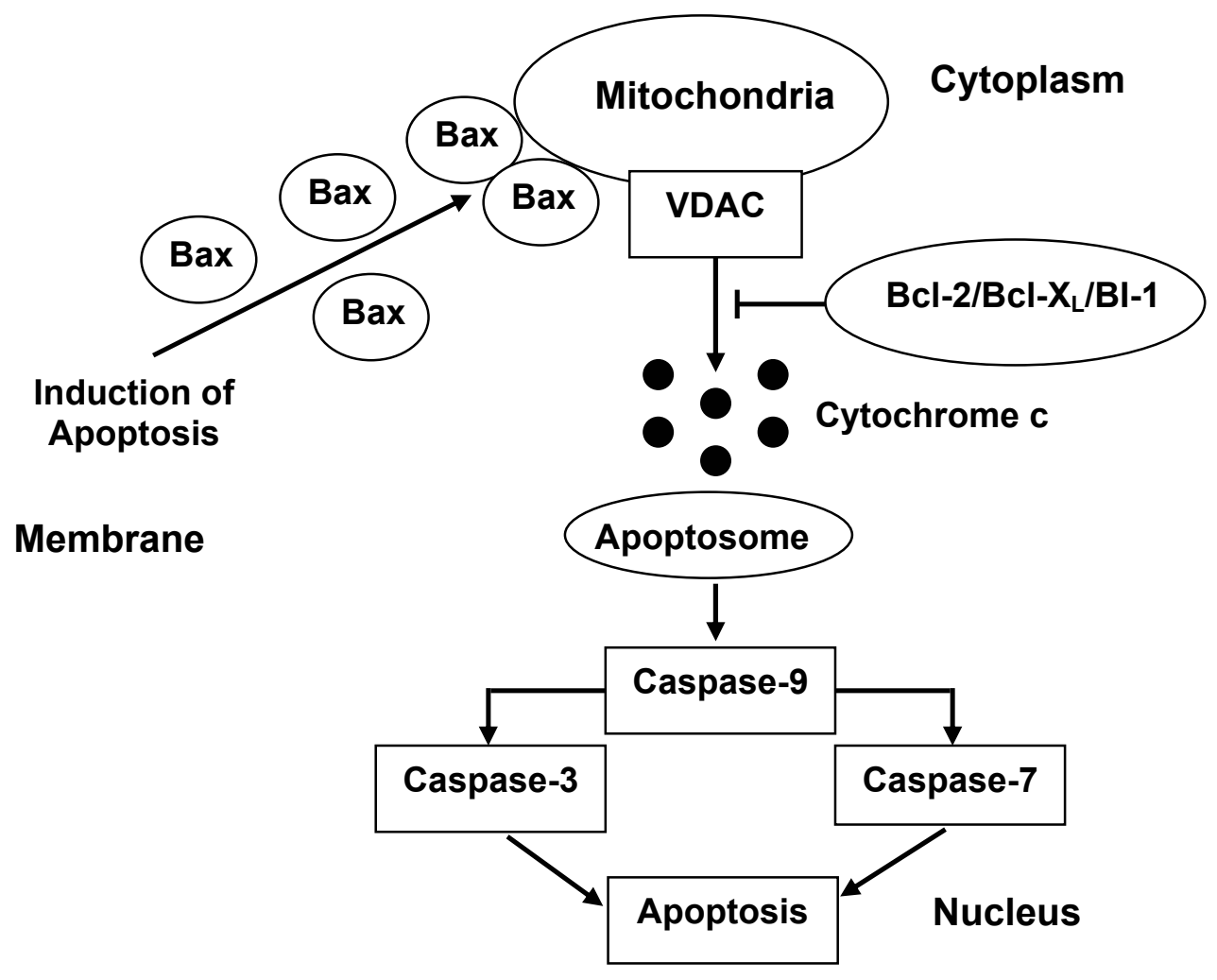

Figure 34. Schematic representation of Bax-mediated apoptosis.

As reviewed by Kim et al. (2002), after induction of apoptosis, the activation of the Bax gene leads to an increase in the amount of protein, which forms Bax homodimers that are translocated from the cytoplasm to the mitochondria. The homodimerized Bax acts on voltage-dependent anion channel (VDAC), which is 
localized in the outer membrane of mitochondria resulting in the release of cytochrome $c$ which activates the caspase cascade. The release of cytochrome $c$ from mitochondria promotes the oligomerization of a cytochrome $c /$ Apoptotic protease activating factor 1 (Apaf-1)/procaspase-9 complex (apoptosome) that activates caspase- 9 resulting in the cleavage of downstream effector caspase- 3 and -7 in the presence of dATP leading to apoptosis. On the other hand, the release of cytochrome $c$ is inhibited by the antiapoptotic proteins $\mathrm{Bcl}-2$ and $\mathrm{Bcl}-\mathrm{X}_{\mathrm{L}}$, which, like Bax, have ion channel activity. In addition, the novel anti-apoptotic protein Bax inhibitor-1 (BI-1) can interact with Bcl-2 and Bcl- $\mathrm{X}_{\mathrm{L}}$ thus suppressing Bax-induced apoptosis.

\subsection{BI-1 expression in human prostate cancer and other cancers}

In the present study one of the genes showing an increased expression in prostate carcinoma is termed Bax inhibitor-1 (BI-1), which was previously found to be involved in cellular apoptosis (Xu et al. 1998). Quantification of the Northern blot using a phosphorimager revealed a 4-fold up-regulation of both BI-1 transcripts $(2.7 \mathrm{~kb}$ and $1.2 \mathrm{~kb})$ in cancerous specimen as compared to the matched normal tissue. It is also worth noting that the array-spotted BI-1 cDNA was originally described by BD Biosciences Clontech to be differentially expressed (up-regulated expression) in breast cancer. This finding was supported by a large scale DNA microarray analysis on primary breast tumors from 117 young patients, showing that BI-1 expression is upregulated in breast cancer and coregulates with the expression of the estrogen receptor $\alpha$ gene (Van 't Veer et al. 2002). Furthermore, Schmitts and coworkers (2002) reported that BI-1 expression was between 5 and 10 times stronger in 16 glioma samples tested compared with normal brain and other normal tissues. Finally, microarray analyses of the expression levels of more than 8900 different human genes in a set of normal and malignant prostate tissues revealed that BI-1 is highly and specifically expressed in malignant samples (Welsh et al. 2001).

Subsequently, we analyzed BI-1 mRNA expression by quantitative RT-PCR on RNAs from laser-capture microdissected (LCM)-derived samples from thirteen radical prostatectomies from cancer patients which were prepared as described in the material and methods section. In all cases BI-1 expression was up-regulated up to 7.4-fold in LCM-samples derived from tumorous areas as compared to the paired normal prostate tissues. However, the quantitative RT-PCR analysis did not show a significant correlation with specific clinicopathological features such as pathologic and clinical stage and further studies are now warranted to address the correlation between BI-1 
expression and the various phases of prostate cancer. A larger study of whole mount prostate specimens is in progress for further investigation of this issue

Additionally, in order to determine BI-1 expression in different human cancers the cancer profiling array was used. As a result, the up-regulation of $B I-1$ gene expression in the following cancers was determined: ovarian cancer, cancer of the uterus, prostate cancer and breast cancer, whereas down-regulation was determined in kidney cancer, lung cancer, colon cancer, stomach cancer and rectum cancer. On the basis of the present observations and previous findings it can be suggested that the regulation of BI-1 expression depends on different human tumors and could even differ between various tumor stages. However, these preliminary observations of BI-1 expression in different human cancers require further studies to determine the clinical relevance of these findings.

\subsection{Down-regulation of BI-1 expression leads to prostate cancer cell death}

In order to evaluate the function of BI-1 in human PC-3 and LNCaP prostate carcinoma cells the novel approach of gene silencing through RNAi was applied. RNA interference (RNAi) or RNA silencing is the process whereby double-stranded RNA (dsRNA or duplex RNA) induces the homology-dependent and specific degradation of cognate mRNA. As reviewed by Hutvagner and Zamore (2002), the specific knockdown of expression of several genes was studied in a wide variety of species, such as Caenorahbditis elegans, Drosophila melanogaster, Arabidopsis thaliana, Neurospora crassa and embryonic cells from Mus musculus. More recently, the use of RNAi has been extended to differentiated mammalian cells (Elbashir et al. 2001, Harborth et al. 2001).

To determine the function of BI-1 in vitro, human androgen-independent PC-3 and androgendependent LNCaP prostate carcinoma cells were transfected with small interfering doublestranded RNA (siRNA) oligonucleotides against the BI-1 gene leading to a specific downregulation of BI-1 expression in both cell lines either at the RNA or the protein level. After treatment of PC-3 cells with duplex siRNA oligonucleotides against $B I-1$, the number of apoptotic PC-3 cells reached its maximum at 45 hours after treatment (35\% to 44\%) by using three independent methods (DAPI, ISEL and caspase-3 assay). In addition, the amount of PC-3 
cell death was analyzed by trypan blue staining where induction of PC-3 cell death by duplex siRNA oligonucleotides against BI-1 peaked at $45 \mathrm{~h}$ after treatment (59\% positively stained cells). The activation of caspase-3 paralleled the induction of apoptosis in duplex siRNAtransfected PC-3 cells. Furthermore, the increase in DNA fragmentation was almost comparable to that of trypan blue-positively stained cells, which suggests that the cytotoxicity induced by duplex siRNA against BI-1 is attributable to both necrotic and apoptotic death. However, it cannot be ruled out that trypan blue staining of PC-3 cells was accomplished due to secondary necrotic cells which are known to be readily formed from apoptotic cells over time. This hypothesis is supported by the fact that only apoptotic cells were observed after DAPI staining of transfected PC-3 cells. Further, the treatment of LNCaP cells with duplex siRNA oligonucleotides against BI-1 revealed a similar effect as in PC-3 cells at 5 days after treatment (39\% of apoptotic cells).

In agreement with our results in human PC-3 and $\mathrm{LNCaP}$ prostate carcinoma cells, it has been previously demonstrated that the BI-1 protein inhibits Bax-induced apoptosis in mammalian cells and when ectopically expressed in yeast (Xu et al. 1998). Furthermore, it was shown that BI-1 contains six or seven predicted transmembrane domains and the localization of BI-1 was found to be similar to Bcl-2, exhibiting a nuclear envelope and endoplasmic reticulum (ER)-associated pattern. When overexpressed in human cells, an association of BI-1 with Bcl-2 and Bcl- $\mathrm{X}_{\mathrm{L}}$ was demonstrated by both chemical cross-linking and co-immunoprecipitation experiments (Xu et al. 1998). Furthermore, it is a well known fact that a potential connection exists between the close relative Bcl-2 and hormone-independent prostate cancer (Colombel et al. 1993, McDonnel et al. 1992). Moreover, BI-1 was isolated as one of the candidate suppressors of TRAIL, an apoptosisinducing member of the tumor necrosis factor (Burns and El-Deiry 2001).

Among the various prostate cancer cell lines, recent studies demonstrated that PC-3 cells are more resistant to apoptosis than LNCaP cells (Marcelli et al. 2000, Wang et al. 1999, Chen et al. 1999). $\mathrm{Li}$ and coworkers (2001) reported that overexpression of Bcl- $\mathrm{X}_{\mathrm{L}}$ underlies the molecular basis for resistance to staurosporine-induced apoptosis in PC-3 cells. Taken together, these previous findings and the results observed in the present study showing similar expression of the BI-1 gene in both PC-3 and LNCaP cells indicate that a higher apoptosis ratio in PC-3 cells as compared to LNCaP cells after treatment with siRNA oligonucleotides against BI-1 could be due to the overexpression of $\mathrm{Bcl}-\mathrm{X}_{\mathrm{L}}$ in PC-3 cells and an existing interaction between $\mathrm{BI}-1$ and $\mathrm{Bcl}-$ $\mathrm{X}_{\mathrm{L}}$. Moreover, to support this hypothesis, pilot experiments were performed on human prostate 
carcinoma DU-145 cells. As a consequence, we observed a similar apoptosis ratio in DU-145 cells $(14.4 \%)$ as compared to $\mathrm{LNCaP}$ cells $(17.4 \%)$ after 45 hours treatment with small interfering double-stranded RNA (siRNA) oligonucleotides against the BI-1 gene (Figure $35 \mathrm{~A}$ ). As shown in Figure $35 \mathrm{~B}, \mathrm{Bcl}-\mathrm{X}_{\mathrm{L}}$ is overexpressed in PC-3 cells as compared to LNCaP and DU145 cells, therefore, it can be suggested that specific down-regulation of BI-1 (which expression is known to be associated with $\mathrm{Bcl}-\mathrm{X}_{\mathrm{L}}$ ) leads to a higher apoptosis ratio in PC-3 cells as compared to LNCaP and DU-145. However, it can not be ruled out that these differences in the number of apoptotic cells are due to a slower cell proliferation of LNCaP cells as compared to PC-3 cells. This hypothesis is supported by the fact that a similar effect in cellular apoptosis in LNCaP cells was observed after 5 days of treatment with siRNA oligonucleotides against the BI1 gene.

A

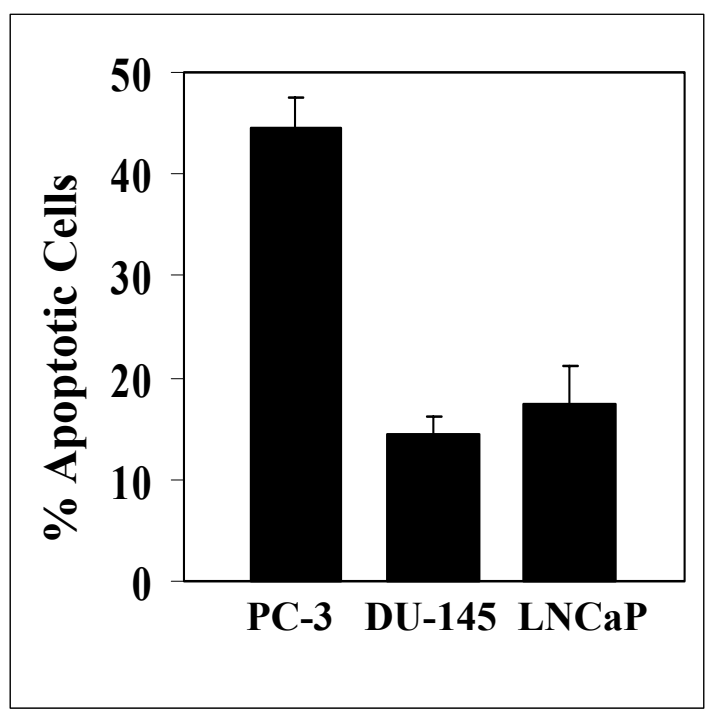

B

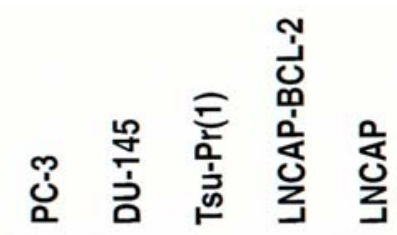

$\beta$-actin

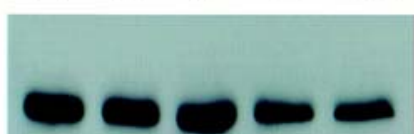

$B c l-x_{L}$

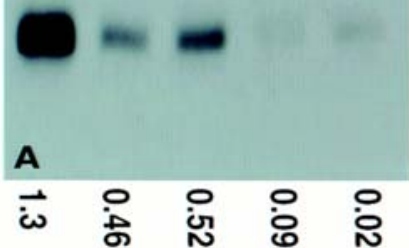

Figure 35. Cellular apoptosis mediated by siRNA oligonucleotides against the human BI-1 gene and previous reported $\mathrm{Bcl}-\mathrm{X}_{\mathrm{L}}$ expression in human prostate cancer cells

A) Induction of prostate carcinoma cell death in prostate cancer cells (PC-3, DU-145 and LNCaP) determined in the present study by using siRNAs against the human BI-1 gene. Bar graphs represent the percentage of positively DAPI-stained apoptotic cells at 45 hours after treatment with siRNA oligonucleotides against the human $B I-1$ gene. Data, means of three independent experiments $( \pm \mathrm{SE})$. B) Overexpression of Bcl- $\mathrm{X}_{\mathrm{L}}$ in PC-3 cells (Li et al. 2001). Cell extracts $(10 \mu \mathrm{g})$ were sized and subjected to Western analysis with antibodies for $\beta$-actin and Bcl- $\mathrm{X}_{\mathrm{L}}$. Arbitrary densitometric units of the $\mathrm{Bcl}-\mathrm{X}_{\mathrm{L}}$ band were corrected for those of the $\beta$-actin band. The ratio is reported at the bottom of each lane. 
The results presented in this study and the previous results demonstrating in vitro binding of BI-1 with Bcl- $\mathrm{X}_{\mathrm{L}}$ and Bcl-2 indicate that down-regulation of BI-1 expression in PC-3 and LNCaP cells could change the balance of $\mathrm{Bcl}-\mathrm{X}_{\mathrm{L}} / \mathrm{BI}-1 / \mathrm{Bcl}-2$ and Bax proteins and consequently, the cell death pathway can be activated as a Bax-induced apoptotic event. On the other hand, up-regulated BI-1 expression in prostate cancer cells (and other cancers) could lead to an imbalance of $\mathrm{Bcl}-\mathrm{X}_{\mathrm{L}} / \mathrm{BI}$ 1/Bcl-2 and Bax proteins, thus, inhibiting programmed cell death. On the basis of our results, we conclude that down-regulation of BI-1 expression using the novel RNAi technique could serve as an attractive approach for the treatment of prostate cancer in the future.

\subsection{Further perspectives}

In view of the observations reported in this study regarding the inhibition of IGF-IR expression in human prostate cancer PC-3 cells, further studies are now warranted to analyze the suppression of both tumorigenesis and the metastatic potential in vivo of these IGF-IR-reduced PC-3 cells. To address this purpose the $I G F-I R$ antisense-RNA transfected PC-3 cells and the IGF-IR senseRNA transfected PC-3 cells and parental PC-3 cells (controls) will be subcutaneously injected into nude mice and these mice will be checked for tumor formation and also for lung and bone metastasis. Furthermore, for a better understanding of the regulation of IGFBP-3 and MMP-2 expression through the IGF-IR pathway in prostate carcinoma it is important to analyze more patients with different tumor stages for the expression of these genes. Additionally, it is also very important to investigate not only the expression of the IGF-IR, but also the expression of its ligands (IGF-I and IGF-II) in cancer cells as well as in stromal cells.

In the second part of the present study, several genes were identified as putative human prostate cancer markers (complement component $\mathrm{C} 1 \mathrm{~s}$, ferritin heavy chain, MAT8 protein, peptidylproryl cis-trans isomerase A, RNA-binding protein regulatory subunit DJ-1 protein and vacuolar ATP synthase subunit F). However, there is a clear need for further studies to confirm the overexpression of these selected genes on RNAs derived from more prostate cancer specimens. As the well-established role of BI-1 as a powerful antiapoptotic factor in prostate cancer cells was demonstrated in the present work, further studies are now needed to address the correlation 
between BI-1 overexpression and the various phases of prostate cancer. On the one hand, more prostate carcinoma specimens with different tumor stages are required to be analyzed for the expression of the BI-1 gene. On the other hand, it would be also very important to investigate the overexpression of the BI-1 gene in non-transformed cells (e. g. mice fibroblasts NIH3T3) and to analyze phenotypical changes of these cells (proliferation, invasion, transformation and apoptosis). Next, to answer the question if $\mathrm{Bcl}-2$ and $\mathrm{Bcl}-\mathrm{X}_{\mathrm{L}}$ are the only binding proteins for BI1 the yeast two hybrid system can be applied to identify other interaction partners.

Moreover, as it was shown that the RNA interference technique was able to suppress BI-1 expression and significantly increases the apoptosis ratio in human prostate carcinoma cells, it will also be very important to investigate the potential of duplex small interfering RNA oligonucleotides against the BI-1 gene for the specific reduction of BI-1 expression and for suppression of tumor growth in vivo. To address this purpose two approaches by using nude mice can be applied: First, by the subcutaneous injection of prostate carcinoma cells transfected with duplex siRNA oligonucleotides against the BI-1 gene and cells transfected with duplex siRNA oligonuclotides against the luciferase gene (control). These mice can be analyzed for tumor formation. In the second approach, the parental prostate carcinoma cells will be injected into nude mice and prostate tumors will develop. In the second step, either duplex siRNA oligonuclotides against the BI-1 gene or duplex siRNA oligonucleotides against the luciferase gene (control) will be injected into the tumors to investigate tumor growth suppression. Another alternative to investigate suppression of tumor growth in vivo can be reached by the injection of duplex siRNA oligonucleotides against the BI-1 gene into prostate tumors of the previously established transgenic adenocarcinoma mouse prostate (TRAMP) model (Gingrich et al. 1997). Furthermore, it was previously reported ( $\mathrm{Li}$ et al. 2001) that among human prostate cancer cell lines LNCaP but not PC-3 cells undergo apoptosis after treatment with the protein kinase inhibitor staurosporine (STS) and that overexpression of Bcl- $\mathrm{X}_{\mathrm{L}}$ is one of the mediators of resistance to STS-induced apoptosis in prostate cancer PC-3 cells. It would be important to investigate the apoptosis ratio after treatment with siRNA oligonucleotides against the BI-1 gene (which expression is known to be associated with $\mathrm{Bcl}-\mathrm{X}_{\mathrm{L}}$ ) together with staurosporine in $\mathrm{PC}-3$ cells and also in other prostate carcinoma cells. This study could contribute for the development of therapeutic strategies for prostate cancer. 
between BI-1 overexpression and the various phases of prostate cancer. On the one hand, more prostate carcinoma specimens with different tumor stages are required to be analyzed for the expression of the BI-1 gene. On the other hand, it would be also very important to investigate the overexpression of the BI-1 gene in non-transformed cells (e. g. mice fibroblasts NIH3T3) and to analyze phenotypical changes of these cells (proliferation, invasion, transformation and apoptosis). Next, to answer the question if Bcl-2 and Bcl- $\mathrm{X}_{\mathrm{L}}$ are the only binding proteins for BI1 the yeast two hybrid system can be applied to identify other interaction partners.

Moreover, as it was shown that the RNA interference technique was able to suppress BI-1 expression and significantly increases the apoptosis ratio in human prostate carcinoma cells, it will also be very important to investigate the potential of duplex small interfering RNA oligonucleotides against the BI-1 gene for the specific reduction of BI-1 expression and for suppression of tumor growth in vivo. To address this purpose two approaches by using nude mice can be applied: First, by the subcutaneous injection of prostate carcinoma cells transfected with duplex siRNA oligonucleotides against the BI-1 gene and cells transfected with duplex siRNA oligonuclotides against the luciferase gene (control). These mice can be analyzed for tumor formation. In the second approach, the parental prostate carcinoma cells will be injected into nude mice and prostate tumors will develop. In the second step, either duplex siRNA oligonuclotides against the BI-1 gene or duplex siRNA oligonucleotides against the luciferase gene (control) will be injected into the tumors to investigate tumor growth suppression. Another alternative to investigate suppression of tumor growth in vivo can be reached by the injection of duplex siRNA oligonucleotides against the BI-1 gene into prostate tumors of the previously established transgenic adenocarcinoma mouse prostate (TRAMP) model (Gingrich et al. 1997). Furthermore, it was previously reported (Li et al. 2001) that among human prostate cancer cell lines LNCaP but not PC-3 cells undergo apoptosis after treatment with the protein kinase inhibitor staurosporine (STS) and that overexpression of Bcl- $\mathrm{X}_{\mathrm{L}}$ is one of the mediators of resistance to STS-induced apoptosis in prostate cancer PC-3 cells. It would be important to investigate the apoptosis ratio after treatment with siRNA oligonucleotides against the BI-1 gene (which expression is known to be associated with $\mathrm{Bcl}-\mathrm{X}_{\mathrm{L}}$ ) together with staurosporine in $\mathrm{PC}-3$ cells and also in other prostate carcinoma cells. This study could contribute for the development of therapeutic strategies for prostate cancer. 


\section{SUMMARY}

In the present study, endogenous $I G F-I R$ gene expression was reduced in stably transfected PC-3 cells by employing the antisense RNA strategy resulting in a significant suppression of PC-3 cell invasion and proliferation and in an increase in PC-3 cell apoptosis. Furthermore, it was demonstrated that a direct correlation exists between the inhibition of $I G F-I R$ gene expression and an up-regulation of $I G F B P-3$ or a down-regulation of $M M P-2$ expression in androgen-independent PC-3 cells. In addition, both $I G F-I R$ and IGFBP-3 expression were investigated by quantitative real time RT-PCR analyses on RNA from LCM-derived matched normal prostate and prostate tumor epithelial tissue samples of 12 patients demonstrating that the $I G F-I R$ is up-regulated in most prostate cancers (9 out of 12) and that IGFBP-3 is downregulated in all prostate carcinomas. Furthermore, by using the cancer profiling array the upregulation of $I G F B P-3$ gene expression was determined in the following cancers: kidney cancer, lung cancer, rectum cancer, colon cancer, stomach cancer and thyroid cancer, whereas down-regulation was determined in breast cancer, cancer of the uterus and ovarian cancer. These results indicate an important role for the IGF-IR and the IGFBP-3 in cellular homeostasis of prostate carcinoma and provide a further basis for targeting $I G F-I R$ as a potential treatment for prostate cancer as well as a better understanding of the IGF-IRactivated signaling pathways.

Next, in order to analyze differential gene expression of putative prostate tumor markers the expression levels of more than 400 cancer-related genes were compared using the cDNA array technique in a set of prostate tumor and matched normal prostate tissue. In total, 46 differentially expressed genes were identified to be up- or down-regulated in prostate carcinoma. From these differentially expressed genes, seven genes (Bax inhibitor-1 ,complement component $\mathrm{C} 1 \mathrm{~s}$, ferritin heavy chain, MAT8 protein, peptidyl-proryl cis-trans isomerase A, RNA-binding protein regulatory subunit DJ-1 protein and vacuolar ATP synthase subunit F) displaying an up-regulated expression in human prostate carcinoma were further confirmed to be overexpressed in prostate cancer by using real time RT-PCR analysis on whole tumor RNA. The overexpression of Bax inhibitor-1 (BI-1) in prostate carcinoma was confirmed by using both Northern blot analysis on whole tumor RNA and real time RTPCR on RNA from thirteen laser captured microdissected prostate tumor tissue samples. In addition, by using the cancer profiling array the up-regulated expression of the $B I-1$ gene was 
determined in the following cancers: ovarian cancer, cancer of the uterus, prostate cancer and breast cancer, whereas down-regulated expression was determined in kidney cancer, lung cancer, colon cancer, stomach cancer and rectum cancer.

Furthermore, to determine the function of BI-1 in vitro, human androgen-independent PC-3 and androgen-dependent LNCaP prostate carcinoma cells were transfected with small interfering double-stranded RNA (siRNA) oligonucleotides against the BI-1 gene leading to a specific down-regulation of BI-1 expression. Moreover, transfection of PC-3 and LNCaP cells with BI-1 sequence-specific siRNAs caused a significant increase both in cellular apoptosis and necrosis. Taken together, the present results indicate that the human BI-1 gene contains the potential to serve as a prostate cancer expression marker and as a novel target for developing therapeutic strategies for prostate cancer. 


\section{References}

Ahmed M. M., Chendil D., Lele S., Venkatasubbarao K., Dey S., Ritter M., Rowland R. G., Mohiuddin M. (2001). Early growth response-1 gene: potential radiation response gene marker in prostate cancer. Am J Clin Oncol. 24:500-505.

Altschul S. F., Gish W., Miller W., Myers E. W., Lipman D. J. (1990). Basic local alignment search tool. J Mol Biol. 215:403-410.

Angelloz-Nicoud P., Binoux M. (1995). Autocrine regulation of cell proliferation by the insulin-like growth factor (IGF) and IGF binding protein-3 protease system in a human prostate carcinoma cell line (PC-3). Endocrinology. 136:5485-5492.

Aoyagi K., Shima I., Wang M., Hu Y., Garcia F. U., Stearns M. E. (1998). Specific transcription factors prognostic for prostate cancer progression. Clin Cancer Res. 4:21532160 .

Asamoto, M., Hokaiwado, N., Cho, Y. M., Takahashi, S., Ikeda, Y., Imaida, K., and Shirai, T. (2001). Prostate carcinomas developing in transgenic rats with SV40 T Antigen expression under probasin promoter control are strictly androgen-dependent. Cancer Res. 61:4693-4700.

Baquet C. R., Horm J. W., Gibbs T., Greenwald P. (1991). Socioeconomic factors and cancer incidence among blacks and whites. J Natl Cancer Inst. 83:551-557.

Baserga R. (2000). The contradictions of the IGF-I receptor. Oncogene. 19:5574-5581.

Baserga R., Morrione A. (1999). Differentiation and malignant transformation: two roads diverged in a wood. $J$ Cell Biochem. 33:68-75.

Baserga R., Prisco M., Hongo A. (1999) IGFs and cell growth. In: Rosenfeld R. G., Roberts C. T. Jr., (eds), In: The IGF system. Totowa: NJ:329-353.

Bass B. L. (2000). Double-stranded RNA as a template for gene silencing. Cell. 101:235-238 
Becker C., Piironen T., Kiviniemi J., Lilja H., Pettersson K. (2000). Sensitive and specific immunodetection of human glandular kallikrein 2 in serum. Clin Chem. 46:198-206.

Berges R. R., Vucanovic J., Epstein J. I., Walsh P. C., Isaacs J. T. (1995). Implication of cell cycle changes during the progression of human prostate cancer. Clin Cancer Res. 1: 473-480.

Bernstein E., Caudy A. A., Hammond S. M., Hannon G. J. (2001). Role for a bidentate ribonuclease in the initiation step of RNA interference. Nature. 409:363-366.

Bettuzzi S., Davalli P., Astancolle S., Carani C., Madeo B., Tampieri A., Corti A., Saverio B., Pierpaola D., Serenella A., Cesare C., Bruno M., Auro T., Arnaldo C. (2000). Tumor progression is accompanied by significant changes in the levels of expression of polyamine metabolism regulatory genes and clusterin (sulfated glycoprotein 2) in human prostate cancer specimens. Cancer Res. 60:28-34.

Bini L., Magi B., Marzocchi B., Arcuri F., Tripodi S., Cintorino M., Sanchez J. C., Frutiger S., Hughes G., Pallini V., Hochstrasser D. F., Tosi P. (1997). Protein expression profiles in human breast ductal carcinoma and histologically normal tissue. Electrophoresis. 18:28322841.

Birkedal-Hansen H., Moore W. G., Bodden M. K., Windsor L. J., Birkedal-Hansen B., DeCarlo A., Engler J. A. (1993). Matrix metalloproteinases: a review. Crit Rev Oral Biol Med. 4:197-250.

Blakesley V. A., Butler A. A., Koval A. P. (1999). IGF-I receptor function: transducing the IGF-I signal into intracellular events. In: The IGF system, Rosenfeld R. G., Roberts C. T. Jr., (eds), Totowa: NJ:143-163.

Bostwick D. G. (1997). Staging prostate cancer-1997: current methods and limitations. Eur Urol. 3:2-14.

Bruckheimer E. M., Kyprianou N. (2000). Apoptosis in prostate carcinogenesis: a growth regulator and a therapeutic target: a review. Cell Tissue Res. 301:153-162. 
Buckbinder L., Talbott R., Velasco-Miguel S., Takenaka I., Faha B., Seizinger B. R., Kley N. (1995). Induction of the growth inhibitor IGF-bindind protein 3 by p53. Nature. 377:646-649.

Burfeind P., Chernicky C. L., Rininsland F., Ilan J., Ilan J. (1996). Antisense RNA to the type I insulin-like growth factor receptor suppresses tumor growth and prevents invasion by rat prostate cancer cells in vivo. Proc Natl Acad Sci USA. 93:7263-7268.

Burger M. J., Tebay M. A., Keith P. A., Samaratunga H. M., Clements J., Lavin M. F., Gardiner R. A. (2002). Expression analysis of delta-catenin and prostate-specific membrane antigen: their potential as diagnostic markers for prostate cancer. Int J Cancer. 100:228-237.

Burns T. F., El-Deiry W. S. (2001). Identification of inhibitors of TRAIL-induced death (ITIDs) in the TRAIL-sensitive colon carcinoma cell line SW480 using a genetic approach. $J$. Biol. Chem. 276:37879-37886.

Carter B. S., Beaty T. H., Steinberg G. D., Childs B., Walsh P. C. (1992). Mendelian inheritance of familial prostate cancer. Proc Natl Acad Sci USA. 89:3367-3371.

Carter H. B., Coffey D. S. (1990). The prostate: an increasing medical problem. Prostate. 16:39-48.

Carter H. B., Pearson J. D. (1999). Prostate-specific antigen testing for early diagnosis of prostate cancer: formulation of guidelines. Urology. 54:780-6.

Chalifour L. E., Fahmy R., Holder E. L., Hutchinson E. W., Osterland C. K., Schipper H. M., Wang E. (1994). A method for analysis of gene expression patterns. Anal Biochem. 216:299304.

Chan JM, Stampfer MJ, Ma J, Gann P, Gaziano JM, Pollak M, Giovannucci E. (2002). Insulin-like growth factor-I (IGF-I) and IGF binding protein-3 as predictors of advanced-stage prostate cancer. J Natl Cancer Inst 94:1099-1106.

Chen Y. R., Zhou G., Tan T-H. (1999). c-Jun N-terminal kinase mediates apoptotic signaling induced by N-(4-hydroxyphenyl) retinamide. Mol Pharmacol. 56:1271-1279. 
Chernicky C. L., Yi L., Tan H., Gan S. U., Ilan J. (2000). Treatment of human breast cancer cells with antisense RNA to the type I insulin-like growth factor receptor inhibits cell growth, suppresses tumorigenesis, alters the metastatic potential, and prolongs survival in vivo. Cancer Gene Ther. 7:384-95.

Cogoni C., Macino G. (2000). Post-transcriptional gene silencing across kingdoms. Review. Curr Opin Genet Dev. 10:638-43.

Cohen P., Peehl D. M., Lamson G., Rosenfeld R. G. (1991). Insulin-like growth factors (IGFs), IGF receptors, and IGF-binding proteins in primary cultures of prostate epithelial cells. J Clin Endocrinol. Metab. 73:401-407.

Cohen P., Peehl D. M., Rosenfeld R. G. (1994). The IGF axis in the prostate. Horm Metab Res. 26:81-84.

Collins J. A., Schandi C. A., Young K. K., Vesely J., Willingham M. C. (1997). Major DNA fragmentation is a late event in apoptosis. J Histochem Cytochem. 45:923-934.

Colombel M., Symmans F., Gil S., O'Toole K. M., Chopin D., Benson M., Olsson C. A., Korsmeyer S., Buttyan R. (1993). Detection of the apoptosis-suppressing oncoprotein bc1-2 in hormone-refractory human prostate cancers. Am J Pathol. 143:390-400.

Coussens L. M., Fingleton B., Matrisian L. M. (2002). Matrix metalloproteinase inhibitors and cancer: trials and tribulations. Science. 295:2387-2392.

Craven R. A., Totty N., Harnden P., Selby P. J., Banks R. E. (2002). Laser capture microdissection and two-dimensional polyacrylamide gel electrophoresis: evaluation of tissue preparation and sample limitations. Am J Pathol. 160:815-822.

Culig Z., Hobisch A., Cronauer M. V., Radmayr C., Trapman J., Hittmair A., Bartsch G., Klocker H. (1994). Androgen receptor activation in prostatic tumor cell lines by insulin-like growth factor-I, keratinocyte growth factor, and epidermal growth factor. Cancer Res. 54: 5474-5478. 
Dhanasekaran S. M., Barrette T. R., Ghosh D., Shah R., Varambally S., Kurachi K., Pienta K. J., Rubin M. A., Chinnaiyan A. M. (2001). Delineation of prognostic biomarkers in prostate cancer. Nature. 412:822-826.

DiGiovanni J., Kiguchi K., Frijhoff A., Wilker E., Bol D. K., Beltran L., Moats S., Ramirez A., Jorcano J., Conti C. (2000). Deregulated expression of insulin-like growth factor 1 in prostate epithelium leads to neoplasia in transgenic mice. Proc Natl Acad Sci USA. 97:34553460.

Dunn S. E., Ehrlich M., Sharp N. J., Reiss K., Solomon G., Hawkins R., Baserga R., Barrett J. C. (1998). A dominant negative mutant of the insulin-like growth factor-I receptor inhibits the adhesion, invasion, and metastasis of breast cancer. Cancer Res. 58:3353-3361.

Duque J. L., Loughlin K. R., Adam R. M., Kantoff P. W., Zurakowski D., Freeman M. R. (1999). Plasma levels of vascular endothelial growth factor are increased in patients with metastatic prostate cancer. Urology. 54:523-527.

Elbashir S. M., Harborth J., Lendeckel W., Yalcin A., Weber K., Tuschl T. (2001)b. Duplexes of 21-nucleotide RNAs mediate RNA interference in cultured mammalian cells. Nature. 411:494-498.

Elbashir S. M., Lendeckel W., Tuschl T. (2001)a. RNA interference is mediated by 21- and 22-nucleotide RNAs. Genes Dev. 15:188-200.

Elgamal A. A., Holmes E. H., Su S. L., Tino W. T., Simmons S. J., Peterson M., Greene T. G., Boynton A. L., Murphy G. P. (2000). Prostate-specific membrane antigen (PSMA): current benefits and future value. Semin Surg Oncol. 18:10-6.

Ernst T., Hergenhahn M., Kenzelmann M., Cohen C. D., Bonrouhi M., Weninger A., Klaren R., Grone E. F., Wiesel M., Gudemann C., Kuster J., Schott W., Staehler G., Kretzler M., Hollstein M., Grone H. J. (2002). Decrease and gain of gene expression are equally discriminatory markers for prostate carcinoma: a gene expression analysis on total and microdissected prostate tissue. Am J Pathol Jun. 160:2169-80. 
Feinberg A. P., Vogelstein B. (1983). A technique for radiolabeling DNA restriction endonuclease fragments to high specific activity. Anal Biochem. 132:6-13.

Feldkamp J., Pascher E., Perniok A., Scherbaum W. A. (1999). Fas-Mediated apoptosis is inhibited by TSH and iodine in moderate concentrations in primary human thyrocytes in vitro. Horm Metab Res. 31:355-358.

Fisher D. E. (2001). Pathways of apoptosis and the modulation of cell death in cancer. Hematol Oncol Clin North Am. 15:931-956.

Fukutome K., Watanabe M., Shiraishi T., Murata M., Uemura H., Kubota Y., Kawamura J., Ito H., Yatani R. (1999). N-acetyltransferase 1 genetic polymorphism influences the risk of prostate cancer development. Cancer Lett. 136:83-87.

Gershoni J. M., Palade G. E. (1983). Protein blotting: principles and applications. Review. Anal Biochem. 131:1-15.

Gingrich J. R., Barrios R. J., Kattan M. W., Nahm H. S., Finegold M. J., Greenberg N. M. (1997). Androgen-independent prostate cancer progression in the TRAMP model. Cancer Res. 57:4687-4691.

Giovannucci E. (1999). Insulin-like growth factor-I and binding protein-3 and risk of cancer. Horm Res. 3:34-41.

Golub T. R., Slonim D. K., Tamayo P., Huard C., Gaasenbeek M., Mesirov J. P., Coller H., Loh M. L., Downing J. R., Caligiuri M. A., Bloomfield C. D., Lander E. S. (1999). Molecular classification of cancer: class discovery and class prediction by gene expression monitoring. Science. 286:531-537.

Gorczyca W., Gong J., Darzynkiewicz Z. (1993). Detection of DNA strand breaks in individual apoptotic cells by the in situ terminal deoxynucleotidyl transferase and nick translation assays. Cancer Res. 53:1945-1951.

Greenlee R. T., Murray T., Bolden S., Wingo P. A. (2000). Cancer statistics, 2000. CA Cancer J Clin. 50:7-33. 
Grimberg A,. Cohen P. (2000). Role of insulin-like growth factors and their binding proteins in growth control and carcinogenesis. J Cell Physiol. 183:1-9.

Gucev Z. S., Oh Y., Kelley K. M., Rosenfeld R. G. (1996). Insulin-like growth factor binding protein 3 mediates retinoic acid- and transforming growth factor B2-induced growth inhibition in human breast cancer cells. Cancer Res. 56:1545-1550.

Hammond S. M., Boettcher S., Caudy A. A., Kobayashi R., Hannon G. J. (2001). Argonaute2, a link between genetic and biochemical analyses of RNAi. Science 293:1146-1150

Hammond S. M., Caudy A. A., Hannon G. J. (2001). Post-transcriptional gene silencing by double-stranded RNA. Nature Rev Genet. 2:110-119.

Hanahan D. (1983). Studies on transformation of Escherichia coli with plasmids. J Mol Biol. 166:557-580.

Hannon G. J. (2002). RNA interference. Review. Nature. 418:244-251.

Harborth J., Elbashir S. M., Bechert K., Tuschl T., Weber K. (2001). Identification of essential genes in cultured mammalian cells using small interfering RNAs. J Cell Sci. 114: 4557-4565.

Hellawell G. O., Turner G. D., Davies D. R., Poulsom R., Brewster S. F., Macaulay V. M. (2002). Expression of the type 1 insulin-like growth factor receptor is up-regulated in primary prostate cancer and commonly persists in metastatic disease. Cancer Res. 62:2942-2950.

Hintz R. L., Bock S., Thorsson A. V., Bovens J., Powell D. R., Jakse G., Petrides P. E. (1991). Expression of the insulin like growth factor-binding protein 3 (IGFBP-3) gene is increased in human renal carcinomas. J Urol. 146:1160-1163.

Horoszewicz J. S., Leong S. S., Kawinski E., Karr J. P., Rosenthal H., Chu T. M., Mirand E. A., Murphy G. P. (1983). LNCaP model of human prostatic carcinoma. Cancer Res. 43:18091818. 
Hsing A. W., Deng J., Sesterhenn I. A., Mostofi F. K., Stanczyk F. Z., Benichou J., Xie T., Gao Y. T. (2000). Body size and prostate cancer: a population-based case-control study in China. Cancer Epidemiol Biomarkers Prev. 9:1335-1341.

Hutvagner G., McLachlan J., Pasquinelli A. E., Balint E., Tuschl T., Zamore P.D. (2001). A cellular function for the RNA-interference enzyme Dicer in the maturation of the let-7 small temporal RNA. Science. 293:834-838.

Hutvagner G., Zamore P. D. (2002). RNAi: nature abhors a double-strand. Curr Opin Genet Dev. 12:225-232.

Huynh H., Pollak M., Zhang J. C. (1998). Regulation of insulin-like growth factor (IGF) II and IGF binding protein 3 autocrine loop in human PC-3 prostate cancer cells by vitamin D metabolite 1,25(OH)2 $\mathrm{D}_{3}$ and its analog EB1089. Int J Oncol. 13:137-143.

Huynh H., Yang X., Pollak M. (1996). Estradiol and antiestrogens regulate a growth inhibitory insulin-like growth factor binding protein 3 autocrine loop in human breast cancer cells. J Biol Chem. 271:1016-1021.

Hwa V., Oh Y., Rosenfeld R. G. (1999). The insulin-like growth factor-binding protein (IGFBP) superfamily. Endocr Rev. 20:761-787.

Jiang Z., Wu C. L., Woda B. A., Dresser K., Xu J., Fanger G. R., Yang X. J. (2002). P504S/alpha-methylacyl-CoA racemase: a useful marker for diagnosis of small foci of prostatic carcinoma on needle biopsy. Am J Surg Pathol. 26:1169-1174.

Kaighn M. E., Narayan K. S., Ohnuki Y., Lechner J. F., Jones L. W. (1979). Establishment and characterization of a human prostatic carcinoma cell line (PC-3). Invest Urol. 17:16-23.

Kansra S., Ewton D. Z., Wang J., Friedman E. (2000). IGFBP-3 mediates TGF beta 1 proliferative response in colon cancer cells. Int J Cancer Aug. 87:373-378. 
Kato H., Faria T. N., Stannard B., Roberts C. T. Jr., LeRoith D. (1994). Essential role of tyrosine residues 1131, 1135, and 1136 of the insulin-like growth factor-I (IGF-I) receptor in IGF-I action. Mol Endocrinol. 8:40-50.

Katsaros D., Yu H., Piccinno R., Puopolo M., Rigault De La Longrais I. A., Fracchioli S., Massobrio M. (2002). IGFBP-3. Expression and prognostic significance in epithelial ovarian cancer. Minerva Ginecol. 54:15-24.

King H. C., Sinha A. A. (2001). Gene expression profile analysis by DNA microarrays: promise and pitfalls. JAMA. 286:2280-2288.

Kothakota S., Azuma T., Reinhard C., Klippel A., Tang J., Chu K., McGarry T. J., Kirschner M. W., Koths K., Kwiatkowski D. J., Williams L. T. (1997). Caspase-3-generated fragment of gelsolin: effector of morphological change in apoptosis. Science. 278:294-298.

Krajewska M., Krajewski S., Epstein J. I., Shabaik A., Sauvageot J., Song K., Kitada S., Reed J. C. (1996). Immunohistochemical analysis of bcl-2, bax, bcl-X, and mcl-1 expression in prostate cancers. Am J Pathol. 148:1567-1576.

Laemmli U. K. (1970). Cleavage of structural proteins during the assembly of the head of bacteriophage T4. Nature. 227:680-685.

Lee D. Y., Yi H. K., Hwang P. H., Oh Y. (2002). Enhanced expression of insulin-like growth factor binding protein-3 sensitizes the growth inhibitory effect of anticancer drugs in gastric cancer cells. Biochem Biophys Res Commun. 294:480-486.

Li S. L., Goko H., Xu Z. D., Kimura G., Sun Y., Kawachi M. H., Wilson T. G., Wilczynski S., Fujita-Yamaguchi Y. (1998) Expression of insulin-like growth factor (IGF)-II in human prostate, breast, bladder, and paraganglioma tumors. Cell Tissue Res. 291:469-479.

Li X., Marani M., Mannucci R., Kinsey B., Andriani F., Nicoletti I., Denner L., Marcelli M. (2001). Overexpression of $\mathrm{Bcl}-\mathrm{X}_{\mathrm{L}}$ underlies the molecular basis for resistance to staurosporine-induced apoptosis in PC-3 cells. Cancer Res. 61:1699-1706. 
Li X., Marani M., Yu J., Nan B., Roth J. A., Kagawa S., Fang B., Denner L., Marcelli M. (2001). Adenovirus-mediated Bax overexpression for the induction of therapeutic apoptosis in prostate cancer. Cancer Res. 61:186-191.

Lichtenstein P., Holm N. V., Verkasalo P. K., Iliadou A., Kaprio J., Koskenvuo M., Pukkala E., Skytthe A., Hemminki K. (2000). Environmental and heritable factors in the causation of cancer-analyses of cohorts of twins from Sweden, Denmark, and Finland. $N$ Engl J Med. 343:78-85.

Lindblom A., Liljegren A. (2000). Regular review: tumour markers in malignancies. BMJ. 320:424-427.

Lintula S., Stenman U. H. (1997). The expression of prostate-specific membrane antigen in peripheral blood leukocytes. J Urol. 157:1969-1972

Lockhart D. J., Dong H., Byrne M. C., Follettie M. T., Gallo M. V., Chee M. S., Mittmann M., Wang C., Kobayashi M., Horton H., Brown E. L. (1996). Expression monitoring by hybridization to high-density oligonucleotide arrays. Nature Biotech. 14:1675-1680.

Long L., Navab R., Brodt P. (1998). Regulation of the Mr 72,000 type IV collagenase by the type I insulin-like growth factor receptor. Cancer Res. 58:3243-3247.

Long L., Rubin R., Brodt P. (1998). Enhanced invasion and liver colonization by lung carcinoma cells overexpressing the type 1 insulin-like growth factor receptor. Exp Cell Res. 238:116-121.

Lowe F. C., Trauzzi S. J. (1993). Prostatic acid phosphatase in 1993. Its limited clinical utility. Urol Clin North Am. 20:589-595.

Maniatis T., Efstratiadis A. (1980). Fractionation of low molecular weight DNA or RNA in polyacrylamide gels containing 98\% formamide or $7 \mathrm{M}$ urea. Methods Enzymol 65:299-305.

Marcelli M., Marani M., Li X., Sturgis L., Haidacher S. J., Trial J. A., Mannucci R., Nicoletti I., Denner L. (2000). Heterogeneous apoptotic responses of prostate cancer cell lines identify 
an association between sensitivity to staurosporine-induced apoptosis, expression of Bcl-2 family members, and caspase activation. Prostate. 42:260-73.

Martin J. L., Weenink S. M., Baxter R. C. (2002). Insulin-like growth factor binding protein-3 potentiates EGF action in MCF-10A mammary epithelial cells: Involvement of p44/42 and p38 MAP kinases. J Biol Chem. (epub ahead of print).

Martinez-Pineiro L., Tabernero A., Contreras T., Madero R., Lozano D., Lopez-Tello J., Alonso-Dorrego J. M., Picazo M. L., Gonzalez Gancedo P., Martinez-Pineiro J. A., de La Pena J. J. (2000). Determination of the percentage of free prostate-specific antigen helps to avoid unnecessary biopsies in men with normal rectal examinations and total prostate-specific antigen of 4-10 ng/ml. Eur Urol. 37:289-296.

Marzo A. M., Putzi M. J., Nelson W. G. New concepts in the pathology of prostatic epithelial carcinogenesis. Urology. (2001). 57:103-114.

McDonnel T. J., Troncoso P., Brisbay S. M., Logothesis C., Chang L. W. K., Hsieh J-T., Tu S-M., Campbell M. L. (1992). Expression of the protooncogene bcl-2 in the prostate and its association with emergence of androgen-independent prostate cancer. Cancer Res. 52:69406944.

Monroe K. R., Yu M. C., Kolonel L. N., Coetzee G. A., Wilkens L. R., Ross R. K., Henderson B. E. (1995). Evidence of an X-linked or recessive genetic component to prostate cancer risk. Nat Med. 1:827-829.

Morrison B. W., Moorman J. R., Kowdley G. C., Kobayashi Y. M., Jones L. R., Leder P. (1995). Mat-8, a novel phospholemman-like protein expressed in human breast tumors, induces a chloride conductance in Xenopus oocytes. J Biol Chem. 270:2176-2182.

Morrison B.W., Leder P. (1994). Neu and ras initiate murine mammary tumors that share genetic markers generally absent in c-myc and int-2-initiated tumors. Oncogene. 9:3417-3426. Moul J. W. (1997). Epidemiology and screening for prostate cancer. Am J Manag Care. 3:1200-1205. 
Nagakubo D., Taira T., Kitaura H., Ikeda M., Tamai K., Iguchi-Ariga S. M., Ariga H. (1997). DJ-1, a novel oncogene which transforms mouse NIH3T3 cells in cooperation with ras. Biochem Biophys Res Commun. 231:509-513.

Nagase H., Woessner J. F. Jr. Matrix metalloproteinases. (1999). J Biol Chem. 274:2149121494.

Naour F., Brichory F., Misek D. E., Brechot C., Hanash S. M., Beretta L. (2002). A distinct repertoire of autoantibodies in hepatocellular carcinoma identified by proteomic analysis. $\mathrm{Mol}$ Cell Proteomics. 1:197-203.

Nickerson T., Chang F., Lorimer D., Smeekens S. P., Sawyers C. L., Pollak M. (2001). In vivo progression of LAPC-9 and LNCaP prostate cancer models to androgen independence is associated with increased expression of insulin-like growth factor I (IGF-I) and IGF-I receptor (IGF-IR). Cancer Res. 61:6276-6280.

Nickerson T., Pollak M. (1999). Bicalutamide [Casodex]-induced prostate regression involves increased expression of genes encoding insulin-like growth factor binding proteins. Urology. 54:1120-1125.

Oh Y., Muller H. L., Ng L., Rosenfeld R. (1995). Transforming growth factor-ß induced cell growth inhibition in human breast cancer cells is mediated through insulin-like growth factorbinding protein-3 action. J Biol Chem. 270:13589-13592.

Ohnuki Y., Marnell M. M., Babcock M. S., Lechner J. F., Kaighn M. E. (1980). Chromosomal analysis of human prostatic adenocarcinoma cell lines. Cancer Res. 40:524534.

Palmqvist R., Hallmans G., Rinaldi S., Biessy C., Stenling R., Riboli E., Kaaks R.. (2002). Plasma insulin-like growth factor 1, insulin-like growth factor binding protein 3, and risk of colorectal cancer: a prospective study in northern Sweden. Gut. 50:642-646. 
Park H. I., Ni J., Gerkema F. E., Liu D., Belozerov V. E., Sang Q. X. (2000). Identification and characterization of human endometase (Matrix metalloproteinase-26) from endometrial tumor. J Biol Chem. 275:20540-20544.

Partin A. W., Catalona W. J., Finlay J. A., Darte C., Tindall D. J., Young C. Y., Klee G. G., Chan D. W., Rittenhouse H. G., Wolfert R. L., Woodrum D. L. (1999). Use of human glandular kallikrein 2 for the detection of prostate cancer: preliminary analysis. Urology. 54:839-45.

Patel D, White PA, Milford Ward A. (2000). A comparison of six commercial assays for total and free prostate specific antigen (PSA): the predictive value of the ratio of free to total PSA. BJU Int. 85:686-689.

Peehl D. M., Cohen P., Rosenfeld R. G. (1996). Role of insulin-like growth factors in prostate biology. J Androl. 17:2-4.

Pentyala S. N, Lee J., Hsieh K., Waltzer W. C., Trocchia A., Musacchia L., Rebecchi M. J., Khan S. A. (2000). Prostate cancer: a comprehensive review. Med Oncol. 17:85-105.

Pienta K. J. (1998). Etiology, epidemiology, and prevention of carcinoma of the prostate. In: Walsh P. C., Retik A. B., Vaughan E. D., Wein A. J. (eds.) Campbell's Urology. W.B. Saunders, Philadelphia, pp 2489-2496.

Pirtskhalaishvili G., Nelson J. B. (2000). Endothelium-derived factors as paracrine mediators of prostate cancer progression. Prostate. 44:77-87.

Pollak M., Beamer W., Zhang J. C. (1998-99). Insulin-like growth factors and prostate cancer. Cancer Metastasis Rev. 17:383-390.

Putz T., Culig Z., Eder I. E., Nessler-Menardi C., Bartsch G., Grunicke H., Uberall F., Klocker H. (1999). Epidermal growth factor (EGF) receptor blockade inhibits the action of EGF, insulin-like growth factor I, and a protein kinase A activator on the mitogen-activated protein kinase pathway in prostate cancer cell lines. Cancer Res. 59:227-233. 
Rajah R., Lee K. W., Cohen P. (2002). Insulin-like growth factor binding protein-3 mediates tumor necrosis factor-alpha-induced apoptosis: role of Bcl-2 phosphorylation. Cell Growth Differ. 13:163-171.

Rajah R., Valentinis B., Cohen P. (1997). Insulin-like growth factor binding protein-3 induces apoptosis and mediates the effects of transforming growth factor- $\beta 1$ on programmed cell death through a p53- and IGF-independent mechanism. J Biol Chem. 272:12181-12188.

Recker F., Kwiatkowski M. K., Piironen T., Pettersson K., Huber A., Lummen G., Tscholl R. (2000). Human glandular kallikrein as a tool to improve discrimination of poorly differentiated and non-organ-confined prostate cancer compared with prostate-specific antigen.Urology. 55:481-485.

Reinmuth N., Fan F., Liu W., Parikh A. A., Stoeltzing O., Jung Y. D., Bucana C. D., Radinsky R., Gallick G. E., Ellis L. M. (2002). Impact of insulin-like growth factor receptor-I function on angiogenesis, growth, and metastasis of colon cancer. Lab Invest. 82:1377-1389.

Kanoh Y., Akahoshi T., Ohara T., Ohtani N., Mashiko T., Ohtani S., Egawa S., Baba S. (2002). Expression of matrix metalloproteinase-2 and prostate-specific antigen in localized and metastatic prostate cancer. Anticancer Res. 22:1813-1817.

Rinaldy A. R., Steiner M. S. (1999). Application of an improved cDNA competition technique to identify prostate cancer-associated gene. DNA Cell Biol. 18:829-836.

Rinker-Schaeffer C. W., Partin A. W., Isaacs W. B., Coffey D. S., Isaacs J. T. (1994). Molecular and cellular changes associated with the acquisition of metastatic ability by prostatic cancer cells. Prostate. 25:249-265.

Rozen F., Zhang J., Pollak M. (1998). Antiproliferative action of tumor necrosis factor- $x$ on MCF-7 breast cancer cells is associated with increased insulin-like growth factor binding protein-3 accumulation. Int J Oncol. 13:865-869.

Rubin M. A. (2001). Use of laser capture microdissection, cDNA microarrays, and tissue microarrays in advancing our understanding of prostate cancer. J Pathol. 195: 80-86. 
Saiki R. K., Scharf S., Faloona F., Mullis K. B., Horn G. T., Erlich H. A., Arnheim N. (1985). Enzymatic amplification of beta-globin genomic sequences and restriction site analysis for diagnosis of sickle cell anemia. Science. 230:1350-1354.

Sakai H., Tsurusaki T., Kanda S., Koji T., Xuan J. W., Saito Y. (1999). Prognostic significance of beta-microseminoprotein mRNA expression in prostate cancer. Prostate. 38:278-84.

Sakai N., Kusunoki M., Nishida M., Toyoguchi T., Fukutomi H., Sakiyama H. (1994). Tumorigenicity of BALB3T3 A31 cells transfected with hamster-complement-C1s cDNA. Int J Cancer. 58:309-313.

Sakiyama H., Nishida M., Sakai N., Nagino K., Miyatake S., Saito T., Imajoh-Ohmi S. (1996). Site-directed mutagenesis of hamster complement C1S: characterization with an active form-specific antibody and possible involvement of $\mathrm{C} 1 \mathrm{~S}$ in tumorigenicity. Int $J$ Cancer. 66:768-771.

Sambrook J., Fritsch E. F., Maniatis T. Molecular cloning: a laboratory manual (2 ${ }^{\text {nd }}$ edition). (1989) Cold Spring Habour, New York, USA.

Sanger F., Nicklen S., Coulson A. R. (1992). DNA sequencing with chain-terminating inhibitors. 1977. Biotechnology 24:104-108.

Schmits R., Cochlovius B., Treitz G., Regitz E., Ketter R., Preuss K. D., Romeike B. F., Pfreundschuh M. (2002). Analysis of the antibody repertoire of astrocytoma patients against antigens expressed by gliomas. Int J Cancer. 98:73-77.

Schweyer S., Hemmerlein B., Radzun H. J., Fayyazi A. (2000).Continuous recruitment, coexpression of tumour necrosis factor-alpha and matrix metalloproteinases, and apoptosis of macrophages in gout tophi. Virchows Arch. 437:534-539.

Sciacca L., Mineo R., Pandini G., Murabito A., Vigneri R., Belfiore A. (2002). In IGF-I receptor-deficient leiomyosarcoma cells autocrine IGF-II induces cell invasion and protection from apoptosis via the insulin receptor isoform A. Oncogene. 21:8240-8250. 
Sepp-Lorenzino L. (1998). Structure and function of the insulin-like growth factor I receptor. Breast Cancer Res Treat. 47:235-253.

Sharp P. A. RNA interference-2001. (2001).Genes Dev. 15:485-490.

Simard J., Dumont M., Soucy P., Labrie F (2002). Perspective: prostate cancer susceptibility genes. Endocrinology. 143:2029-2040.

Srivastava M., Bubendorf L., Srikantan V., Fossom L., Nolan L., Glasman M., Leighton X., Fehrle W., Pittaluga S., Raffeld M., Koivisto P., Willi N., Gasser T. C., Kononen J., Sauter G., Kallioniemi O. P., Srivastava S., Pollard H. B. (2001). ANX7, a candidate tumor suppressor gene for prostate cancer. Proc Natl Acad Sci USA. 98:4575-80.

Stetler-Stevenson W. G., Aznavoorian S., Liotta L. A. (1993). Tumor cell interactions with the extracellular matrix during invasion and metastasis. Annu Rev Cell Biol. 9:541-573.

Stetler-Stevenson W. G., Liotta L. A., Kleiner D. E. Jr. (1993). Extracellular matrix 6: role of matrix metalloproteinases in tumor invasion and metastasis. FASEB J. 7:1434-1441.

Stracke M. L., Murata J., Aznavoorian S., Liotta L. A. (1994). The role of the extracellular matrix in tumor cell metastasis. In Vivo. 8:49-58.

Tanno S., Tanno S., Mitsuuchi Y., Altomare D. A., Xiao G. H., Testa J. R. (2001). AKT activation up-regulates insulin-like growth factor I receptor expression and promotes invasiveness of human pancreatic cancer cells. Cancer Res. 61:589-593.

Tripathi P. K., Chatterjee S. K. (1996). Elevated expression of ferritin H-chain mRNA in metastatic ovarian tumor. Cancer Invest. 14:518-526.

Tu H., Borkowski A., Jacobs S. C., Kyprianou N. (1996). Incidence of apoptosis and cell proliferation in prostate cancer: relationship with TGF- $\beta$ and bcl-2 expression. Int $J$ Cancer. 69: $357-363$ 
Tuschl T. (2001). RNA Interference and Small Interfering RNAs. Chembiochem Europ $J$ Chem Biol. 2:239-245.

Tuschl T., Zamore P. D., Lehmann R., Bartel D. P., Sharp P. A. (1999). Targeted mRNA degradation by double-stranded RNA in vitro. Genes Dev 13:3191-3197.

Vaarala M. H., Porvari K., Kyllonen A., Vihko P. (2000). Differentially expressed genes in two LNCaP prostate cancer cell lines reflecting changes during prostate cancer progression. Lab Invest. 80:1259-1268.

Van 't Veer L. J., Dai H., van de Vijver M. J., He Y. D., Hart A. A., Mao M., Peterse H. L., van der Kooy K., Marton M. J., Witteveen A. T., Schreiber G. J., Kerkhoven R. M., Roberts C., Linsley P. S., Bernards R., Friend S. H. (2002). Gene expression profiling predicts clinical outcome of breast cancer. Nature. 415:530-536.

Varambally S., Dhanasekaran S. M., Zhou M., Barrette T. R., Kumar-Sinha C., Sanda M. G., Ghosh D., Pienta K. J., Sewalt R. G., Otte A. P., Rubin M. A., Chinnaiyan A. M. (2002). The polycomb group protein EZH2 is involved in progression of prostate cancer. Nature 419:624629.

Vollenhoven B. J., Herington A. C., Healy D. L. (1993). Messenger ribonucleic acid expression of the insulin-like growth factors and their binding proteins in uterine fibroids and myometrium. J Clin Endocrinol Metab. 76:1106-1110.

Walter L., Marynen P., Szpirer J., Levan G., Günther E. (1995). Identification of a novel conserved human gene, TEGT. Genomics. 28:301-304.

Wang X. Z., Beebe J. R., Pwiti L., Bielawska A., Smyth M. J. (1999). Aberrant sphingolipid signaling is involved in the resistance of prostate cancer cell lines to chemotherapy. Cancer Res. 59:5842-5848.

Wang Y., Sun Y. (2002). Insulin-like growth factor receptor-1 as an anti-cancer target: blocking transformation and inducing apoptosis. Curr Cancer Drug Targets. 2:191-207. 
Welsh J. B., Sapinoso L. M., Su A. I., Kern S. G., Wang-Rodriguez J., Moskaluk C. A., Frierson H. F. Jr., Hampton G. M. (2001). Analysis of gene expression identifies candidate markers and pharmacological targets in prostate cancer. Cancer Res. 61:5974-5978.

Whitmore W. F. Jr. (1984). Natural history and staging of prostate cancer. Urol Clin North Am.11:205-20.

Wingo P. A., Ries L. A., Rosenberg H. M., Miller D. S., Edwards B. K. (1998). Cancer incidence and mortality, 1973-1995: a report card for the U.S. Cancer. 182:1197-1207.

Wingo P. A., Tong T., Bolden S. (1995) Cancer statistics, 1995. CA Cancer J Clin. 45:8-30.

Xu J., Kalos M., Stolk J. A., Zasloff E. J., Zhang X., Houghton R. L., Filho A. M., Nolasco M., Badaro R., Reed S. G. (2001). Identification and characterization of prostein, a novel prostate-specific protein. Cancer Res. 61:1563-1568.

Xu J., Zheng S. L., Hawkins G. A., Faith D. A., Kelly B., Isaacs S. D., Wiley K. E., Chang B., Ewing C. M., Bujnovszky P., Carpten J. D., Bleecker E. R., Walsh P. C., Trent J. M., Meyers D. A., Isaacs W. B. (2001) Linkage and association studies of prostate cancer susceptibility: evidence for linkage at 8p22-23. Am J Hum Genet. 69:341-350.

Xu L. L., Stackhouse B. G., Florence K., Zhang W., Shanmugam N., Sesterhenn I. A., Zou Z., Srikantan V., Augustus M., Roschke V., Carter K., McLeod D. G., Moul J. W., Soppett D., Srivastava S. (2000). PSGR, a novel prostate-specific gene with homology to a G proteincoupled receptor, is overexpressed in prostate cancer. Cancer Res. 60: 6568-6572.

Xu Q., Reed J. C. (1998). Bax inhibitor-1, a mammalian apoptosis suppressor identified by functional screening in yeast. Mol Cell. 1:337-346.

Yang D. C., Wang F., Elliott R. L., Head J. F. (2001). Expression of transferrin receptor and ferritin H-chain mRNA are associated with clinical and histopathological prognostic indicators in breast cancer. Anticancer Res. 21:541-549.

Yoneda T., Akira S., Mundy G. R. (1994). Osteolytic bone metastasis in breast cancer. Breast Cancer Res Treat. 32:73-84. 
Zamore P. D., Tuschl T., Sharp P. A., Bartel D. P. (2000). RNAi: double-stranded RNA directs the ATP-dependent cleavage of mRNA at 21 to 23 nucleotide intervals. Cell. 101:2533.

Zi X., Zhang J., Agarwal R., Pollak M. (2000). Silibinin up-regulates insulin-like growth factor-binding protein 3 expression and inhibits proliferation of androgen-independent prostate cancer cells. Cancer Res. 60:5617-5620. 


\section{Acknowledgements}

I am highly indebted to Prof. Dr. Wolfgang Engel for accepting to supervise this thesis, his permanent support and his valuable remarks on the theoretical and practical aspects of the present work.

My particular gratitude goes to my supervisor Dr. Peter Burfeind for his brilliant supervising and for friendly relationships during the whole time of this study.

I sincerely thank PD Dr. S. Hoyer-Fender to be my co-referee. I also extend my sincere thanks to Prof. Dr. D. Doenecke and Prof. Dr. D. Gradmann for accepting to be my examiners.

I am indeed thankful to Dr. Paul Thelen, Dr. Bernhard Hemmerlein and Ms. Stefanie Zischkau for their excellent collaboration regarding quantitative RT-PCR analysis on LCM-derived material. I am also very thankful to Dr. Stefan Schweyer for his cooperation regarding the apoptosis study and to Dr. Jürgen Neesen for his help in Western blot analysis.

I would also like to thank my brother Dr. Pawel Grzmil for his help during my experiments and encouragement throughout my research.

Special thanks to my lab colleagues Mr. Michael Kickstein, Ms. Dina Mury and Ms. Silke Voigt and to all the co-workers from the Institute of Human Genetics for their numerous advices, constant support, and fantastic work atmosphere.

I thank my family members, most of all I would like to thank my wife, Ewie Bialek-Grzmil, for her love and unlimited patience, my parents Andrzejowi and Agacie Grzmil, my mother-in-law Grazynie Bialek, my brother-in-law Witkowi Bialkowi and my sister-in-law Renacie BobuliGrzmil for their moral support and constant sense of humor. 


\section{Curriculum vitae}

\section{Personal details:}

Name: Michal Grzmil

Date of birth: 9th December 1975

Place of birth: Tarnobrzeg, Poland

Nationality: Polish

\section{Educational background:}

1981-1994 Primary and Secondary school, Tarnobrzeg, Poland.

1994 High School Diploma.

1994-1999 Studies of Biotechnology, Maria Curie-Sklodowska University, Faculty of Biology and Earth Science, Lublin, Poland.

1998/1999 Diploma work at the Polish Academy of Science, Institute of Biochemistry and Biophysics, Warsaw, Poland under the supervision of Prof. M. Fikus.

1999 Master of Science. Thesis: "Regulation and morphological aspects of functional analysis of RRD1 and RDD2 genes in Saccharomyces cerevisiae".

1999-2003 PhD studies at the Georg-August University Göttingen, Institute of Human Genetics, under the supervision of Prof. Dr. W. Engel. 